\title{
Water sources of major plant species along a strong climatic gradient in the inland Heihe River Basin
}

\author{
Liangju Zhao a, b*, Cong Xie ${ }^{a}$, Xiaohong Liu ${ }^{c}$, Ninglian Wang ${ }^{a}$, Zhang Yuc ${ }^{c}$, Xiying Dong a ${ }^{a}$, Lixin Wang ${ }^{d^{*}}$ \\ ${ }^{a}$ Shaanxi Key Laboratory of Earth Surface System and Environmental Carrying Capacity, College of Urban and \\ Environmental Sciences, Northwest University, Xi'an 710069, China \\ ${ }^{\mathrm{b}}$ State Key Laboratory of Continental Dynamics, Northwest University, Xi'an 710069, China \\ c School of Geography and Tourism, Shaanxi Normal University, Xi'an 710119, China \\ ${ }^{\mathrm{d}}$ Department of Earth Sciences, Indiana University-Purdue University Indianapolis (IUPUI), Indianapolis, IN 46202, \\ USA
}

Running title: Plant water use strategy along climate gradient

\section{*Corresponding author}

\section{Dr. Liangju Zhao}

College of Urban and Environmental Sciences

Northwest University

Xi'an, Shann'xi, 710069, China

E-mail: lzb.ac.cn

Cell phone: 15934832330

\section{Dr. Lixin Wang}

Department of Earth Sciences

Indiana University-Purdue University Indianapolis

Indianapolis, IN, 46202, USA

E-mail: 1xwang@iupui.edu

Office phone number: 317-274-7764

This is the author's manuscript of the article published in final edited form as: 


\begin{abstract}
Aim Knowledge on vegetation water sources is crucial to understand the ecohydrological processes and ecological management of arid and semi-arid ecosystems. The identification and quantification of plant water uptake from precipitation, soil and groundwater remain challenging along large climatic gradient.
\end{abstract}

Methods Stable oxygen isotope compositions of xylem water, soil water and groundwater were analyzed to assess seasonal and spatial patterns of water uptake of 11 major plant species along the Heihe River Basin.

Conclusions In the upper reaches, soil water recharged by precipitation was the main plant water source, and plants extracted water from the shallow soil water in wet season while used more deep soil water in dry season. In the middle reaches of desert-oasis ecotone, the water sources of shrubs shifted between soil moisture and groundwater depending on variations of precipitation and groundwater level, while shrubs at Gobi relied on deep soil water and shallow soil water after rainfall. In the lower reaches, the driest part of the region, groundwater and deep soil water were main water sources for the riparian plants. Groundwater was stable water source for shrubs growing on the planted shrubland, and soil water was stable water sources for shrubs growing at Gobi. Our results also revealed that water use strategies of the same species were plastic under different groundwater level and precipitation. This study identified water use patterns of different plant species along a climatic gradient and provided scientific implication for water management of different ecosystems of the arid and semi-arid ecosystems.

Keywords Groundwater · Heihe River Basin · oxygen isotope · hydrogen isotope · plant water source · soil water 


\section{Introduction}

Water is one of the most important factors affecting plant survival and growth in arid and semiarid regions, where evaporative demand exceeds precipitation and water resources are scarce (Reynolds et al., 2007; Wang et al., 2010; Wang et al., 2012). Depending on their belowground rooting system and habitat, different plants may use different water supplies such as precipitation/snow (winter), groundwater, river and soil water (both shallow and deep). Plants can also shift their water supply depending on seasonality as plants often depend on access to deep and moist soil layers to withstand heat waves and droughts (e.g., Eggemeyer et al., 2009; Rossatto et al., 2012; Schwinning et al., 2005). Therefore, understanding on different water sources in water-limited areas is important to maintain the structure and function of these largely diverse arid and semi-arid ecosystems covering forest, grasslands, shrublands, mountain meadows, desert-oasis ecotones, riparian forest and Gobi of the Heihe River Basin.

Studies have shown that different water sources often have different hydrogen and oxygen isotopic compositions $\left(\delta^{2} \mathrm{H}, \delta^{18} \mathrm{O}\right)$. Therefore, the isotopic composition of plant tissue water can be an effective proxy to determine plant potential water sources (Ehleringer et al., 1998; Lanning et al., 2020), which can be different along a climatic gradient. To understand different plant water sources and areas with effective water uptake, we used the Heihe River Basin, the second largest inland water basin in northwestern China. The area covers semi-arid region in the upper reaches, arid region in the middle reaches, and extremely arid region in the lower reaches. We examined the stable isotope composition of different water pools that support different plant species especially in the lower and middle reaches, where water has become a limiting factor for vegetative growth. Water uptake patterns of Tamarix ramosissima (Sun et al., 2016), Haloxylon ammodendron (Zhou et al., 2017) in the middle reaches, of 
Populus euphratica, Tamarix ramosissima, Sophora alopecuroides, Sonchus oleraceus and Herba Taraxaci (Zhao et al., 2008; Ruan et al., 2014) and Populus euphratica, Taramrix chinensis and Reaumuria soongorica (Fu et al., 2014) in the lower reaches have been studied. These plants may have variations in their belowground rooting strategies, which are critical for plant water access. To our knowledge, at basin scale, there have been no systematic studies on seasonal and annual variations of water uptake patterns across strong climate gradient.

Based on stable oxygen and hydrogen isotopic composition $\left(\delta^{18} \mathrm{O}\right.$ and $\left.\delta^{2} \mathrm{H}\right)$ of precipitation, soil water and shallow groundwater of the Heihe River Basin, we investigated the recharge sources of shallow groundwater and soil water of these ecosystems. In addition, we used variations of $\delta^{18} \mathrm{O}$ of soil water, groundwater and plant xylem water in 11 different plant species in 15 sites, including trees, shrubs and grasses to reveal their water sources and areas with effective water uptake along a climatic gradient of the Heihe River Basin (acronyms are given in Table 1). The information on the mechanisms of plant water use and the strategies of adapting to arid environments will be useful in selecting the adaptive species when restoring and rebuilding degraded desert ecosystems and maintaining their stability.

\section{Table 1 here}

\section{Materials and Methods}

\section{Study sites}

The study took place at the upper reaches (Qilian Mountains), the middle reaches (Linze) and the lower reaches (Ejina) with distinct climatic conditions within the Heihe River Basin, northwestern China (Table 2 and Fig. 1). 
Fig. 1 + Table 2 here

We used Pailugou and Yeniugou to represent middle mountains and alpine region of the Qilian Mountains. In Yeniugou, the long-term (1959-2000) mean annual precipitation is $401.4 \mathrm{~mm}, 80 \%$ of it occurs between June and September. The annual mean temperature is about $-3.1^{\circ} \mathrm{C}$, with the lowest monthly mean temperature being recorded in January $\left(-17.2^{\circ} \mathrm{C}\right)$ and the highest monthly mean temperature in July $\left(9.2^{\circ} \mathrm{C}\right)$. The temperature is above $0^{\circ} \mathrm{C}$ from May to September. Meanwhile, the highest and the lowest temperature in Pailugou, which is located in the middle of the Qilian Mountains, are $12.2^{\circ} \mathrm{C}$ (July) and $-12.9^{\circ} \mathrm{C}$ (January), respectively. The area has a mean annual temperature of $0.7^{\circ} \mathrm{C}$. Annual precipitation averages $369.2 \mathrm{~mm}$. Both areas have similar ecosystem types consisting of mountain grasslands, mountain meadows, high mountain meadows, swamp meadows and forests.

Due to the absence of long-term climatic data in Linze (middle reaches), we used climatic data in Zhangye, which is about $60 \mathrm{~km}$ from Linze. The long-term (1951- 2012) mean annual temperature is about $7.3^{\circ} \mathrm{C}$, with a mean January temperature of $-9.8^{\circ} \mathrm{C}$ and a mean July temperature of $21.8^{\circ} \mathrm{C}$. Mean annual precipitation is $129.9 \mathrm{~mm} \cdot \mathrm{year}^{-1}$, with $73.7 \%$ of the rainfall occurring between June and September. The main ecosystem types are planted oasis, desert-oasis ecotone and Gobi Desert in the middle reaches.

In the lower reaches (Ejina), the long-term (1960-2012) mean annual temperature is $8.9^{\circ} \mathrm{C}$, with a mean January temperature of $-11.5{ }^{\circ} \mathrm{C}$ and a mean July temperature of $27.0{ }^{\circ} \mathrm{C}$. Mean annual precipitation is $34.9 \mathrm{~mm} \cdot$ year $^{-1}$, with $74.3 \%$ of the rainfall occurring between June and September. Ejina is considered one of the driest regions in China. The main ecosystem types are riparian forest, planted shrubland and Gobi in the lower reaches.

\section{Field sampling}


Between 2007 and 2012, annual field sampling was conducted during the growing seasons in each region. In the upper reaches, sampling was conducted in June 2009 and 2011, August 2007, 2009 and 2012 and September 2011. In the middle reaches, sampling was in June 2010 and August 2012, and in June 2007 and 2010, August 2008, 2009, and August 2012 in the lower reaches of the Heihe River Basin. The detailed sampling information is shown in Table 2.

Ten different ecosystems along the Heihe River Basin were selected (Fig. 1; Table 2). Nine sites were selected at mountain grassland (U1), swamp meadow (U2 and U4), mountain meadow (U3) and Qinghai spruce forest (from U5 to U9-9) at the upper reaches; four sites were selected at desert-oasis ecotone (from M1-10 to M3-12) and Gobi (M4-10 and M4-12) at the middle reaches; and six sites were selected at riparian forest (from L1-07 to L4-08), planted shrubland (L5-10 and L5-12) and Gobi (L6-10 and L6-12:) at the lower reaches, respectively (Fig. 1; Table 2).

\section{Plant sampling}

In the upper reaches: the dominated plants were Stipa capillata at U1 site, Polygonum viviparum at U2 site, Stipa purpurea at U3 site and Stipa capillata at U4 site. The root samples of Stipa capillata, Polygonum viviparum, and Stipa purpurea were taken from above sites. In the Qinghai spruce forest, the dominated plants were Qinghai spruce and Potentilla fruticosa at U5 site, Qinghai spruce at U6, U7 site and U8-12 site, Qinghai spruce and Stipa capillata at U8-11, and Qinghai spruce, Potentilla fruticosa and Polygonum viviparum at U9-6 and U9-9. The root samples of Stipa capillata and stem samples of Qinghai spruce and Potentilla fruticosa were taken from the above sites. At U7 site, samples were taken from 5 pm on July 31 to 10 pm on August 22009 with 2 h interval for Qinghai spruce stem. At U9-6 site, samples were taken from 6 am on June 23 to 8 am on June 24 and from 6 am to 8 pm on June 25, 2011 with $1 \mathrm{~h}$ interval for Qinghai spruce and Potentilla fruticosa stem and with $2 \mathrm{~h}$ interval 
for Polygonum viviparum root. At U9-9 site, samples were taken from 6 am to $10 \mathrm{pm}$ on September 2 and from 8 am on September 6 to 5 pm 82011 with 1 h interval for Qinghai spruce and Potentilla fruticosa stem and with $2 \mathrm{~h}$ interval for Polygonum viviparum root. At U8-11 site, plant samples were taken from 6 am on June 27 to $6 \mathrm{pm}$ on June 282011 with 1h interval for Qinghai spruce stem and with $2 \mathrm{~h}$ interval for Stipa capillata root (Table 2).

In the middle reaches: The dominated plants were Tamarix ramosissima at M1-10 and M1-12, Haloxylon ammodendron at M2-10, M2-12, and M3-12 at the desert-oasis ecotone. At Gobi, the dominated plants were Reaumuria soongorica and Nitraria tangutorum at M4-10 and Reaumuria soongorica at M4-12. The stem samples Tamarix ramosissima, Haloxylon ammodendron, Reaumuria soongorica and Nitraria tangutorum were taken from above sites. Especially, in M1-10 and M2-10 sites, stem samples of Tamarix ramosissima and Haloxylon ammodendron were taken from 6 am on June 15 to 6 am on June 162010 with 2h interval. In M4-10, stem samples of Reaumuria soongorica and Nitraria tangutorum were taken from 6 am on June 18 to 6 am on June 192010 with 2 h interval (Table 2).

In the lower reaches: The dominated plants were Populus euphratica and Sophora alopecuroides at L1-07, L1-09 and L1-10, Populus euphratica at L1-12, Tamarix ramosissima at L2-10 and L2-12, and Populus euphratica, Tamarix ramosissima and Sophora alopecuroides at L3-08 and L4-08 in the riparian forest. The dominated plant was Haloxylon ammodendron at L5-10 and L5-12 at the planted shrubland, and the dominated plant was Reaumuria soongorica at L6-10 and L6-12 at Gobi. The root samples of Sophora alopecuroides and stem samples of Populus euphratica, Tamarix ramosissima, Haloxylon ammodendron and Reaumuria soongorica were taken from above sites. At L9-09 site, stem samples of Populus euphratica and root samples of Sophora alopecuroides from August 6 6am to 
August 9 2pm 2009 with $2 \mathrm{~h}$ interval were taken with three replicates. In both L1-10 and L2-10, stem samples of Populus euphratica and Tamarix ramosissima were taken from 6 am on June 21 to 6 am on June 222010 with $2 \mathrm{~h}$ interval, and root samples of Sophora alopecuroides were also taken with three replicates. In the L5-10, stem samples of Haloxylon ammodendron were taken from 6 am on June 23 to 6 am on June 242010 with $2 \mathrm{~h}$ interval. At Gobi (L6-10), stem samples of Reaumuria soongorica were taken from 6 am on June 26 to 10 am on June 272010 with $2 \mathrm{~h}$ interval. In both L3-08 and L408, root samples of Sophora alopecuroides and stem samples of Populus euphratica and Tamarix ramosissima were taken from 5 am to 9 pm on August 202008 with 2h interval (Table 2).

For plant samples, two bottles with $8 \mathrm{ml}$ root samples from 10 to 15 herbaceous plants, 4 to 6 shrub plants and 3 to 4 woody plants around one soil profile were selected to extract water and measure $\delta^{2} \mathrm{H}$ and $\delta^{18} \mathrm{O}$. The sampling date, species and plant parts are listed in Table 2.

\section{Soil and groundwater sampling}

In the upper reaches: In June 2009, soil samples in 5, 10, 30 and $50 \mathrm{~cm}$ deep at U1 and U2, in 5, 10 and $20 \mathrm{~cm}$ deep at $\mathrm{U} 3$ and $\mathrm{U} 4$, and in 10,30 and $70 \mathrm{~cm}$ at $\mathrm{U} 6$ were taken in June 2009. At U5, soil samples in 5, 10, 15, 20, 40 and $60 \mathrm{~cm}$ deep, and at U7, in $5 \mathrm{~cm}$ and from 10 to $60 \mathrm{~cm}$ with $10 \mathrm{~cm}$ increment were taken in August 2007 and 2009, respectively. At U8-11, soil samples in 3 and $5 \mathrm{~cm}$, as well as from 10 to $60 \mathrm{~cm}$ with $10 \mathrm{~cm}$ increment, followed by 80,100 and $120 \mathrm{~cm}$ were collected in June 2011. At U8-12, soil samples in $5 \mathrm{~cm}$ and from 10 to $160 \mathrm{~cm}$ with $20 \mathrm{~cm}$ increment were collected in August 2012. At both L9-6 and L9-9 sites, soil samples in 3, 5, 10, 15, 20, 40, 60, 80 and $90 \mathrm{~cm}$ of soil profile were collected in June and September 2011.

In the middle reaches: In the desert-oasis ecotone, soil samples in 10, 40, 70, 100, and $130 \mathrm{~cm}$, 
and from 160 to $220 \mathrm{~cm}$ with $20 \mathrm{~cm}$ increment in the soil profile were taken at M1-10 in June 2010. In August 2012, soil samples in 5, 10, and from 20 to $300 \mathrm{~cm}$ with $20 \mathrm{~cm}$ increment in the soil profile were taken at M1-12. At M2-10, soil samples in 10, 40, 60, 70, 100, 150 and $200 \mathrm{~cm}$ were taken in June 2010. In August 2012, soil samples in 5 and $10 \mathrm{~cm}$, and from 20 to $300 \mathrm{~cm}$ with $20 \mathrm{~cm}$ increment at M2-12, and in 5 and $10 \mathrm{~cm}$, and from 20 to $260 \mathrm{~cm}$ with $20 \mathrm{~cm}$ interval at M2-13 were taken, respectively. At Gobi site, soil samples in 10, 20, 40, and $50 \mathrm{~cm}$, and from 80 to $200 \mathrm{~cm}$ with $20 \mathrm{~cm}$ increment at M4-10 were taken in June 2010. At M4-12 site, soil samples in 10, 15, 20, 25, from 30 to $80 \mathrm{~cm}$ with $10 \mathrm{~cm}$ interval, 100,110 , and from 120 to $200 \mathrm{~cm}$ with $20 \mathrm{~cm}$ increment were taken in August 2012.

In the lower reaches: At the riparian forest of the lower reaches of the Heihe River Basin, at L107, soil samples in 20 to $160 \mathrm{~cm}$ deep with $20 \mathrm{~cm}$ increment and saturated layer in the soil profile were taken in June 2007. Groundwater was also sampled and the depth of groundwater table at this site was $160 \mathrm{~cm}$. At L1-09, groundwater and soil samples of 5, 8, 10, $30 \mathrm{~cm}$, and from 40 to $160 \mathrm{~cm}$ with 20 $\mathrm{cm}$ interval in the soil profile were taken in August 2009. At this site, the depth of groundwater table was almost $160 \mathrm{~cm}$. At L1-10, groundwater table depth was almost $180 \mathrm{~cm}$ and soil samples were taken from 20 to $180 \mathrm{~cm}$ deep with $20 \mathrm{~cm}$ increment in June 2010. At L1-12, groundwater at nearly $200 \mathrm{~cm}$ deep was sampled, followed by soil sample collection from the following depths: $5,10 \mathrm{~cm}$, and from 20 to $200 \mathrm{~cm}$ with $20 \mathrm{~cm}$ interval in the soil profile in August 2012. At L2-10 and L2-12 sites, groundwater (200 cm depth) and soil samples from 20 to $200 \mathrm{~cm}$ with $20 \mathrm{~cm}$ interval and in $5,10 \mathrm{~cm}$, and from 20 to $160 \mathrm{~cm}$ with $20 \mathrm{~cm}$ interval were taken in June 2010 and August 2012, respectively. At L3-08 and L4-08, soil samples of 3, $5 \mathrm{~cm}$, and from 20 to $240 \mathrm{~cm}$ with $20 \mathrm{~cm}$ interval in the soil profile were taken in August 2008. At these sites, the groundwater table was deeper than $5.0 \mathrm{~m}$. At the planted 
shrubland site (L5-10), soil samples from 20, 40, 50, 60, 80, 100, 140, 170, 200, 230 and $250 \mathrm{~cm}$ deep were taken in June 2010. Soil samples were taken from 20 to $160 \mathrm{~cm}$ with a $20 \mathrm{~cm}$ interval, in addition to surface soils (5 and $10 \mathrm{~cm}$ ) and deep soils (165, 180, 200 and $220 \mathrm{~cm}$ ) in August 2012 (L5-12). Groundwater tables were 250 and $220 \mathrm{~cm}$ at L5-10 and L5-12, respectively; samples of groundwater were taken simultaneously with the soil samples. At the Gobi sites (L6-10), soil samples were taken from 20 to $160 \mathrm{~cm}$ deep with $20 \mathrm{~cm}$ interval, as well as from 175, 180, 185, 200, 220 and $255 \mathrm{~cm}$ soil layers in June 2010. Soil samples from 5 and $10 \mathrm{~cm}$, and from 20 to $300 \mathrm{~cm}$ with $20 \mathrm{~cm}$ interval were taken in August 2012 (L6-12). Groundwater table was deeper than $5.0 \mathrm{~m}$ in both L6-10 and L6-12. All soil samples were put in glass containers and were sealed immediately with Parafilm. To measure soil gravimetric water content (w/w \%), $20 \mathrm{ml}$ of soil samples from all soil layers with three glass bottles were used. In addition, two glass bottles, each contained $8 \mathrm{ml}$ soil sample, were used to measure $\delta^{2} \mathrm{H}$ and $\delta^{18} \mathrm{O}$ in every soil profile by extracting the water.

\section{Precipitation sampling}

Precipitation samples were collected at Yeniugou (P1: 3320 m a.s.1.), Hulugou (P2: 3020 m a.s.1.), and Pailugou (P3: $2700 \mathrm{~m}$ a.s.1.) in the upper reaches, at Zhangye (P4: $1483 \mathrm{~m}$ a.s.1.) in the middle reaches, and at Ejina (P5: $920 \mathrm{~m}$ a.s.1.) in the lower reaches (Fig. 1a). At Yeniugou, samples were collected for individual events from June 2008 to September 2009. At Hulugou, single-event precipitation samples were collected from July to September 2009 and May to October 2014. At Pailugou, precipitation was sampled once per two hours during two precipitation periods in July and August 2009, and single-event samples were collected from September to November 2008 and June 2011 to October 2014. At Ejina, single-event precipitation samples were collected from January 2007 
to December 2010. Stable isotope composition of previous years precipitation (1986-2003) at Zhangye (Fig. 1a P4) were obtained from the GNIP database (http://nds121.iaea.org/wiser) (Zhao et al., 2012). To prevent evaporation of the sampled water, rain samples for each precipitation event were collected and immediately transferred to fill air-tight $8 \mathrm{ml}$ or $20 \mathrm{ml}$ plastic bottles (Brand $\mathrm{CNW}$, Germany). The solid samples (snow and hail) were collected and then melted in low-density polyethylene zip-lock bags at room temperature before being sealed into plastic bottles. We used new low-density polyethylene bags for each sample. All samples were stored at 6 to $8^{\circ} \mathrm{C}$ prior to analysis.

\section{Water extraction for isotope analyses}

All samples were processed at the Key Laboratory of Ecohydrology of the Inland River Basin, Northwest Institute of Eco-Environment and Resources, Chinese Academy of Sciences. Water was extracted from root, stem and soil with cryogenic vacuum distillation (Ehleringer et al., 2000, West et al., 2006). Samples in extraction vials were heated to $100^{\circ} \mathrm{C}$ and evaporated water was trapped in Utubes, submerged in liquid nitrogen. We have done extensive water extraction tests in the laboratory including using species from other regions that do not show any significant difference between source water and xylem water after the extraction. West et al., (2006) estimated a minimum extraction time of 60-75 min for woody stems, $40 \mathrm{~min}$ for clay soils, $30 \mathrm{~min}$ for sandy soils, and 20 to $30 \mathrm{~min}$ for leaves during vacuum distillation to obtain an unfractionated water sample. In our study, extraction was performed under a vacuum of $0.03 \mathrm{hPa}$ for at least two hours in order to ensure an unfractionated water sample (West et al., 2006). The extracted water samples were sealed with Parafilm, placed in a bath and allowed to thaw. The liquid water was then transferred to a $2 \mathrm{ml}$ vial for $\delta^{18} \mathrm{O}$ and $\delta^{2} \mathrm{H}$ analysis.

\section{Measurement of soil water content}


Gravimetric water content of each soil sample was measured by weighing the soil sample, then heating the sample for $24 \mathrm{~h}$ at $105^{\circ} \mathrm{C}$. The samples were then cooled in a desiccator and the dry soil was weighted.

\section{Isotope analysis}

The $\delta^{18} \mathrm{O}$ and $\delta^{2} \mathrm{H}$ values of the water samples were measured using Isoprime isotope ratio mass spectrometer (Isoprime Ltd, UK) coupled to a Euro EA3000 element analyzer at Heihe Key Laboratory of Ecohydrology and River Basin Science, Northwest Institute of Eco-Environment and Resources. To avoid any memory effect associated with continuous-flow methods, measurements of each sample were repeated five times, and the first values were discarded. The accuracy was better than $\pm 1.0 \%$ for $\delta^{2} \mathrm{H}$ and $\pm 0.2 \%$ for $\delta^{18} \mathrm{O}$. The $\delta^{18} \mathrm{O}$ and $\delta^{2} \mathrm{H}$ were calibrated using two international standard materials (V-SMOW and GISP or SLAP) and one working standard. The $\delta^{18} \mathrm{O}$ and $\delta^{2} \mathrm{H}$ values are expressed in \%o on a V-SMOW-SLAP scale. This method is a mass-based method of analysis, and trace amounts of contaminants are unlikely to have a large effect on the isotopic value of a water sample measured by IRMS due to the relatively small mass contribution that they make to the total amount of ${ }^{1} \mathrm{H},{ }^{2} \mathrm{H},{ }^{16} \mathrm{O}$ and ${ }^{18} \mathrm{O}$ isotopes in the sample (West et al., 2010).

\section{Data analysis}

The Bayesian isotope mixing model (MixSIAR) was used to determine the uptake fractions of water sources (Parnell et al., 2010), and the software package MixSIAR (Stock and Semmens, 2013) was used for the analysis of source water contributions to the plant isotopic composition. MixSIAR is

a flexible framework to create mixing models based on the Bayesian theory (Bowen et al., 2018; 
Erhardt and Bedrick, 2013; Moore and Semmens, 2008; Parnell et al., 2010, 2013), and it is available to download from the packages section of the Comprehensive R Archive Network site (CRAN)http://cran.r-project.org/.

One of the main principles of the isotope tracing methodology is the assumption that isotope fractionation during root water uptake does not occur (Allison et al., 1983; Dawson and Ehleringer, 1991; Ehleringer and Dawson, 1992; White et al., 1985). If it is true, the $\delta^{18} \mathrm{O}$ and $\delta^{2} \mathrm{H}$ of xylem water should always be within the range of values of all water sources. However, xylem water $\delta^{18} \mathrm{O}$ could always be interpreted as a mixture of deep and shallow soil waters, but the $\delta^{2} \mathrm{H}$ of xylem water was sometimes more depleted than the considered water sources (Barbeta et al., 2019). Vargas et al. (2017) showed that $P$. americana plants discriminated against hydrogen isotopes about 10 times more than oxygen isotopes during water uptake. Brooks et al. (2010) and Oerter and Bowen (2019) reported that $\delta^{18} \mathrm{O}-\delta^{2} \mathrm{H}$ plots of xylem water occupy the $\delta^{18} \mathrm{O}-\delta^{2} \mathrm{H}$ space well below the soil water line, suggestive of deuterium fractionation processes during root water uptake. Other previous studies also found that the isotopic compositions of xylem water are relatively depleted compared to those of the considered sources (De Deurwaerder et al., 2018; Ellsworth and Williams, 2007; Evaristo et al., 2017; Geris et al., 2017; Oerter and Bowen, 2019; Oerter et al., 2014; Wang et al., 2017; Zhao et al., 2016). If such fractionation processes are not considered, the estimation of plant water sources may be inaccurate. Evaristo et al. (2017) showed that erroneous results could be obtained when a simple mass balance approach using only hydrogen isotopes was implemented, but they also concluded that results were less sensitive to deuterium fractionation when both deuterium and oxygen isotopes were combined within a Bayesian inference approach. Therefore, we selected typical sites characteristic of deuterium fractionation (M1-10, L2-12, L5-10 and L3-08) and deuterium non-fractionation (U7, U9-9, M4-12 
and L6-12) to calculate the water source contributions using $\delta^{18} \mathrm{O}$ alone, $\delta^{2} \mathrm{H}$ alone and both $\delta^{18} \mathrm{O}$ and $\delta^{2} \mathrm{H}$ by the Bayesian isotope mixing model. We find remarkedly differences among the three methods if deuterium fractionation occurs, especially at L5-10, which contributions of groundwater to HA were $70.0 \%$ for $\delta^{18} \mathrm{O}, 0.2 \%$ for $\delta^{2} \mathrm{H}$ and $49.9 \%$ for both $\delta^{18} \mathrm{O}$ and $\delta^{2} \mathrm{H}$ methods, respectively (Table S1). We also compared the results with deuterium fractionation using $\delta^{18} \mathrm{O}$ alone, $\delta^{2} \mathrm{H}$ alone and both $\delta^{18} \mathrm{O}$ and $\delta^{2} \mathrm{H}$ between the Iso-Source model (Phillips and Gregg, 2003) and the Bayesian isotope mixing model (Table S2), and found similar results using $\delta^{18} \mathrm{O}$ alone by both approaches in the calculated sites. Therefore, in this study, similar to previous studies, we assumed that oxygen isotope fractionation does not occur during plant uptake water, and we used the Bayesian isotope mixing model to quantify the relative contribution of water sources for different plant species based on $\delta^{18} \mathrm{O}$ data alone. In addition, in our study, when $\delta^{18} \mathrm{O}$ of plant xylem water was not within the range of values of all water sources, we took $100 \%$ as the contributions of their nearest water sources such as U1, U2, M1-12 and L3-08

(Table 5). The most probable sources of water uptake were estimated by comparing the $\delta^{18} \mathrm{O}$ of stem water with soil water and groundwater. Precipitation and river water were not considered as precipitation is low and all sites are far away from the main river.

\section{Results}

\section{Seasonal precipitation and soil water content}

\section{Fig. 2+Table 3 here}

Mean annual precipitation of the upper reaches, middle reaches and lower reaches are 404.1, 129.9, and $34.9 \mathrm{~mm}$, respectively (Fig. 1b). In order to indicate the plant water use strategy responses to precipitation, the precipitation of two months before sampling date was used (Fig. S1). During our 
study periods, corresponding to precipitation along the basin scale and in the lower reaches with water supply from the middle reaches, the profile mean soil water content varied greatly from the upper reaches to the lower reaches. The profile mean soil water content were $34.2 \%, 2.0 \%$ and $8.2 \%$, and varied from $17.0 \pm 2.3$ (U3) to $64.5 \% \pm 3.9$ (U4), from $1.6 \pm 0.4$ (M3-12) to $2.3 \% \pm 0.6$ (M1-10), and from $6.6 \pm 5.9$ (L1-12) to $12.4 \% \pm 7.5$ (L2-10) in the upper, middle and lower reaches, respectively (Table 3 ). Soil water content (SWC) of the profiles at each study site also varied greatly (Fig. 2a-2g). The SWC of the profiles in the upper reaches (Fig. 2a-2b) and middle reaches (Fig. 2c-2e) were relatively stable. However, the riparian forest, planted shrubland and Gobi in the lower reaches have steeper SWC gradients than those of the upper and middle reaches, and the water table is overlain by uniformly dry soil in the lower reaches (Fig. 2f-2g).

\section{Isotopic compositions of different water pools}

\section{Fig. $3+4$ and Table 4 here}

The $\delta^{18} \mathrm{O}$ and $\delta^{2} \mathrm{H}$ in event-based precipitation varied from -33.3 to $13.1 \%$ and -253.4 to $113.0 \%$ o at three mountainous sites of the upper reaches, and from -25.3 to $4.9 \%$ and -217.8 to $36.4 \%$ at Ejina of the lower reaches, respectively (Fig. S2). The slopes and intercepts of the local meteoric water lines (LMWLs) were 7.883 and $14.270,7.013$ and -2.871 , and 7.731 and -6.948 , respectively at the upper, the middle and the lower reaches (Fig. S2).

The isotopic composition of soil water exhibited both rainfall and groundwater effects and varied greatly along the strong climatic gradient in the inland Heihe River Basin (Fig. 3 and 4; Table 4). In general, the $\delta^{18} \mathrm{O} / \delta^{2} \mathrm{H}$ values of soil water were most negative in the upper reaches $(-6.6 \pm 2.5 \%$ /$48.8 \pm 12.9 \%$ ) associated with greater precipitation amount, and were negative at the riparian site ($3.6 \pm 3.4 \% 0 /-39.3 \pm 11.1 \%$ o $)$ and the planted shrubland $(-4.4 \pm 3.6 \%$ / $-55.3 \pm 7.2 \%$ o $)$ in the lower reaches 
associated with shallower groundwater level. They were more positive at the desert-oasis ecotone ($0.5 \pm 4.2 \%$ o/ $-37.4 \pm 16.3 \%$ o $)$ and the Gobi $(1.8 \pm 1.9 \%$ / $-30.3 \pm 8.7 \%$ ) in the middle reaches, and the Gobi $(0.4 \pm 2.8 \%$ o/-45.5 $\pm 5.7 \%$ ) in the lower reaches (Fig. 3 and 4; Table 4). In addition, except for 2012 (a precipitation event occurred just before sampling), the $\delta^{18} \mathrm{O}$ values of soil water in the upper soil layers were higher than those of the lower layers due to evaporation (Fig. 4). The slope and intercept of the soil water evaporation lines (SWELs) decreased from the upper to lower reaches (except 2009 in the lower reaches), and were lower than those of their corresponding local meteoric water lines (LMWLs) (Fig. S2; Fig. 3). During the study period, the $\delta^{18} \mathrm{O} / \delta^{2} \mathrm{H}$ value of groundwater was more negative in the middle reaches $(-7.8 \pm 0.2 \%$ o $-49.7 \pm 0.5 \%$ o $)$ than that of the lower reaches $(-6.7 \pm 1.0 \%$ o $/-47.7 \pm 9.7 \%$ o $)$ (Fig. 3 and 4; Table 4), while the groundwater exhibited relatively more steady isotope values in the middle reaches than those of the lower reaches, especially at planted shrubland and Gobi (Fig. 3; Table 4). Different from soil water variations, the $\delta^{18} \mathrm{O} / \delta^{2} \mathrm{H}$ values of xylem water varied with their potential water sources (Fig. 3 and 4; Table 4). For example, the more negative $\delta^{18} \mathrm{O} / \delta^{2} \mathrm{H}$ values of xylem water were found at sites in the middle $(-7.5 \pm 0.3 \%$ o/ $-60.9 \pm 4.1 \%$ for Tamarix ramosissima, and $-7.4 \%$ / $/-67.8 \%$ o for Haloxylon ammodendron) and the lower reaches (-7.6 $\pm 0.3 \%$ / $-69.2 \pm 2.4 \%$ at planted shrubland, and $-5.4 \%{ }_{0} \pm 1.3 \%$ / $/-50.5 \pm 5.2 \%$ at riparian forest), where groundwater is available to plants. And the more negative $\delta^{18} \mathrm{O} / \delta^{2} \mathrm{H}$ values of xylem water were also found in the upper reaches $(-6.1 \pm 1.9 \%$ /$48.1 \pm 11.6 \%$ at Qinghai spruce forest, and $-3.5 \pm 1.9 \% /-48.9 \pm 8.4 \%$ at alpine grassland meadow region) (Fig. 3 and 4; Table 4) affected by precipitation. In addition, the $\delta^{18} \mathrm{O} / \delta^{2} \mathrm{H}$ values of xylem water of tree, shrub and herbaceous plants became progressively more positive at Qinghai spruce forest in the upper reaches and riparian forest in the lower reaches (Fig. 3 and 4; Table 4). The more positive $\delta^{18} \mathrm{O} / \delta^{2} \mathrm{H}$ values of xylem water were found at sites in the middle $(-0.6 \pm 0.6 \%$ o $/-33.4 \pm 5.1 \%$ for 
Haloxylon ammodendron at desert-oasis ecotone, and $0.8 \pm 0.8 \%$ / $-33.5 \pm 1.8 \%$ at Gobi) and lower reaches $(-2.5 \pm 0.2 \%$ o/ $-49.1 \pm 5.5 \%$ at Gobi) (Fig. 3 and 4; Table 4), where soil water is likely the main water source to plants.

\section{Contributions of potential water sources along the climatic gradient}

Figure 5 and Table 5 here

The contributions of potential water sources to different plant species varied along the strong climatic gradient and different soil water environments (Fig. S1; Fig. 2, 4 and 5; Table 5). In the upper reaches, the water use patterns of plant species were varied and controlled by precipitation. For example, grasses and herbaceous plants used water chiefly from the top $10 \mathrm{~cm}$ of the soil profile throughout the year, and more than $70 \%$ water sources came from the top $5 \mathrm{~cm}$ of the soil profile during wet season and at high soil water content sites. Shrubs such as Potentilla fruticosa also used surface soil water during wet season $(0-5 \mathrm{~cm})$ and used shallow soil water during dry season (up to 15 $\mathrm{cm}$ ). Qinghai spruce used deeper water sources, chiefly down to $40 / 60 \mathrm{~cm}$ in wet season and deeper (up to $120 \mathrm{~cm}$ ) in dry season (Fig. S1a; Fig. 2a-b; Fig. 4a-b and 5a; Table 5).

In the middle reaches, main water sources were deep soil water/groundwater/precipitation, and their contributions varied with precipitation (Fig. S1b; Fig. 2c-e, 4c-d and 5b; Table 5). At the desertoasis ecotone, groundwater was the main water source for Tamarix ramosissima, which were not affected by precipitation. For Haloxylon ammodendron, when groundwater was available, it was completely dependent on it. However, when groundwater was too deep, deep soil water was the main water sources for it, and the contributions varied with precipitation. Similarly, Reaumuria soongorica and Nitraria tangutorum used deeper layer soil water at Gobi with low precipitation (Fig. S1b; Fig. 2c-e, 4c-d and 5b; Table 5). 
In the lower reaches, in the extremely arid region such as Ejina, where the annual precipitation is about $39 \mathrm{~mm}$, the main and stable water sources of plants were shallow groundwater/deep soil water recharged by groundwater, which were not affected by precipitation (Fig. 2f-i, 4e-g and 5c-d; Table 5). At the riparian forest, groundwater and their corresponding saturated layer soil water were the main water source to Populus euphratica. Soil water was the stable water source of herbaceous plant such as Sophora alopecuroides. For shrub such as Tamarix ramosissima, deep soil water was its main water source, and it also used groundwater. In addition, water sources of Populus euphratica, Tamarix ramosissima and Sophora alopecuroides differed remarkably at the same site such as L3-08 and L408. Populus euphratica mainly depended on groundwater, Tamarix ramosissima depended on deep soil water and groundwater, and Sophora alopecuroides depended on soil water (Fig. 4e; Fig. 5c; Table 5). For the planted shrubs of the planted shrubland, groundwater and deep soil water recharged from groundwater were main water sources for Haloxylon ammodendron (Fig. 4f; Fig. 5d; Table 5). For shrubs at Gobi, deep soil water recharged from groundwater was the stable water source of Reaumuria soongorica (Fig. 4g; Fig. 5d; Table 5).

\section{Discussion}

\section{Isotopic patterns of different water pools}

For precipitation, the slopes of the LMWLs of the upper (7.883), the middle (7.013) and the lower reaches (7.731) (Fig. S2) were slightly lower than that of the GMWL (8), and the intercepts of the upper reaches (14.270) was higher than that of the GMWL (10), while of the middle (-2.871) and lower reaches (-6.948) were very low (Fig. S2). Our results indicated that the local climatic factors (e.g., strong moisture recycling, re-evaporation of raindrops during precipitation and seasonality of 
precipitation) affected the precipitation isotope ratios along the Heihe River Basin, and stronger evaporation occurred at the middle and lower reaches (Fig. 1; Fig. S2) (Mook, 2000; Zhao et al., 2019).

For soil water isotopes, the mean $\delta^{18} \mathrm{O}$ and $\delta^{2} \mathrm{H}$ values varied significantly (Fig. 3; Table 4). These soil $\delta^{18} \mathrm{O}$ and $\delta^{2} \mathrm{H}$ variations revealed the complex affecting factors on isotopic discrimination under different environments, for example, precipitation infiltration and evaporation at the upper reaches, evaporation, groundwater recharge and precipitation infiltration at the middle reaches, and evaporation, groundwater recharge and surface water delivery at the lower reaches (Cheng et al. 2014; Hu et al. 2015; Vereecken et al. 2016; Zhang et al. 2018). The decreases of slopes and intercepts of SWELs from the upper to the lower reaches (Fig. 3) revealed the significant decrease of relative humidity from the upper to the lower reaches of the Heihe River Baisn (Fig. 1), and these variations can be explained by the increase in the effective thickness of the vapor transport layer (Barnes and Allison, 1988) and the stronger soil isotopic kinetic effect from the upper to the lower reaches (Cooper et al. 1991). The slopes and intercepts of SWELs were significantly lower than their corresponding LMWLs, which revealed strong evaporation effect on soil water, and these evaporation effect increased gradually from the upper to lower reaches (Fig. 1). For most sampling dates, the profile of soil water $\delta^{18} \mathrm{O}$ was characterized by more positive isotopic values in shallow soil layers and more negative values in deeper and saturated soil layers, and these profile variation ranges increased gradually from the upper to the lower reaches (Fig. 3 and 4). However, at U8-12, U9-6 and U9-9 of the upper reaches, at M212 and M4-12 in the middle reaches and at L5-12 and L6-12 in the lower reaches, an inverse curve was found with depleted values in shallow soil layers, and this inverse pattern could be explained by infiltration of precipitation characterized by negative isotopic values (Newman et al., 1997).

For xylem water isotopes, significant differences were found among the mean $\delta^{18} \mathrm{O} / \delta^{2} \mathrm{H}$ values of 
plant xylem water along the Heihe River Basin (Fig. 3 and 4; Table 4). These results revealed that there were very complex water sources for different plants along the Heihe River Basin. The mean $\delta^{2} \mathrm{H}$ of groundwater were much higher than those of xylem water of Populus euphratica, Tamarix ramosissima and Haloxylon ammodendron, suggesting possible deuterium fractionation occurred between xylem sap/stem tissue water and their water source for these three species (Brooks et al., 2010; De Deurwaerder et al., 2018; Evaristo et al., 2017; Geris et al., 2017; Oerter and Bowen, 2019; Wang et al., 2017; Zhao et al., 2016).

Biplots of $\delta^{2} \mathrm{H}$ and $\delta^{18} \mathrm{O}$ : In the upper reaches, the plots of $\delta^{2} \mathrm{H}-\delta^{18} \mathrm{O}$ of shallow soil water and xylem water were relatively far away from its corresponding LMWL. This trend was particularly obvious for $\delta^{2} \mathrm{H}$ and $\delta^{18} \mathrm{O}$ of xylem water, suggesting that: (i) plant water source originated from soil water, (ii) soil water came from the local precipitation, and (iii) strong soil evaporation was occurred in the shallow soil layer in the upper reaches (Fig. 3a). In the middle reaches, the plots of $\delta^{2} \mathrm{H}$ and $\delta^{18} \mathrm{O}$ of xylem water in desert-oasis ecotone and Gobi suggested that plant water source of these sites came mainly from shallow groundwater and soil water (Fig. 3b). At the riparian forest and planted shrubland of the lower reaches, the plots of $\delta^{2} \mathrm{H}$ and $\delta^{18} \mathrm{O}$ of xylem water and soil water were near the shallow groundwater and river water, indicating that soil water and xylem water were from groundwater recharged from river (Fig. 3c). The $\delta^{2} \mathrm{H}-\delta^{18} \mathrm{O}$ plots of soil water and xylem water were far away from the plots of river water and groundwater in Gobi, indicating the strong evaporation occurred at these regions, and soil water was the main water source for Reaumuria soongorica (Fig. 3d).

\section{Contributions of potential water sources along the climatic gradient}

In the upper reaches: Surface soil water (up to $5 \mathrm{~cm}$ ) and shallow soil water (up to $10 / 15 \mathrm{~cm}$ ) were the main water sources for herbaceous plants and shrubs, and the herbaceous plants and shrubs 
preferentially used 0-5 cm soil water during wet season or under well-watered conditions. During dry season or under well-stressed conditions, the herbaceous plants shifted to use 0-10 $\mathrm{cm}$ soil water, and shrubs shifted to $15 \mathrm{~cm}$ soil water (Fig. S1a; Fig. 2a; Fig. 4a; Fig. 5a; Table 5). These results indicated that as herbaceous plants and shrubs usually have shallow rooting system, the alpine steppe meadow zone in the upper reaches of the Heihe River Basin where these herbaceous plants dominate is prone to degradation due to decreasing precipitation, and these results also highlighted the importance of precipitation as the main controlling factor of water use patterns for shrubs in the upper reaches of the Heihe River Basin. Trees such as Qinghai Spruce appeared to be acquiring water preferentially from the upper $40 / 60 \mathrm{~cm}$ of the soil profile during wet season. However, Qinghai spruce seemed to be tapping water mostly from greater depths during dry season, and the depths reached $120 \mathrm{~cm}$ (Fig. S1a; Fig. 2b; Fig. 4b; Fig. 5a; Table 5). Our results indicated that the controlling factor of water uptake was precipitation and water use patterns of different plant species varied with precipitation and species in the upper reaches.

As climate becomes drier from the upper to the middle reaches, we observed that groundwater or deep soil moisture contributed majority of the water needs of shrubs (Fig. 4c-d; Fig. 5b; Table 5). Some species exhibited strong plasticity in water uptake sources (Fig. 4c-d; Fig. 5b; Table 5). For example, groundwater was only water source for Tamarix ramosissima. Haloxylon ammodendron preferentially access to groundwater even under high precipitation if groundwater is its stable water source. However, contributions of $0-40 \mathrm{~cm}$ soil water to Haloxylon ammodendron increased dramatically after large precipitation when it cannot use groundwater (Fig. S1b; Fig. 1c; Fig. 4c; Fig. 5b; Table 5), revealing that water use strategy of Haloxylon ammodendron was controlled by groundwater level, deep soil water and precipitation (Fig. 4d; Fig. 5; Table 45). Deep soil water and precipitation were the main 
water source for Reaumuria soongorica and Nitraria tangutorum, and their water use strategy was controlled by both deep soil water and precipitation (Fig. S1b; Fig. 4d; Fig. 5b; Table 5).

In the extremely arid region (i.e., Ejina) of the lower reaches, the main and stable water sources of plants were shallow groundwater and deep soil water recharged by groundwater (Fig. 4e-g; Fig. 5cd; Table 5). For trees: shallow groundwater and statured soil water layer in the riparian forest were the main water sources for Populus euphratica (Fig. 4e; Fig. 5c; Table 5). These results were consistent with the results of Pettit et al. (2018) who reported that the dominant tree species Eucalyptus camaldulensis (river red gum) growing at riparian of Maules Creek is capable of utilizing groundwater even to depths $>10 \mathrm{~m}$. At L1-10, the main water source of Populus euphratica came from deep soil water $(71.1 \%)$ and groundwater $(21.1 \%)$, relating to water delivery from the middle reaches to the lower reaches (Table 5; Cheng et al. 2014; Hu et al. 2015; Zhang et al. 2018). For herbaceous plants: soil water was the stable water source of herbaceous plant such as Sophora alopecuroides, although the contributions of soil water varied with soil water content (Fig. 2; Fig. 4e; Fig. 5c; Table 5). For shrub such as Tamarix ramosissima, except at L2-10, deep soil water was its main water source, and it also used groundwater (Fig. 4e; Fig. 5c; Table 5). In addition, as aridity and groundwater depth increased, we found that coexisting plant species adopted different water use strategies in extremely water-limited environments. For example, water sources of Populus euphratica, Tamarix ramosissima and Sophora alopecuroides differed remarkably, and their main water sources were groundwater for Populus euphratica, deep soil water and groundwater for Tamarix ramosissima, and soil water for Sophora alopecuroides with groundwater level $>10.0 \mathrm{~m}$, (Table 5). Our results were consistent with the findings of several other studies, which demonstrated that coexisting plant species would adopt different plasticity in water use strategies in water-limited environments (West et al., 2007; Eggemeyer 
et al., 2009). For the planted shrubland: deep soil water recharged from groundwater and groundwater were main water sources of Haloxylon ammodendron (Fig. 4f; Fig. 5d; Table 5). For Gobi: due to the extremely low precipitation, pulses of high precipitation (e.g., $12.1 \mathrm{~mm}$ precipitation in July 2012) did not affect the water sources for the shrubs. Deep soil water recharged from groundwater below $160 \mathrm{~cm}$ was the stable water source of Reaumuria soongorica at Gobi (Fig. 4g; Fig. 5d; Table 5). Therefore, in the lower reaches, the riparian forest and the planted shrubland relied primarily on groundwater and deep soil moisture to survive. Deep soil water recharged from groundwater below $220 \mathrm{~cm}$ was a stable water source of Reaumuria soongorica. The maintenance of groundwater level has a vital role in maintaining the stability of oasis in the lower reaches of the Heihe River Basin (Fig. 5c-d; Table 5).

\section{The species-specific water use strategy adaptations}

In our study, Tamarix ramosissima, Haloxylon ammodendron and Reaumuria soongorica appear in both the middle and lower reaches. In the middle reaches, groundwater was the only water source for Tamarix ramosissima under low soil water conditions, and its water use patterns did not respond to precipitation (Fig. 2c, Fig. 4c; Fig. 5b; Table 5). However, its water use patterns showed great flexibility in the lower reaches. It used soil water when soil water content was high, and then used deep soil water and groundwater when it can get groundwater (Fig. 2g; Fig. 4e; Fig. 5c; Table 5). These results indicated that Tamarix ramosissima increase its adaptive capacity through changing its water use mode under extremely arid environment in the lower reaches. For Haloxylon ammodendron, it used soil water when it cannot access groundwater and contributions of shallow soil water varied depending on precipitation. Its main water source shifted to groundwater when it can get groundwater 
in the middle reaches (Fig. 2d; Fig. 4c; Fig. 5b; Table 5). In the lower reaches, groundwater and deep soil water recharged from groundwater were its only water sources even under relatively high water soil content ( $>10 \%$ at about $140 \mathrm{~cm}$ ) at L5-10 (Fig. 2h; Fig. 4f; Fig. 5d; Table 5). These results indicated that in the lower reaches, groundwater was the main water source for Haloxylon ammodendron and maintaining a suitable groundwater level is very important. For Reaumuria soongorica, soil water was its main water source in both middle and lower reaches. However, its water use patterns varied remarkably. In the middle reaches, Reaumuria soongorica used shallow soil water when there is a large precipitation (45.0\% water from 0 to $80 \mathrm{~cm}$ at M4-12; 9.6\% water from 0 to $80 \mathrm{~cm}$ at M4-10 (Fig. 2e; Fig. 4d; Fig. 5b; Table 5), and the contributions of below $120 \mathrm{~cm}$ soil water to Reaumuria soongorica were $80.2 \%$ at M4-10 $(6.7 \mathrm{~mm})$ and $36.7 \%$ at M4-12 $(32.8 \mathrm{~mm})$ (Table 5). In the lower reaches, main water sources of Reaumuria soongorica were from below $220 \mathrm{~cm}$ soil water recharged from groundwater, and its water use patterns did not respond to precipitation (Fig. 2i; Fig. 4g; Fig. 5d; Table 5). These results also highlighted that in the lower reaches, groundwater was the main water source for Reaumuria soongorica ecosystem at Gobi.

\section{Summary and implications}

Our study suggested that there were significantly different water sources for various plants under different climatic conditions in the Heihe River Basin, northwestern China. In the upper reaches, when precipitation is ample, it recharges soil water, which then becomes the main plant water source. Plants used shallow soil water during wet season, and used deeper soil water during dry season. Water uptake patterns thus vary inter-annually following seasonal fluctuations in precipitation and soil water. As climate becomes drier in the middle reaches, plants relied on groundwater/deeper soil water sources, 
although precipitation still had contributions to a certain degree. Some variations occurred with species and ecosystem types. At the driest part of the Heihe River Basin, water use strategy was not affected by precipitation. Groundwater and deep soil water recharged by groundwater were potential water sources for different plants in the riparian forest, the planted shrubland and Gobi. The maintenance of groundwater level has vital role in maintaining the stability of oasis in the lower reaches of the Heihe River Basin. Lastly, there are emerging evidence that there are potential deuterium fractionation during plant water uptake (Brooks et al., 2010; De Deurwaerder et al., 2018; Evaristo et al., 2017; Geris et al., 2017; Oerter and Bowen, 2019; Wang et al., 2017; Zhao et al., 2016), our extensive field observation added critical information on this aspect.

\section{Acknowledgments}

This study was supported by the National Natural Science Foundation of China (Grant No. 41771028, 41571025 and 41730751), the National Key Research and Development Program of China (2017YFC0404302), and the Opening Foundation of State Key Laboratory of Continental Dynamics,

Northwest University (19LCD04). Lixin Wang acknowledges support from the Division of Earth Sciences of National Science Foundation (NSF EAR-1554894) and the President's International Research Awards from Indiana University.

\section{References}

Alessio GA, De Lillis M, Brugnoli E, Lauteri M (2004) Water sources and water-use efficiency in Mediterranean coastal dune vegetation. Plant Biology 6: 350-357. https://doi.org/10.1055/s-2004-820882

Allison GB and Hughes MW (1983) The use of natural tracers as indicators of soil-water movement in a temperate semi-arid region. Journal of Hydrology 60: 157-173. https://doi.org/10.1016/0022-1694(83)90019-7

Barbeta A, Jones SP, Clavé L, Wingate L, Gimeno TE, Fréjaville B, Wohl S, Ogée J (2019) Unexplained hydrogen 
isotope offsets complicate the identification and quantification of tree water sources in a riparian forest. Hydrol. Earth Syst. Sci 23: 2129-2146. https://doi.org/10.5194/hess-23-2129-2019

Barbeta A, Mejía-Chang M, Ogaya R, Voltas J, Dawson TE, Peñuelas J (2015) The combined effects of a long-term experimental drought and an extreme drought on the use of plant-water sources in a Mediterranean forest. Global Change Biology 21: 1213-1225. https://doi.org/10.1111/gcb.12785

Barnes CJ, Allison GB (1988) Tracing of water movement in the unsaturated zone using stable isotopes of hydrogen and oxygen. J Hydrol 100: 143-176

Bowen GJ, Putman A, Brooks JR, Bowling DR, Oerter EJ, Good SP (2018) Inferring the source of evaporated waters using stable $\mathrm{H}$ and $\mathrm{O}$ isotopes. Oecologia 187: 1025-1039. https://doi.org/10.1007/s00442-018-4192-5

Brooks JR, Barnard HR, Coulombe R, McDonnell JJ, Renée Brooks J, Barnard HR, Coulombe R, McDonnell JJ (2010) Ecohydrologic separation of water between trees and streams in a Mediterranean climate. Nat. Geosci 3: 100-104. https://doi.org/10.1038/ngeo722

Cheng GD, Li X, Zhao WZ, Xu ZM, Feng Q, Xiao SC, Xiao HL (2014) Integrated study of the water-ecosystemeconomy in the Heihe River Basin. Nat. Sci. Rev 1: 413-428

Cooper LW, DeNiro MJ, Keeley JE (1991) The relationship between stable oxygen and hydrogen isotope ratios of water in astomatal plants. In: HP Taylor Jr, JR O’Neil, IR Kaplan (eds) Stable isotope geochemistry: A tribute to Samuel Epstein. Geochemical Society, St. Louis, MO, pp 247-255

Craig H, Gordon LI (1965) Deuterium and oxygen-18 variations in the ocean and the marine atmosphere. In E. Tongiorgi (ed.), Proceedings of the Conference on Stable Isotopes in Oceanographic Studies and Paleotemperatures. Laboratory of Geology and Nuclear Science Pisa. pp 9-130

Dawson TE, Ehleringer JR (1991) Streamside trees that do not use stream water. Nature 350: 335-337

Dawson TE, Ehleringer JR (1993) Isotopic enrichment of water in the "woody" tissues of plants: Implications for plant water source, water uptake, and other studies which use the stable isotopic composition of cellulose. Geochimica et Cosmochimica Acta 57: 3487-3492. https://doi.org/10.1016/0016-7037(93)90554-A

Dawson TE, Pate JS (1996) Seasonal water uptake and movement in root systems of Australian phraeatophytic plants of dimorphic root morphology: A stable isotope investigation. Oecologia 107: 13-20. https://doi.org/10.1007/BF00582230

De Deurwaerder H, Hervé-Fernández P, Stahl C, Burban B, Petronelli P, Hoffman B, Bonal D, Boeckx P, Verbeeck H (2018) Liana and tree below-ground water competition - evidence for water resource partitioning during the dry season. Tree Physiol 38: 1-13. https://doi.org/10.1093/treephys/tpy002

Dzikiti S, Ntshidi Z, Le Maitre DC, Bugan RDH, Pienaar HH (2017) Assessing water use by Prosopis invasions and Vachellia karroo trees: Implications for groundwater recovery following alien plant removal in an arid 
catchment in South Africa. Forest Ecology and Management 398:153-163. https://doi.org/10.1016/j.foreco.2017.05.009

Eggemeyer KD, Awada T, Harvey FE, Wedin DA, Zhou XH, Zanner CW (2009) Seasonal changes in depth of water uptake for encroaching trees Junipe-rus virginiana and Pinus ponderosa and two dominant $\mathrm{C} 4$ grasses in a semiarid grassland. Tree Physiol 29 (2): 157-169. https://doi.org/10.1093/treephys/tpn019

Ehleringer JR, Dawson TE (1992) Water uptake by plants: perspectives from stable isotope composition. Plant, Cell \& Environment 15: 1073-1082. https://doi.org/10.1111/j.1365-3040.1992.tb01657.x

Ehleringer JR, Roden J, Dawson TE (2000) Assessing ecosystem-level water relations through stable isotope ratio analyses. Osvaldo ES, Robert BJ, Harold AM, et al (eds.). Methods in Ecosystem Science. Springer-Verlag, New York, pp 181-198. https://doi.org/10.1007/978-1-4612-1224-9_13

Ehleringer JR, Schwinning S, Gebauer R (1998) Water use in arid land ecosystems. Physiological plant ecology: 347-366.

Ellsworth PZ, Williams DG (2007) Hydrogen isotope fractionation during water uptake by woody xerophytes. Plant and Soil 291: 93-107. https://doi.org/10.1007/s11104-006-9177-01

Erhardt EB, Bedrick EJ (2013) A Bayesian framework for stable isotope mixing models. Environ. Ecol. Stat 20: 377 397. https://doi.org/10.1007/s10651-012-0224-1

Evaristo J, McDonnell JJ, Clemens J (2017) Plant source water apportionment using stable isotopes: A comparison of simple linear, two-compartment mixing model approaches. Hydrol. Process 31: 3750-3758. https://doi.org/10.1002/hyp.11233

Fu AH, Chen YN, Weihong LI (2014) Water use strategies of the desert riparian forest plant community in the lower reaches of Heihe River Basin, China. SCIENCE CHINA Earth Sciences 57(6): 1293-1305. https://doi.org/10.1007/s11430-013-4680-8

Gat JR, Matsui E (1991) Atmospheric water balance in the Amazon basin: An isotopic evapotranspiration model. Journal of Geophysical Research: Atmospheres 96: 13179-13188. https://doi.org/10.1029/91JD00054

Geris J, Tetzlaff D, McDonnell JJ, Soulsby C (2017) Spatial and temporal patterns of soil water storage and vegetation water use in humid northern catchments. Science of the Total Environment 595: 486-493. https://doi.org/10.1016/j.scitotenv.2017.03.275

Goebel T, Lascano R, Paxton P, Mahan J (2015) Rainwater use by irrigated cotton measured with stable isotopes of water. Agricultural Water Management 158: 17-25. https://doi.org/10.1016/j.agwat.2015.04.005

Hu XL, Lu L, Li X, Wang JH, Guo M (2015) Land use/cover change in the middle reaches of the Heihe River Basin over 2000-2011 and its implications for sustainable water resource management. PLoS One 10, e0128960

Jackson P, Cavelier J, Goldstein G, Meinzer F, Holbrook N (1995) Partitioning of water resources among plants of a lowland tropical forest. Oecologia 101: 197-203

Jiao L, Lu N, Fu BJ, Wang J, Zhang LW (2018) Evapotranspiration partitioning and its implications for plant water use strategy: Evidence from a black locust plantation in the semi-arid Loess Plateau, China. Forest Ecology and Management 424: 428-438. https://doi.org/10.1016/j.foreco.2018.05.011

Klein T, Rotenberg E, Cohen-Hilaleh E, Raz-Yaseef N, Tatarinov F, Preisler Y, Ogée J, Cohen S, Yakir D (2014) 
Quantifying transpirable soil water and its relations to tree water use dynamics in a water-limited pine forest. Ecohydrology 7: 409-419. https://doi.org/10.1002/eco.1360

Kolb TE, Hart SC, Amundson R (1997) Boxelder water source and physiology at perennial and ephemeral stream sites in Arizona. Tree Physiology 17: 151-160. https://doi.org/10.1093/treephys/17.3.151

Lanning M, Wang LX, Benson M, Zhang Q, Novick QK (2020) Canopy isotopic investigation reveals different water uptake dynamics of maples and oaks. Phytochemistry 175: 112389. https:// doi.org/ 10.1016/j.phytochem.2020.112389

Lin GH, Sternberg LDSL (1992) Comparative study of water uptake and photosynthetic gas exchange between scrub and fringe red mangroves, Rhizophora mangle L. Oecologia 90(3): 399-403

Mahindawansha A, Orlowski N, Kraft P, Rothfuss Y, Racela H, Breuer L (2018) Quantification of plant water uptake by water stable isotopes in rice paddy systems. Plant Soil 429: 281-302. https://doi.org/10.1007/s11104-0183693-7

Mook WG, De Vries JJ (2000) Environmental isotopes in the hydrological cycle: principles and applications. Surface Water Volume 3. https://doi.org/10.1016/0009-8981(91)90277-J

Moore JW, Semmens BX (2008) Incorporating uncertainty and prior information into stable isotope mixing models. Ecology Letters 11: 470-480. https://doi.org10.1111/j.1461-0248.2008.01163.x

Newman BD, Campbell AR, Wilcox BP (1997) Tracer-based studies of soil water movements in semi-arid forests of New Moxico. Journal of Hydrology 196: 251-270. https://doi.org/10.1016/S0022-1694(96)03320-3

Nie YP, Chen HS, Wang KL, Yang J (2012) Water source utilization by woody plants growing on dolomite outcrops and nearby soils during dry seasons in karst region of Southwest China. Journal of Hydrology 420-421, 264-274. https://doi.org/10.1016/j.jhydrol.2011.12.011

Oerter E, Finstad K, Schaefer J, Goldsmith GR, Dawson T, Amundson R (2014) Oxygen isotope fractionation effects in soil water via interaction with cations $(\mathrm{Mg}, \mathrm{Ca}, \mathrm{K}, \mathrm{Na})$ adsorbed to phyllosilicate clay minerals. Journal of Hydrology 515: 1-9. http://dx.doi.org/10.1016/j.jhydrol.2014.04.029

Oerter EJ, Bowen GJ (2019) Spatiotemporal heterogeneity in soil water stable isotopic composition and its ecohydrologic implications in semi-arid ecosystems. Hydrological Processes 0-2, https://doi.org/10.1002/hyp.13434

Ohte N, Koba K, Yoshikawa K, Sugimoto A, Matsuo N, Kabeya N, Wang LH (2003) Water utilization of natural and planted trees in the semiarid desert of Inner Mongolia, China. Ecological Applications 13: 337-351. https://doi.org/10.1890/1051-0761(2003)013[0337:WUONAP]2.0.CO;2

Parnell AC, Inger R, Bearhop S, Jackson AL (2010) Source Partitioning Using Stable Isotopes: Coping with Too Much Variation. PLoS ONE 5(3): e9672. doi:10.1371/journal.pone.0009672

Parnell AC, Phillips DL, Bearhop S, Semmens BX, Ward EJ, Moore JW, Jackson AL, Grey J, Kelly DJ, Inger R 
(2013) Bayesian stable isotope mixing models. Environmetrics 24, n/a-n/a. https://doi.org/10.1002/env.2221

Pettit NE Froend RH (2018) How important is groundwater availability and stream perenniality to riparian and floodplain tree growth? Hydrological Processes 1-13. https://oi.org/10.1002/hyp11510.

Phillips D L, Gregg JW (2003) Source partitioning using stable isotopes: Coping with too many sources. Oecologia 136: 261-269. https://doi.org/10.1007/s00442-003-1218-3

Poca M, Coomans O, Urcelay C, Zeballos SR, Bodé S, Boeckx P (2019) Isotope fractionation during root water uptake by Acacia caven is enhanced by arbuscular mycorrhizas. Plant Soil 441: 485-497. https://doi.org/10.1007/s11104-019-04139-1

Reynolds J, Smith DS, Lambin E, Turner B, Mortimore M, Batterbury S, Downing T, Dowlatabadi H, Fernández R, Herrick J, Huber-Sannwald E, Leemans R, Lynam T, Maestre F, Ayarza M, Walker B (2007) Global desertification: building a science for dryland development. Science 316: 847-851. https://doi.org/10.1126/science.1131634

Romero-Saltos H, da SL Sternberg L, Moreira MZ, Nepstad DC (2005) Rainfall exclusion in an eastern Amazonian forest alters soil water movement and depth of water uptake. American Journal of Botany 92: 443-455. https://doi.org/10.3732/ajb.92.3.443

Rosatto DR, Silva LDCR, Villalobos-Vega R, Sternberg LDSL, Franco AC (2012) Depth of water uptake in woody plants relates to groundwater level and vegetation structure along a topographic gradient in a neotropical savanna. Environmental and Experimental Botany 77: 259-266. https://doi.org/10. 1016/j.envexpbot.2011.11.025

Ruan YF, Zhao LJ, Xiao HL, Cheng GD, Zhou MX, Wang F (2014) Water sources of plants and groundwater in typical ecosystems in the lower reaches of the Heihe River Basin. Sciences in Cold and Arid Regions 6(3): 02260235. https://doi.org/10.3724/SP.J.1226.2014.00226

Schwinning S, Starr BI, Ehleringer JR (2005) Summer and winter drought in a cold desert ecosystem (Colorado Plateau) part I: effects on soil water and plant water uptake. Journal of Arid Environments 60 (4): 547-566. https://doi.org/10.1016/j.jaridenv.2004.07.003

Snyder KA, Williams DG (2003) Defoliation alters water uptake by deep and shallow roots of Prosopis velutina (Velvet Mesquite). Functional Ecology 17: 363-374. https://doi.org/10.1046/j.1365-2435.2003.00739.x

Stock BC, Semmens BX (2013) MixSIAR GUI User Manual. https/doi.org/10.5281/zenodo. 56159

Sun ZY, Long X, Ma R (2016) Water uptake by saltcedar (Tamarix ramosissima) in a desert riparian forest: responses to intra-annual water table fluctuation. Hydrological Processes 30(9): 1388-1402. https://doi.org/10.1002/hyp.10688

Trogisch S, Salmon Y, He JS, Hector A, Scherer-Lorenzen M (2016) Spatio-temporal water uptake patterns of tree saplings are not altered by interspecific interaction in the early stage of a subtropical forest. Forest Ecology and Management 367: 52-61. https://doi.org/10.1016/j.foreco.2016.02.018

Vargas AI, Schaffer B, Yuhong L, Sternberg LdaSL (2017) Testing plant use of mobile vs immobile soil water sources using stable isotope experiments. New Phytol 215: 582-594, https://doi.org/10.1111/nph.14616

Vereecken H, Schnepf A, Hopmans JW, Javaux M, Or D, Roose T, Vanderborght J, Young MH, Amelung W, Aitkenhead M, Allison SD, Assouline S, Baveye P, Berli M, Brüggemann N, Finke P, FluryM, Gaiser T, Govers 
G, Ghezzehei T, Hallett P, Hendricks Franssen HJ, Heppell J, Horn R, Huisman JA, Jacques D, Jonard F, Kollet S, Lafolie F, Lamorski K, Leitner D, McBratney A, Minasny B, Montzka C, Nowak W, Pachepsky Y, Padarian J, Romano N, Roth K, Rothfuss Y, Rowe EC, Schwen A, Šimůnek J, Tiktak A, van Dam J, van der Zee SEATM, Vogel HJ, Vrugt JA,Wöhling T, Young IM (2016) Modeling soil processes: review, key challenges, and new perspectives. Vadose Zone J 15: 57. https://doi. org/10.2136/vzj2015.09.0131

Voltas J, Lucabaugh D, Chambel MR, Ferrio JP (2015) Intraspecific variation in the use of water sources by the circum-Mediterranean conifer Pinus halepensis. New Phytologist 208: 1031-1041. https://doi.org/10.1111/nph.13569

Wang J, Fu B, Lu N, Zhang L (2017) Seasonal variation in water uptake patterns of three plant species based on stable isotopes in the semi-arid Loess Plateau. Sci. Total Environ 609: 27-37, https://doi.org/10.1016/j.scitotenv.2017.07.133

Wang L, D’Odorico P, Ries L, Caylor K, Macko S (2010) Combined effect of soil moisture and nitrogen availability variations on grass productivity in African savannas: The case of the Kalahari Transect. Plant and Soil 328: 95108, doi 10.1007/s11104-009-0085-z

Wang L, D'Odorico P, Evans J, Eldridge D, McCabe M, Caylor K, King E (2012) Dryland ecohydrology and climate change: critical issues and technical advances. Hydrology and Earth System Sciences 16: 2585-2603. https://doi.org/10.5194/hess-16-2585-2012

West AG, Goldsmith GR, Brooks PD, Dawson TE (2010) Discrepancies between isotope ratio infrared spectroscopy and isotope ratio mass spectrometry for the stable isotope analysis of plant and soil waters. Rapid Communications in Mass Spectrometry 24: 1948-1954. https://doi.org/10.1002/rcm.4597

West AG, Hultine KR, Burtch KG, Ehleringer JR (2007) Seasonal variations inmoisture use in a piñon-juniper woodland. Oecologia 153(4): 787-798. https://doi.org/10.1007/s00442-007-0777-0

West AG, Patrickson SJ, Ehleringer JR (2006) Water extraction times for plant and soil materials used in stable isotope analysis. Rapid Commun. Mass Spectrom 20: 1317-1321. https://doi.org/10.1002/rcm.2456

White J, Cook E, Lawrence J, Broecker W (1985) The D/H Ratios of Sap in Trees - Implications for Water Sources and Tree-Ring D/H Ratios. Geochim. Cosmochim. Ac 49: 237-246, https://doi.org/10.1016/00167037(85)90207-8

Zhang MM, Wang S, Fu BJ, Gao GY, Shen Q (2018) Ecological effects and potential risks of the water diversion project in the Heihe River Basin. Science of the Total Environment 619-620: 794-803. https://doi.org/10.1016/j.scitotenv.2017.11.037

Zhang YP, Jiang Y, Wang B, Jiao L, Wang MC (2018) Seasonal water use by Larix principis-rupprechtii in an alpine habitat. Forest Ecology and Management 409: 47-55. https://doi.org/10.1016/j.foreco.2017.11.009

Zhao LJ, Liu XH, Wang NL, Kong YL, Song YX, He ZB, Liu QY, Wang LX (2019) Contribution of recycled moisture to local precipitation in the inland Heihe River Basin. Agricultural and Forest Meteorology, 271: 316335 .

Zhao LJ, Wang LX, Cernusak LA, Liu XH, Xiao HL, Zhou MX, Zhang SQ (2016) Significant difference in hydrogen 
isotope composition between xylem and tissue water in Populus Euphratica. Plant, Cell and Environment 39: 1848-1857. https://doi. 10.1111/pce.12753

Zhao LJ, Xiao HL, Cheng GD, Song YX, Zhao L, Li CZ, Yang Q (2008) A preliminary study of water sources of riparian plants in the lower reaches of the Heihe Basin. Acta Geoscientica Sinica 29(6): 709-718.

Zhao LJ, Xiao HL, Zhou MX, Cheng GD, Wang LX, Yin L, Ren J (2012) Factors controlling spatial and seasonal distributions of precipitation $\delta^{18} \mathrm{O}$ in China. Hydrological Processes 26: 143-152.

Zhou H, Zhao WZ, Zhang GF (2017) Varying water utilization of Haloxylon ammodendron plantations in a desertoasis ecotone. Hydrological Processes 31(4): 825-835. https://doi.org/10.1002/hyp.11060 
Table 1 The acronyms of hydrogen and oxygen isotopic parameters as well as plants with their functional types of the species.

Table 2 The sampling species, sampling plant components and sampling dates in different regions of the Heihe River Basin.

Table 3 The mean soil water content (\%) of soil profile at the different study sites in the Heihe River Basin. The detailed information is shown in the Table 2.

Table 4 Variations of $\delta^{18} \mathrm{O}$ and $\delta^{2} \mathrm{H}(\%)$ in plant xylem water and their potential water source of the Heihe River Basin.

Table 5 Contributions of possible water sources to different plants (\%) of different ecosystem types based on oxygen isotopes. The acronyms of plants as well as hydrogen and oxygen isotopic parameters are shown in the Table 1. The UR, MR and LR indicate the upper, middle and lower reaches, respectively. The SW and GW indicate soil water and groundwater. The U1, U2, U3 and U4 indicate mountain grassland, mountain meadow, high mountain meadow and swamp meadow in the upper reaches, respectively, in the upper reaches. U5, U6, U7, U8-11, U8-12, U9-6 and U9-9 indicate Qinghai Spruce forest in the upper reaches. M1-10, M1-12, M2-10, M2-12 and M3-12 indicate desert-oasis ecotone, and M4-10 and M4-12 indicate Gobi in the middle reaches. L1-07, L1-09, L1-10, L1-12, L2-10, L2-12, L3-08 and L4-08 indicate riparian forest in the lower reaches. L5-10 and L5-12 indicate planted shrubland, and L6-10 and L6-12 indicate Gobi in the lower reaches. Because $\delta^{18} \mathrm{O}$ of plant xylem water was not within the range of values of all water sources, we took $100 \%$ as the contributions of their nearest water sources of U1, U2, M1-12 and L3-08. 
Table 1 The acronyms of hydrogen and oxygen isotopic parameters as well as plants with their functional types of the species.

\begin{tabular}{lllll}
\hline \multicolumn{1}{c}{ Acronym } & \multicolumn{1}{c}{ The full name } & Acronym & \multicolumn{2}{c}{ Plant species } \\
& \multicolumn{1}{c}{ The full name } & Functional type of the species \\
\hline UR & The upper reaches of the HRB & QS & Qinghai Spruce & Evergreen coniferous tree \\
MR & The middle reaches of the HRB & PE & Populus euphratica & Deciduous broadleaf tree \\
LR & The lower reaches of the HRB & HA & Haloxylon ammodendron & Deciduous broadleaf shrub \\
HRB & The Heihe River Basin & NT & Nitraria tangutorum & Deciduous broadleaf shrub \\
Qilian Mt. & Qilian Mountain & PF & Potentilla fruticosa & Deciduous broadleaf shrub \\
QSF & Qinghai spruce forest & RS & Reaumuria soongorica & Deciduous shrub \\
MG & Mountain grassland & TR & Tamarix ramosissima & Deciduous lanceolate leaf shrub \\
MM & Mountain meadow & PV & Polygonum viviparum & Polygonaceae perennial herb \\
SM & Swamp meadow & SA & Sophora alopecuroides & Leguminous perennial herb \\
DO & Desert-oasis ecotone & SC & Stipa capillata & Gramineous perennial herb \\
GB & Gobi & SP & Stipa purpurea Griseb & Gramineous perennial herb \\
RF & Riparian forest & & & \\
ASF & Artificial shrubbery forest & & & \\
GMWL & Global meteoric water line & & & \\
LMWL & Local meteoric water line & & & \\
$\delta^{18} \mathrm{O}$ & Oxygen isotope ratio & & & \\
$\delta^{2} \mathrm{H}$ & Hydrogen isotope ratio & & & \\
\hline
\end{tabular}


Table 2 The sampling species, sampling plant components and sampling dates in different regions of the Heihe River Basin.

\begin{tabular}{|c|c|c|c|c|c|c|c|c|}
\hline Study region & Ecosystem type & Study time & Locations ID & Altitude (m) & Longitude & Latitude & Plant species & Groundwater level \\
\hline \multirow{11}{*}{ The UR } & Mountain grassland & $2009 / 6 / 7$ & U1 & 2774 & 99.9 & 38.8 & $\mathrm{SC}$ root & \multirow{11}{*}{ Spring } \\
\hline & Swamp meadow & $2009 / 6 / 7$ & $\mathrm{U} 2$ & 3040 & 99.9 & 38.8 & PV root & \\
\hline & Mountain meadow & $2009 / 6 / 8$ & U3 & 3476 & 99.5 & 38.6 & SP root & \\
\hline & Swamp meadow & $2009 / 6 / 8$ & U4 & 3732 & 99.6 & 38.6 & $\mathrm{SC}$ root & \\
\hline & \multirow{7}{*}{ Qinghai spruce forest } & $2007 / 8 / 21$ & U5 & 2594 & 100.3 & 38.6 & QS and PF stem & \\
\hline & & $2009 / 6 / 7$ & U6 & 2654 & 99.6 & 38.8 & QS stem & \\
\hline & & $2009 / 7 / 31-8 / 2$ & U7 & 2774 & 100.3 & 38.5 & QS stem & \\
\hline & & $2011 / 6 / 27-28$ & U8-11 & \multirow{2}{*}{2780} & \multirow{2}{*}{100.3} & \multirow{2}{*}{38.6} & QS stem and SC root & \\
\hline & & $2012 / 8 / 1$ & U8-12 & & & & QS stem & \\
\hline & & $2011 / 6 / 23-25$ & U9-6 & \multirow{2}{*}{2900} & \multirow{2}{*}{100.3} & \multirow{2}{*}{38.5} & \multirow{2}{*}{ QS, PF and PV } & \\
\hline & & $2011 / 9 / 2-8$ & U9-9 & & & & & \\
\hline \multirow{7}{*}{ The MR } & \multirow{5}{*}{ Desert-oasis ecotone } & $2010 / 6 / 15-16$ & M1-10 & \multirow{2}{*}{1386} & \multirow{2}{*}{100.1} & \multirow{2}{*}{39.4} & \multirow{2}{*}{ TR stem } & \multirow{5}{*}{ About $5.0 \mathrm{~m}$} \\
\hline & & $2012 / 8 / 3$ & M1-12 & & & & & \\
\hline & & $2010 / 6 / 15-16$ & M2-10 & \multirow{2}{*}{1386} & \multirow{2}{*}{100.1} & \multirow{2}{*}{39.4} & \multirow{2}{*}{ HA stem } & \\
\hline & & $2012 / 8 / 3$ & M2-12 & & & & & \\
\hline & & $2012 / 8 / 4$ & M3-12 & 1440 & 1 & 1 & HA stem & \\
\hline & \multirow{2}{*}{ Gobi } & $2010 / 6 / 18-19$ & M4-10 & \multirow{2}{*}{1413} & \multirow{2}{*}{100.1} & \multirow{2}{*}{39.4} & RS and NT stem & \multirow{2}{*}{$>10.0 \mathrm{~m}$} \\
\hline & & $2012 / 8 / 5$ & M4-12 & & & & RS stem & \\
\hline \multirow{9}{*}{ The LR } & \multirow{8}{*}{ Riparian forest } & $2007 / 6 / 19$ & L1-07 & \multirow{4}{*}{930} & \multirow{4}{*}{101.2} & \multirow{4}{*}{42} & & $1.6 \mathrm{~m}$ \\
\hline & & $2009 / 8 / 6-9$ & L1-09 & & & & PE stem and SA root & $1.8 \mathrm{~m}$ \\
\hline & & $2010 / 6 / 21-22$ & L1-10 & & & & & $2.0 \mathrm{~m}$ \\
\hline & & $2012 / 8 / 8$ & $\mathrm{~L} 1-12$ & & & & PE stem & $2.0 \mathrm{~m}$ \\
\hline & & $2010 / 6 / 21-22$ & L2-10 & 000 & 1010 & 19 & $T D$ to & $2.0 \mathrm{~m}$ \\
\hline & & $2012 / 8 / 8$ & $\mathrm{~L} 2-12$ & 930 & 101.2 & 42 & I K stem & $2.0 \mathrm{~m}$ \\
\hline & & $2008 / 8 / 20$ & L3-08 & 920 & 101.1 & 42 & $\mathrm{DC} T \mathrm{TP}$ d $\mathrm{CA}$ & $100 \mathrm{~m}$ \\
\hline & & $2008 / 8 / 20$ & L4-08 & 921 & 101.1 & 42 & $P E, I R$ and $S A$ & $>10.0 \mathrm{~m}$ \\
\hline & Planted shrubland & $2010 / 6 / 23-24$ & L5-10 & 910 & 101 & 41.9 & HA stem & $2.5 \mathrm{~m}$ \\
\hline
\end{tabular}




\begin{tabular}{|c|c|c|c|c|c|c|c|}
\hline \multirow{2}{*}{ Gobi } & $2010 / 6 / 26-27$ & L6-10 & \multirow{2}{*}{906} & \multirow{2}{*}{101.1} & \multirow{2}{*}{42.3} & \multirow{2}{*}{ RS stem } & \multirow{2}{*}{$>5.0 \mathrm{~m}$} \\
\hline & $2012 / 8 / 11$ & L6-12 & & & & & \\
\hline
\end{tabular}

Table 3 The profile mean soil water content (\%) at the different study sites in the Heihe River Basin. The detailed information is shown in the Table 2.

\begin{tabular}{|c|c|c|c|c|c|c|c|c|c|c|c|}
\hline The upper reaches & U1 & U2 & U3 & U4 & U6 & U7 & U8-11 & U8-12 & U9-6 & U9-9 & Mean \\
\hline Profile mean soil water content (\%) & 24.9 & 59.6 & 17.0 & 64.5 & 30.6 & 34.7 & 23.8 & 26.3 & 35.6 & 25.4 & 34.2 \\
\hline Standard deviation & 4.3 & 9.8 & 2.3 & 3.9 & 6.7 & 8.2 & 4.3 & 4.0 & 7.4 & 4.0 & 5.5 \\
\hline The middle reaches & M1-10 & M1-12 & M2-10 & M2-12 & M3-12 & M4-10 & M4-12 & & & & Mean \\
\hline Profile mean soil water content (\%) & 2.3 & 2.3 & 1.9 & 2.0 & 1.6 & 1.4 & 2.2 & & & & 2.0 \\
\hline Standard deviation & 0.6 & 0.3 & 0.4 & 0.4 & 0.4 & 0.3 & 0.7 & & & & 0.4 \\
\hline The lower reaches & L1-09 & $\mathrm{L} 1-10$ & $\mathrm{~L} 1-12$ & $\mathrm{~L} 2-10$ & $\mathrm{~L} 2-12$ & L5-10 & L5-12 & L6-10 & L6-12 & & Mean \\
\hline Profile mean soil water content (\%) & 9.1 & 9.7 & 6.6 & 12.4 & 8.8 & 4.7 & 6.6 & 7.1 & 9.2 & & 8.2 \\
\hline Standard deviation & 7.2 & 7.8 & 5.9 & 7.5 & 8.0 & 3.5 & 5.3 & 9.5 & 9.7 & & 7.2 \\
\hline
\end{tabular}


Table 4 Variations of $\delta^{18} \mathrm{O}$ and $\delta^{2} \mathrm{H}(\%)$ in plant xylem water and their potential water source of the Heihe River Basin.

\begin{tabular}{|c|c|c|c|c|c|c|c|c|c|c|}
\hline \multirow{2}{*}{$\begin{array}{l}\text { The upper reaches } \\
\text { Alpine grassland meadow region }\end{array}$} & & \multicolumn{2}{|c|}{ Soil water } & \multirow[t]{2}{*}{ Plant } & \multicolumn{4}{|c|}{ Xylem water } & \multicolumn{2}{|c|}{ Groundwater } \\
\hline & & $\delta^{18} \mathrm{O}(\%)$ & $\delta^{2} \mathrm{H}(\%)$ & & & $\delta^{18} \mathrm{O}(\%)$ & $\delta^{2} \mathrm{H}(\%)$ & & $\delta^{18} \mathrm{O}(\%)$ & $\delta^{2} \mathrm{H}(\%)$ \\
\hline & Mean \pm SD & $-5.3 \pm 2.7$ & $-45.9 \pm 10.1$ & Herbaceous plants & Mean \pm SD & $-3.5 \pm 1.9$ & $-48.9 \pm 8.4$ & Mean \pm SD & l & / \\
\hline & $\operatorname{Max}$ & 0.2 & -30.7 & & Max & -1.4 & -29.4 & Max & l & 1 \\
\hline & Min & -8.8 & -62.3 & & Min & -6.8 & -59.7 & Min & l & l \\
\hline \multirow[t]{9}{*}{ Qinghai spruce forest } & Mean \pm SD & $-7.0 \pm 2.3$ & $-49.8 \pm 13.6$ & Qinghai Spruce & Mean \pm SD & $-6.9 \pm 1.5$ & $-50.8 \pm 10.4$ & Mean \pm SD & 1 & l \\
\hline & Max & -1.4 & -18.4 & & Max & -4.3 & -37.3 & Max & l & / \\
\hline & Min & -11.7 & -84.7 & & Min & -9.7 & -67.3 & Min & l & l \\
\hline & & & & Potentilla fruticosa & Mean \pm SD & $-5.9 \pm 1.7$ & $-47.5 \pm 13.2$ & & & \\
\hline & & & & & $\operatorname{Max}$ & -4.2 & -36.2 & & & \\
\hline & & & & & Min & -7.6 & -62.0 & & & \\
\hline & & & & Herbaceous plants & Mean \pm SD & $-4.7 \pm 2.7$ & $-43.2 \pm 15.3$ & & & \\
\hline & & & & & Max & -1.7 & -29.4 & & & \\
\hline & & & & & Min & -6.8 & -59.7 & & & \\
\hline \multicolumn{11}{|l|}{ The middle reaches } \\
\hline \multirow[t]{7}{*}{ Desert-oasis ecotone } & Mean \pm SD & $-0.5 \pm 4.3$ & $-37.4 \pm 16.5$ & Tamarix ramosissima & Mean \pm SD & $-7.5 \pm 0.3$ & $-60.9 \pm 4.1$ & Mean \pm SD & $-7.8 \pm 0.2$ & $-49.5 \pm 0.5$ \\
\hline & Max & 11.7 & 5.0 & & Max & -7.3 & -58.0 & Max & -7.6 & -49.1 \\
\hline & Min & -7.4 & -70.1 & & Min & -7.7 & -63.8 & Min & -8.0 & -50.2 \\
\hline & & & & Haloxylon ammodendron & Mean \pm SD & $-2.1 \pm 4.7$ & $-44.9 \pm 20.2$ & & & \\
\hline & & & & & Max & 1.0 & -29.9 & & & \\
\hline & & & & & Min & -7.4 & -67.8 & & & \\
\hline & Mean \pm SD & $1.8 \pm 1.9$ & $-30.3 \pm 8.7$ & Reaumuria soongorica & Mean \pm SD & $0.8 \pm 0.8$ & $-33.5 \pm 1.8$ & Mean \pm SD & -8.0 & -50.2 \\
\hline \multirow[t]{2}{*}{ Gobi } & Max & 5.9 & -12.5 & Nitraria tangutorum & Max & 1.9 & -31.0 & Max & / & / \\
\hline & Min & -0.6 & -43.4 & & Min & 0.1 & -35.0 & Min & l & l \\
\hline \multicolumn{11}{|l|}{ The lower reaches } \\
\hline \multirow{6}{*}{ Riparian forest } & Mean \pm SD & $-3.6 \pm 3.4$ & $-39.3 \pm 11.1$ & Populus euphratica & Mean \pm SD & $-6.2 \pm 1.1$ & $-50.7 \pm 4.5$ & Mean \pm SD & $-6.2 \pm 1.0$ & $-42.0 \pm 4.9$ \\
\hline & Max & 6.1 & -3.6 & & Max & -4.7 & -46.0 & Max & -4.5 & -36.1 \\
\hline & Min & -7.3 & -56.1 & & Min & -7.9 & -58.7 & Min & -7.6 & -50.2 \\
\hline & & & & Tamarix ramosissima & Mean \pm SD & $-5.5 \pm 0.9$ & $-52.2 \pm 7.4$ & & & \\
\hline & & & & & $\operatorname{Max}$ & -4.3 & -42.6 & & & \\
\hline & & & & & Min & -6.5 & -60.0 & & & \\
\hline
\end{tabular}




\begin{tabular}{|c|c|c|c|c|c|c|c|c|c|c|}
\hline & & & & Sophora alopecuroides & Mean \pm SD & $-4.4 \pm 1.4$ & $-48.7 \pm 5.1$ & & & \\
\hline & & & & & Max & -2.6 & -45.6 & & & \\
\hline & & & & & Min & -5.7 & -56.3 & & & \\
\hline \multirow[t]{3}{*}{ Planted shrubland } & Mean \pm SD & $-4.4 \pm 3.7$ & $-55.3 \pm 7.5$ & Haloxylon ammodendron & Mean \pm SD & $-7.6 \pm 0.3$ & $-69.2 \pm 2.4$ & Mean \pm SD & $-7.7 \pm 0.1$ & $-63.0 \pm 1.9$ \\
\hline & Max & 4.7 & -41.6 & & Max & -7.3 & -67.5 & Max & -7.6 & -61.7 \\
\hline & Min & -7.8 & -66.1 & & Min & -7.8 & -70.9 & Min & -7.7 & -64.4 \\
\hline \multirow[t]{3}{*}{ Gobi } & Mean \pm SD & $0.4 \pm 2.9$ & $-45.5 \pm 5.9$ & Reaumuria soongorica & Mean \pm SD & $-2.5 \pm 0.2$ & $-49.1 \pm 5.5$ & Mean \pm SD & $-7.5 \pm 0.1$ & $-55.4 \pm 3.5$ \\
\hline & Max & 7.2 & -36.0 & & Max & -2.3 & -45.2 & Max & -7.4 & -52.9 \\
\hline & Min & -3.3 & -56.9 & & Min & -2.7 & -53.0 & Min & -7.6 & -57.9 \\
\hline
\end{tabular}


Table 5 Contributions of possible water sources to different plants (\%) of different ecosystem types based on oxygen isotopes. The acronyms of plants as well as hydrogen and oxygen isotopic parameters are shown in the Table 1. The UR, MR and LR indicate the upper, middle and lower reaches, respectively. The SW and GW indicate soil water and groundwater. The U1, U2, U3 and U4 indicate mountain grassland, mountain meadow, high mountain meadow and swamp meadow in the upper reaches, respectively, in the upper reaches. U5, U6, U7, U8-11, U8-12, U9-6 and U9-9 indicate Qinghai Spruce forest in the upper reaches. M1-10, M1-12, M2-10, M2-12 and M3-12 indicate desert-oasis ecotone, and M4-10 and M4-12 indicate Gobi in the middle reaches. L1-07, L1-09, L1-10, L1-12, L2-10, L2-12, L3-08 and L4-08 indicate riparian forest in the lower reaches. L5-10 and L5-12 indicate planted shrubland, and L6-10 and L6-12 indicate Gobi in the lower reaches. Because $\delta^{18} \mathrm{O}$ of plant xylem water was not within the range of values of all water sources, we took $100 \%$ as the contributions of their nearest water sources of U1, U2, M1-12 and L3-08.

\begin{tabular}{|c|c|c|c|c|c|c|c|c|c|}
\hline Study region & Ecosystem type & Locations ID & & Plant species & & & & ources and their contribution ratios to plant (Mean $\pm \mathrm{SD}(\%)$ ) & Groundwater level \\
\hline \multirow{11}{*}{ The UR } & Mountain grassland & U1 & Water sources & & $5 \mathrm{~cm} \mathrm{SW}$ & $10 \mathrm{~cm} \mathrm{SW}$ & $30 \mathrm{~cm} \mathrm{SW}$ & $50 \mathrm{~cm} \mathrm{SW}$ & \multirow{11}{*}{ Spring } \\
\hline & & & Contribution percentages & $\mathrm{sc}$ & 100 & 1 & I & I & \\
\hline & \multirow[t]{2}{*}{ Mountain meadow } & \multirow[t]{2}{*}{$\mathrm{U} 2$} & Water sources & & $5 \mathrm{~cm} \mathrm{SW}$ & $10 \mathrm{~cm} \mathrm{SW}$ & $30 \mathrm{~cm} \mathrm{SW}$ & $50 \mathrm{~cm} \mathrm{SW}$ & \\
\hline & & & Contribution percentages & PV & 100 & 1 & I & 1 & \\
\hline & \multirow{2}{*}{ High mountain meadow } & \multirow{2}{*}{ U3 } & Water sources & & $5 \mathrm{~cm} \mathrm{SW}$ & $10 \mathrm{~cm} \mathrm{SW}$ & \multicolumn{2}{|l|}{$20 \mathrm{~cm} \mathrm{SW}$} & \\
\hline & & & Contribution percentages & $\mathrm{SP}$ & $30.2 \pm 17.3$ & $41.3 \pm 23.3$ & \multicolumn{2}{|l|}{$28.5 \pm 17.1$} & \\
\hline & \multirow{2}{*}{ Swamp meadow } & \multirow{2}{*}{$\mathrm{U} 4$} & Water sources & & $5 \mathrm{~cm} \mathrm{SW}$ & $10 \mathrm{~cm} \mathrm{SW}$ & \multicolumn{2}{|l|}{$20 \mathrm{~cm} \mathrm{SW}$} & \\
\hline & & & Contribution percentages & $\mathrm{SC}$ & $84.3 \pm 5.8$ & $9.3 \pm 5.8$ & $6.4 \pm 3.6$ & & \\
\hline & \multirow{3}{*}{ Qinghai Spruce forest } & \multirow{3}{*}{ U5 } & Water sources & & $5 \mathrm{~cm} \mathrm{SW}$ & $10 \mathrm{~cm} \mathrm{SW}$ & $20 \mathrm{~cm} \mathrm{SW}$ & $40 \mathrm{~cm} \mathrm{SW}$ & \\
\hline & & & Contribution percentages & QS & $14.1 \pm 9.6$ & $20.0 \pm 15.7$ & $22.8 \pm 17.0$ & $22.9 \pm 17.4$ & \\
\hline & & & Contributio percentages & $\mathrm{PF}$ & $61.5 \pm 12.4$ & $11.5 \pm 10.3$ & $8.7 \pm 6.5$ & $10.0 \pm 7.7$ & \\
\hline
\end{tabular}




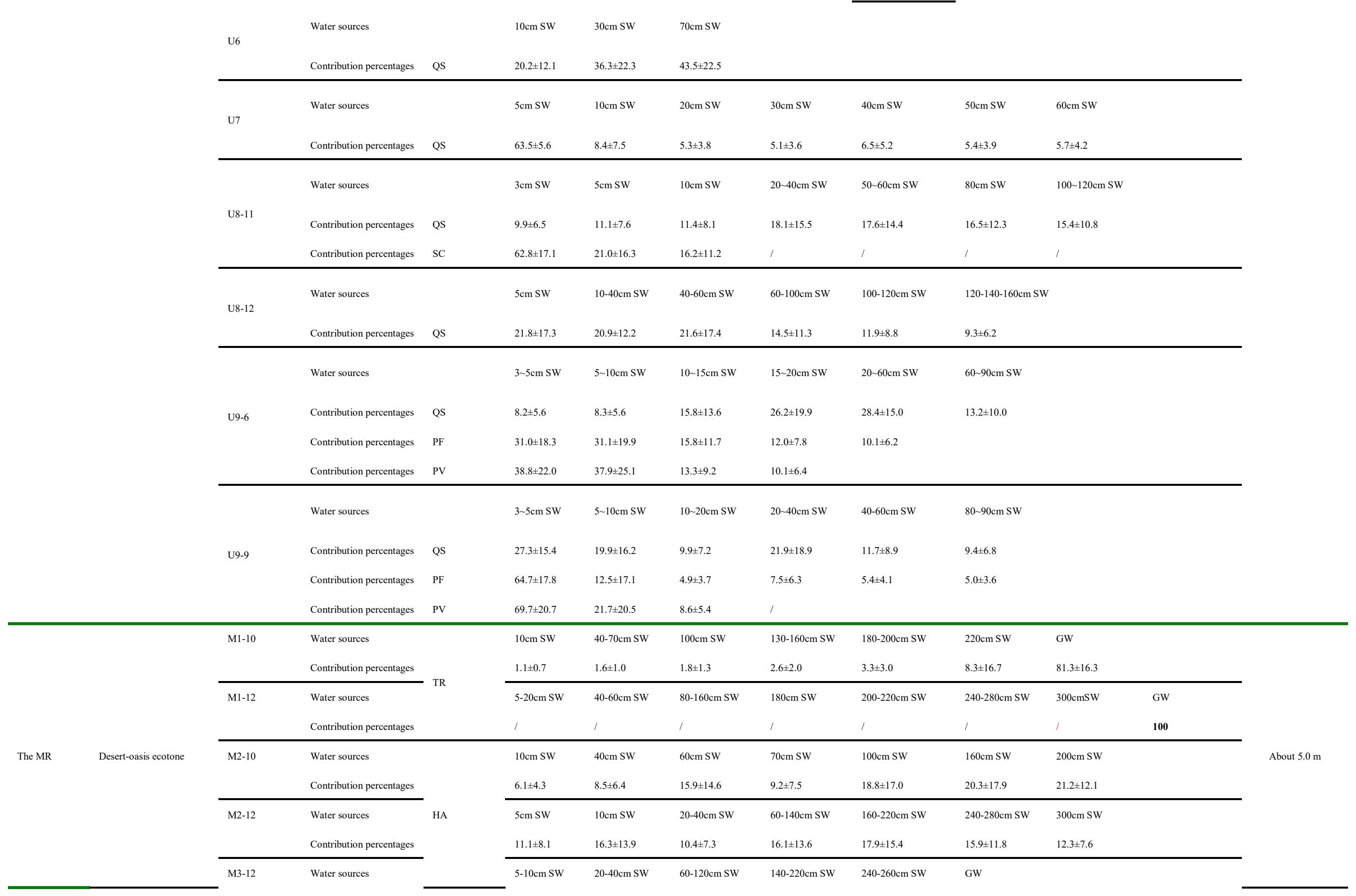




\begin{tabular}{|c|c|c|c|c|c|c|c|c|c|c|c|c|c|}
\hline & & & Contribution percentages & & $0.7 \pm 0.4$ & $0.8 \pm 0.5$ & $1.0 \pm 0.07$ & $1.3 \pm 1.0$ & $2.1 \pm 2.0$ & $94.1 \pm 2.4$ & & & \\
\hline & & & Water sources & & $10 \mathrm{~cm} \mathrm{SW}$ & $20-80 \mathrm{~cm} \mathrm{SW}$ & $100 \mathrm{~cm} \mathrm{SW}$ & $120 \mathrm{~cm} \mathrm{SW}$ & $140 \mathrm{~cm} \mathrm{SW}$ & $160-200 \mathrm{~cm} \mathrm{SW}$ & & & \\
\hline & & M4-10 & Contribution percentages & RS & $3.4 \pm 2.1$ & $6.2 \pm 4.8$ & $10.2 \pm 10.9$ & $18.6 \pm 19.6$ & $23.7 \pm 22.6$ & $37.9 \pm 23.9$ & & & \\
\hline & Gobi & & Contribution percentages & NT & $4.2 \pm 2.5$ & $7.8 \pm 5.8$ & $12.5 \pm 11.8$ & $21.6 \pm 19.6$ & $24.8 \pm 21.2$ & $29.1 \pm 20.3$ & & & $>10.0 \mathrm{~m}$ \\
\hline & & M & Water sources & & $10-15 \mathrm{~cm} \mathrm{SW}$ & $20-40 \mathrm{~cm} \mathrm{SW}$ & $50-70 \mathrm{~cm} \mathrm{SW}$ & $80 \mathrm{~cm} \mathrm{SW}$ & $100-120 \mathrm{~cm} \mathrm{SW}$ & $120-160 \mathrm{~cm} \mathrm{SW}$ & $180-200 \mathrm{~cm} \mathrm{SW}$ & & \\
\hline & & & Contribution percentages & RS & $12.2 \pm 9.9$ & $7.8 \pm 5.3$ & $10.6 \pm 7.9$ & $14.4 \pm 13.0$ & $18.2 \pm 15.3$ & $18.3 \pm 14.6$ & $18.4 \pm 12.9$ & & \\
\hline & & & Water sources & & & & & & $80-100 \mathrm{~cm} \mathrm{SW}$ & & $\mathrm{GW}$ & & \\
\hline & & & Contribution percentages & $\mathrm{PE}$ & & & & & & & 93 & Zhao et al., 2008 & \\
\hline & & & Contribution percentages & TR & & & & & & & 90 & & \\
\hline & & & Contribution percentages & $\mathrm{SA}$ & & & & & 97 & & & & \\
\hline & & & Water sources & & $5 \mathrm{~cm} \mathrm{SW}$ & $8 \mathrm{~cm} \mathrm{SW}$ & $10-30 \mathrm{~cm} \mathrm{SW}$ & $40-60 \mathrm{~cm} \mathrm{SW}$ & $80-120 \mathrm{~cm} \mathrm{SW}$ & $140-160 \mathrm{~cm} \mathrm{SW}$ & $\mathrm{GW}$ & & \\
\hline & & L1-09 & Contribution percentages & $\mathrm{PE}$ & $2.4 \pm 1.6$ & $2.6 \pm 1.8$ & $3.8 \pm 3.0$ & $5.1 \pm 6.7$ & $11.0 \pm 17.3$ & $42.0 \pm 31.0$ & $33.2 \pm 32.0$ & & $1.8 \mathrm{~m}$ \\
\hline & & & Contribution percentages & $\mathrm{SA}$ & $11.3 \pm 7.1$ & $12.7 \pm 8.1$ & $24.5 \pm 18.8$ & $25.6 \pm 18.4$ & $25.9 \pm 16.1$ & & & & \\
\hline & & & Water sources & & $20 \mathrm{~cm} \mathrm{SW}$ & $40 \mathrm{~cm} \mathrm{SW}$ & $60-80 \mathrm{~cm} \mathrm{SW}$ & $100-140 \mathrm{~cm} \mathrm{SW}$ & $160-180 \mathrm{~cm} \mathrm{SW}$ & $\mathrm{GW}$ & & & \\
\hline & & L1-10 & Contribution percentages & $\mathrm{PE}$ & $7.7 \pm 3.2$ & $15.4 \pm 10.6$ & $20.2 \pm 16.4$ & $16.7 \pm 12.8$ & $18.8 \pm 14.9$ & $21.1 \pm 17.2$ & & & \\
\hline & & & Contribution percentages & SA & $26.4 \pm 6.1$ & $31.8 \pm 20.1$ & $22.1 \pm 14.5$ & $19.6 \pm 12.7$ & & & & & \\
\hline & & & Water sources & & $5-10 \mathrm{~cm} \mathrm{SW}$ & $20 \mathrm{~cm} \mathrm{SW}$ & $40-100 \mathrm{~cm} \mathrm{SW}$ & $120 \mathrm{~cm} \mathrm{SW}$ & $140-160 \mathrm{~cm} \mathrm{SW}$ & $180-200 \mathrm{~cm} \mathrm{SW}$ & $\mathrm{GW}$ & & \\
\hline & & L1-12 & Contribution percentages & $\mathrm{PE}$ & $2.8 \pm 1.8$ & $4.0 \pm 3.0$ & $7.9 \pm 9.2$ & $35.2 \pm 25.1$ & $16.7 \pm 19.8$ & $22.5 \pm 23.6$ & $11.0 \pm 11.1$ & & \\
\hline & 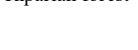 & 隹 & Water sources & & $20 \mathrm{~cm} \mathrm{SW}$ & $40 \mathrm{~cm} \mathrm{SW}$ & $60 \mathrm{~cm} \mathrm{SW}$ & $80-100 \mathrm{~cm} \mathrm{SW}$ & & & & & \\
\hline & & & Contribution percentages & & $9.3 \pm 3.5$ & $17.9 \pm 10.9$ & $37.1 \pm 22.0$ & $35.7 \pm 21.2$ & & & & & \\
\hline & & L2-12 & Water sources & & $5-10 \mathrm{~cm} \mathrm{SW}$ & $20 \mathrm{~cm} \mathrm{SW}$ & $40 \mathrm{~cm} \mathrm{SW}$ & $60-80 \mathrm{~cm} \mathrm{SW}$ & $100-140 \mathrm{~cm} \mathrm{SW}$ & $160 \mathrm{~cm} \mathrm{SW}$ & $\mathrm{GW}$ & & \\
\hline & & & Contribution percentages & & $3.4 \pm 22.0$ & $4.5 \pm 3.1$ & $6.8 \pm 6.6$ & $13.5 \pm 14.8$ & $23.0 \pm 21.6$ & $31.5 \pm 22.4$ & $17.2 \pm 18.3$ & & $2.0 \mathrm{~m}$ \\
\hline & & & Water sources & & $0-5 \mathrm{~cm} \mathrm{SW}$ & $5-20 \mathrm{~cm} \mathrm{SW}$ & $40-60 \mathrm{~cm} \mathrm{SW}$ & $80-120 \mathrm{~cm} \mathrm{SW}$ & $140-180 \mathrm{~cm} \mathrm{SW}$ & $200-240 \mathrm{~cm} \mathrm{SW}$ & $\mathrm{GW}$ & & \\
\hline & & & Contribution percentages & $\mathrm{PE}$ & I & l & I & I & I & I & 100 & & \\
\hline & & & Contribution percentages & TR & $2.5 \pm 1.4$ & $3.1 \pm 2.0$ & $5.4 \pm 4.1$ & $9.1 \pm 10.0$ & $18.2 \pm 20.7$ & $24.0 \pm 24.6$ & $37.7 \pm 26.2$ & & \\
\hline & & & Contribution percentages & $\mathrm{SA}$ & $3.6 \pm 2.1$ & $4.7 \pm 3.0$ & $8.7 \pm 6.9$ & $18.3 \pm 19.1$ & $28.4 \pm 23.9$ & $36.4 \pm 24.8$ & & & \\
\hline & & & Water sources & & $10 \mathrm{~cm} \mathrm{SW}$ & $20 \mathrm{~cm} \mathrm{SW}$ & $40-60 \mathrm{~cm} \mathrm{SW}$ & $100 \mathrm{~cm} \mathrm{SW}$ & $120-200 \mathrm{~cm} \mathrm{SW}$ & $220-240 \mathrm{~cm} \mathrm{SW}$ & $\mathrm{GW}$ & & \\
\hline & & 508 & Contribution percentages & $\mathrm{PE}$ & $2.2 \pm 1.4$ & $3.8 \pm 2.7$ & $4.7 \pm 3.7$ & $5.6 \pm 4.6$ & $6.6 \pm 6.1$ & $33.8 \pm 28.8$ & $43.3 \pm 30.2$ & & \\
\hline & & LA-UO & Contribution percentages & TR & $5.2 \pm 2.9$ & $9.4 \pm 6.8$ & $12.6 \pm 10.5$ & $17.3 \pm 15.5$ & $18.7 \pm 16.3$ & $18.4 \pm 14.0$ & $18.4 \pm 13.5$ & & \\
\hline & & & Contribution percentages & $\mathrm{SA}$ & $11.0 \pm 4.9$ & $19.7 \pm 14.4$ & $20.2 \pm 16.8$ & $17.6 \pm 13.8$ & $16.5 \pm 12.8$ & $14.9 \pm 11.2$ & & & $>10.0 \mathrm{~m}$ \\
\hline
\end{tabular}




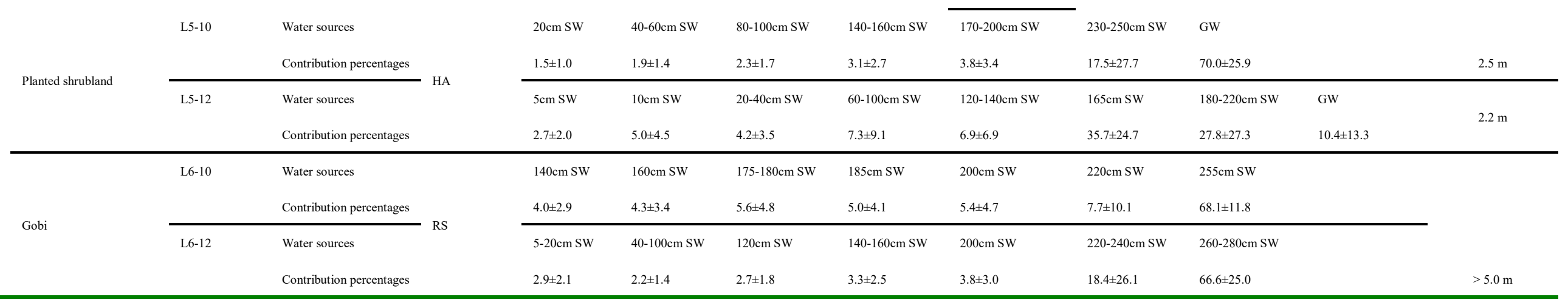




\section{Figure captions}

Fig. 1 Sampling sites (a), environmental conditions of the upper reaches (b), the middle reaches (c), and the lower reaches (e) of the Heihe River Basin.

Fig. 2 Soil water content (\%) of the mountain grassland zone (a) and the Qinghai spruce forest (b) of the upper reaches (UR), the desert-oasis ecotone (c) and the Gobi (d) of the middle reaches (MR), and the riparian forest (f and g), the planted shrubland (h) and the Gobi (i) of the lower reaches (LR) of the Heihe River Basin.

Fig. 3 Relationships of $\delta^{2} \mathrm{H}$ and $\delta^{18} \mathrm{O}$ of soil water, xylem water, river water and shallow groundwater of the upper reaches (the UR) (a), the middle reaches (the MR) (b) and the lower reaches (the LR) in the riparian forest (c) and in the planted shrubland and the Gobi (d) of the Heihe River Basin. The acronyms of plants as well as the LMWL are shown in the Table 1.

Fig. 4 The $\delta^{18} \mathrm{O}$ in soil water and groundwater at the profile and plant stem water of the mountain grassland zone (a) and the Qinghai spruce forest (b) of the upper reaches (UR), the desert-oasis ecotone (c) and the Gobi (d) of the middle reaches (MR), and the riparian forest (e), the planted shrubland (f) and the Gobi (g) of the lower reaches (LR) of the Heihe River Basin. The acronyms of plants as well as the LMWL are shown in the Table 1.

Fig. 5 The summary results of the water sources of different plants and their controlling factors along the climatic gradient of the Heihe River Basin. Figure 5a, b, c and d indicate the Qinghai spruce forest, the mountain grassland, the mountain meadow and the swamp meadow in the upper reaches (a), the desert-oasis ecotone (red dotted box) and the Gobi (green dotted box) in the middle reaches (b), the riparian forest (c), and the planted shrubland (blue dotted box) and Gobi (grey dotted box) (d) in the lower reaches, respectively. GW, SW and SSW indicate the groundwater, soil water and saturated soil water, respectively. The TR, HA, RS, PE and SA indicate Tamarix ramosissima, Haloxylon ammodendron, Reaumuria soongorica, Populus euphratica, and Sophora alopecuroides, respectively. 
Fig. 1
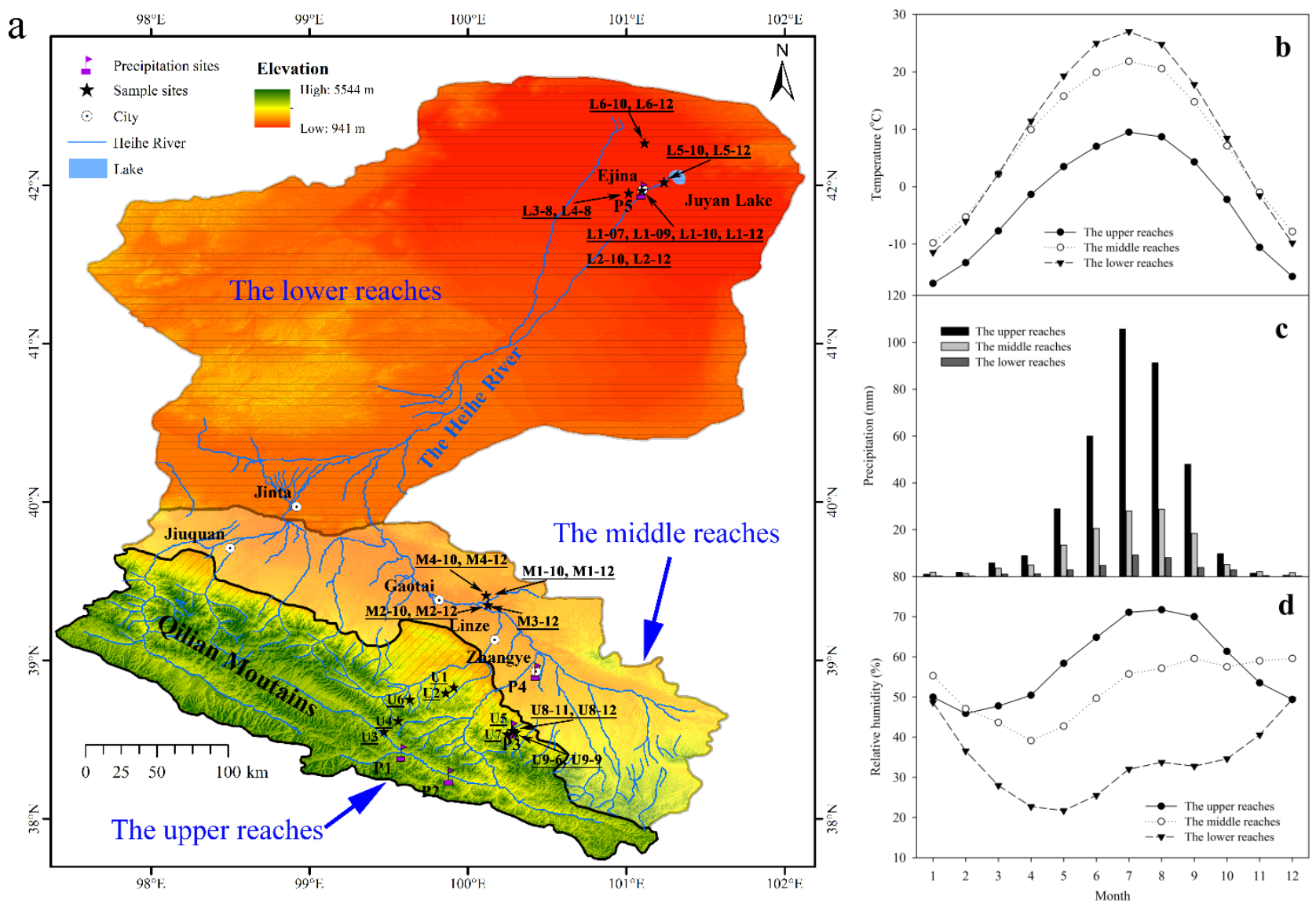
Fig. 2

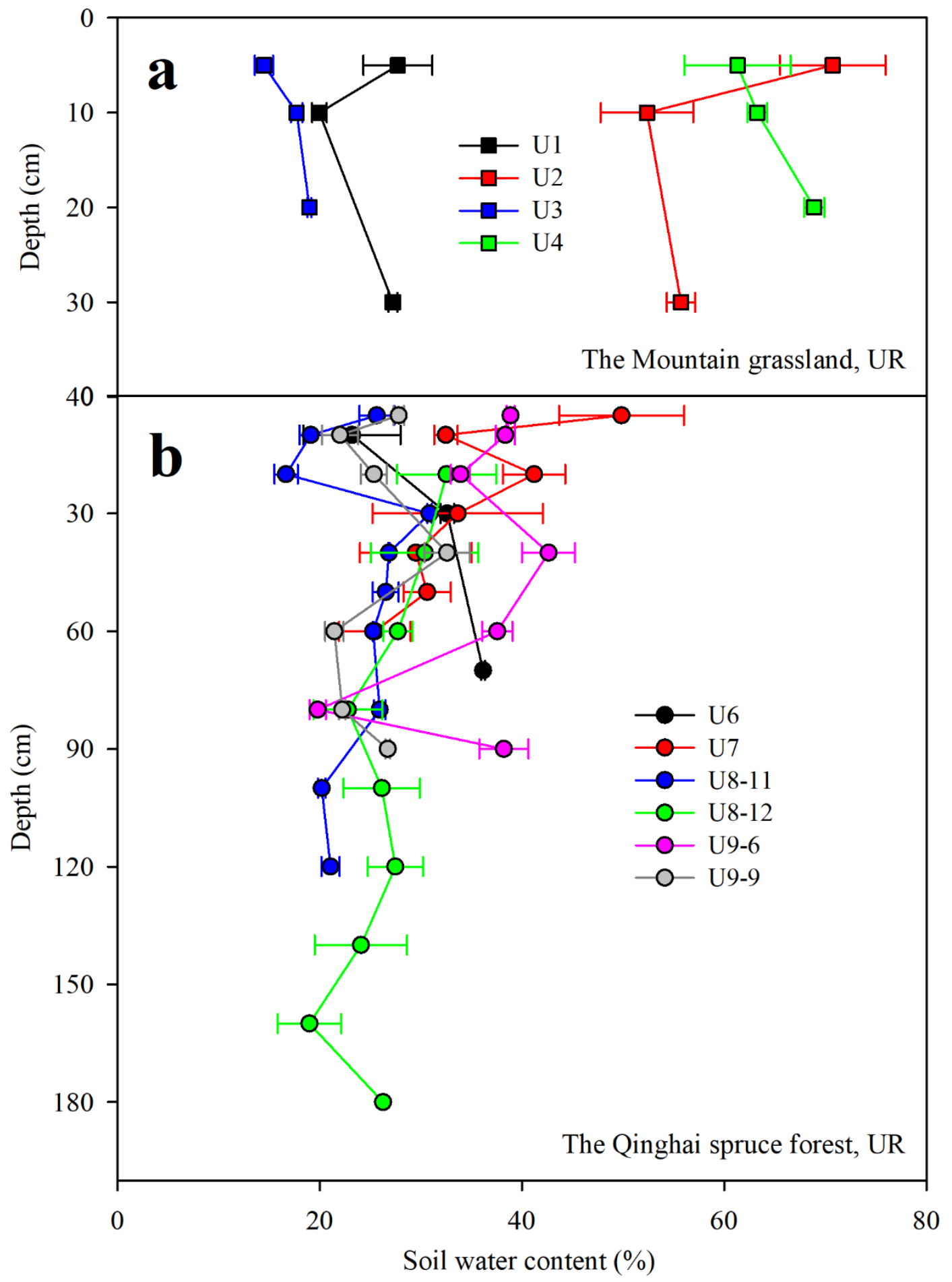



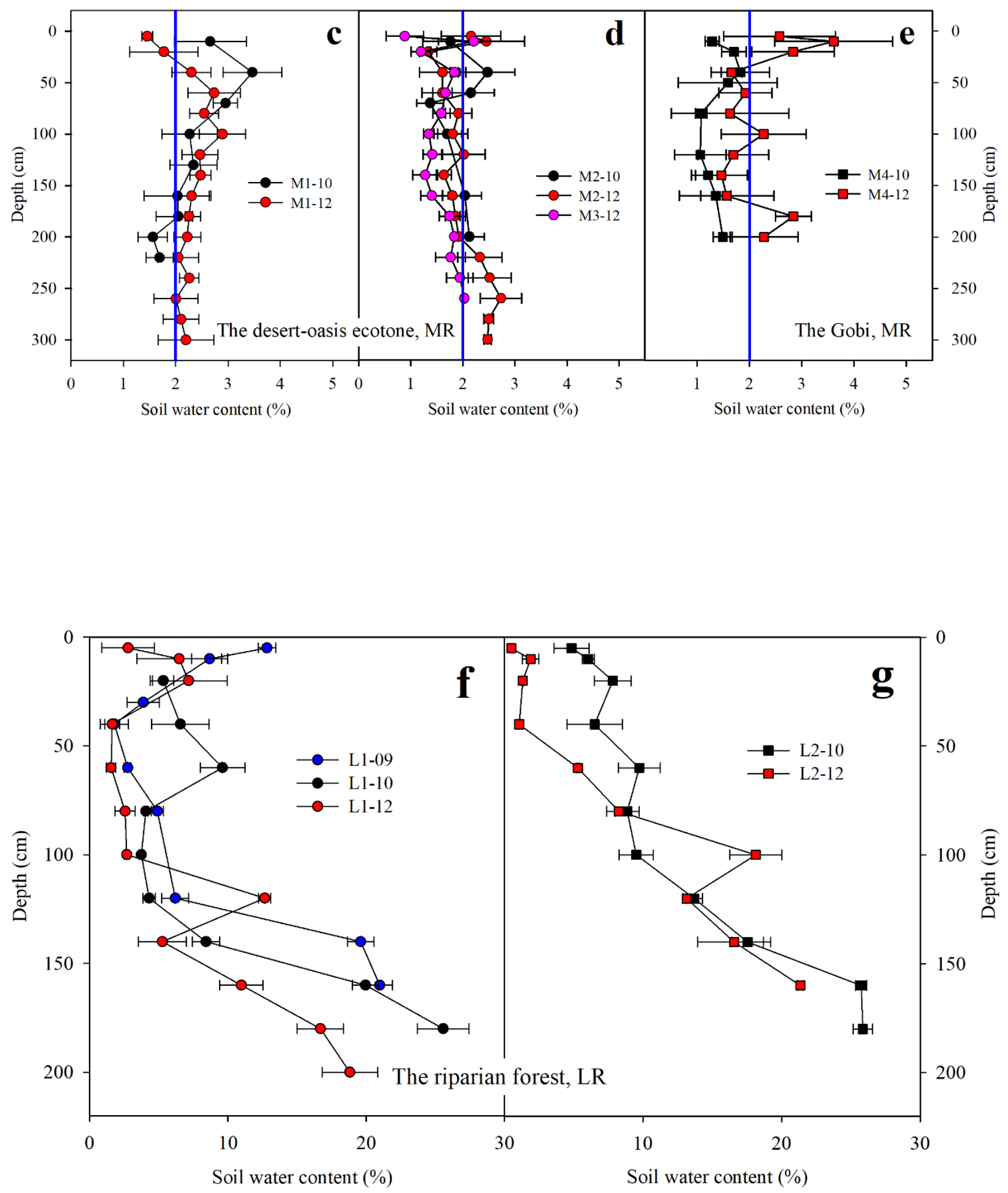


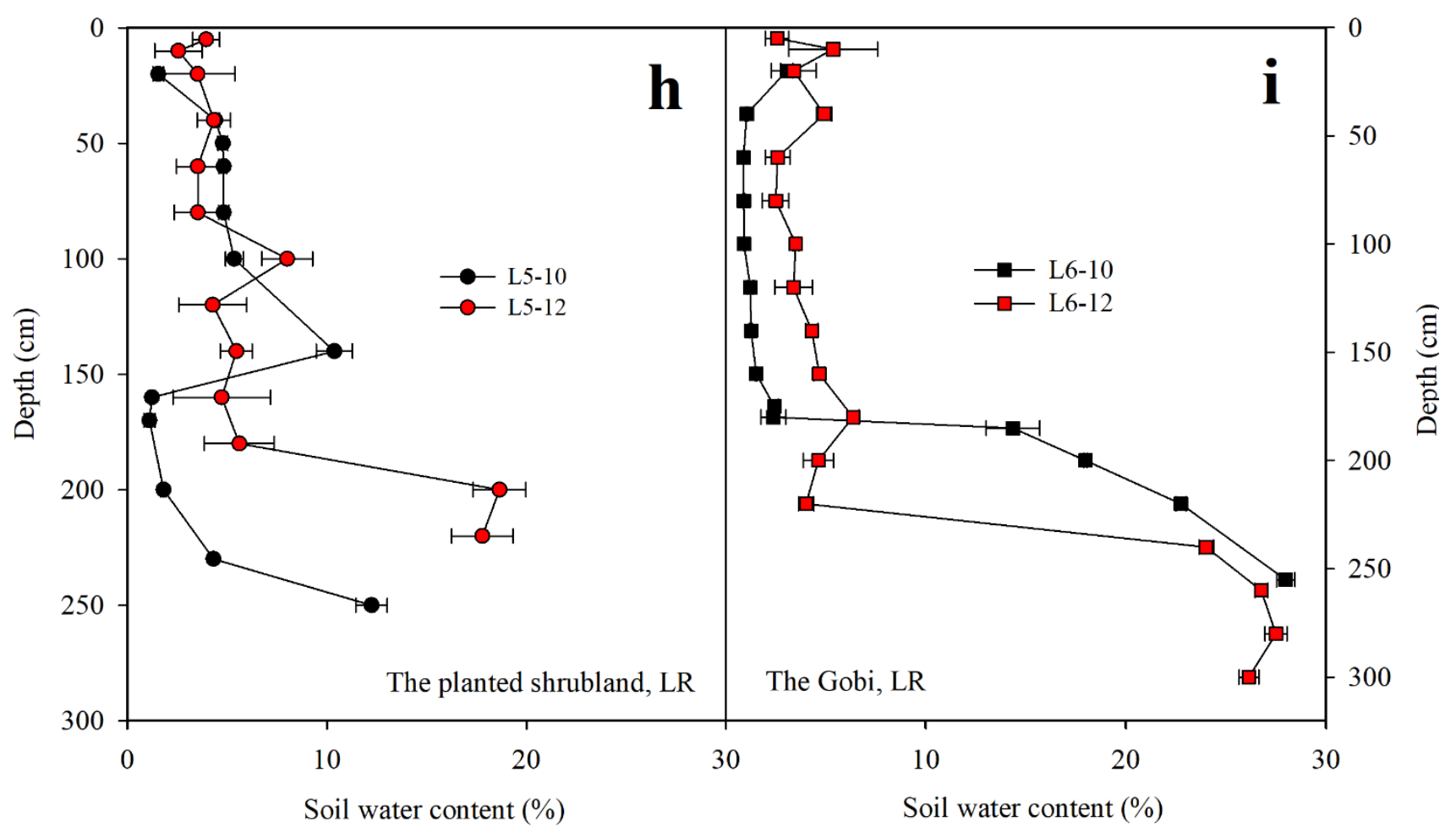


Fig. 3

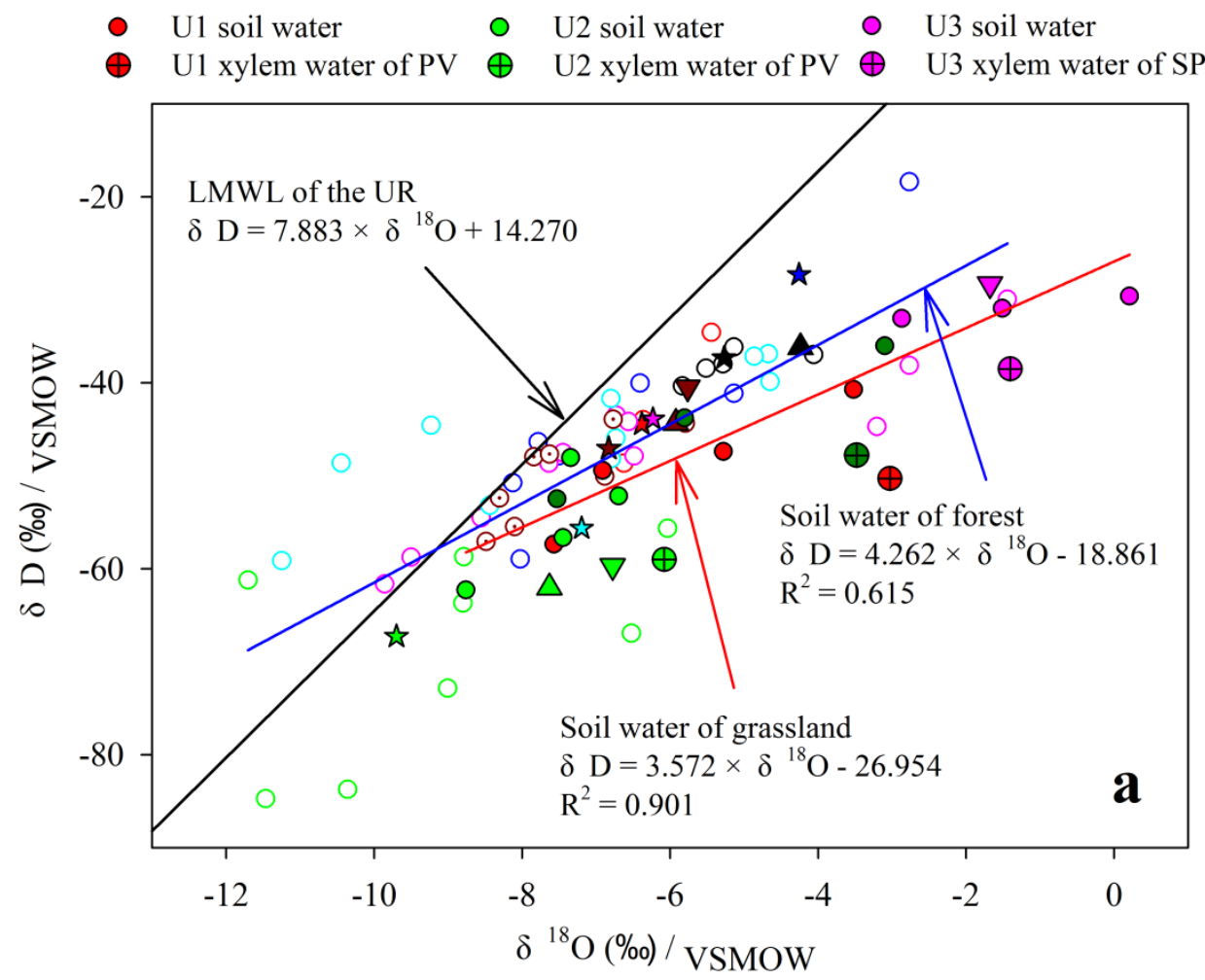

- U4 soil water

$\oplus$ U4 xylem water of SC

○ U5 soil water

$\star \quad$ U5 xylem water of QS

A U5 xylem water of PF

○ U6 soil water

ฟ U6 xylem water of QS

○ U7 soil water

$\star \quad$ U7 xylem water of QS

○ U8-11 soil water

¿ U8-11 xylem water of QS

$\nabla$ U8-11 xylem water of SC

- U8-12 soil water

t. U8-12 xylem water of QS

( U9-6 soil water

4 U9-6 xylem water of QS

$\triangle$ U9-6 xylem water of PF

$\nabla \quad$ U9-6 xylem water of PV

$\odot \quad$ U9-9 soil water

$\star \quad$ U9-9 xylem water of QS

$\Delta \quad$ U9-9 xylem water of PF

$\nabla \quad$ U9-9 xylem water of PV

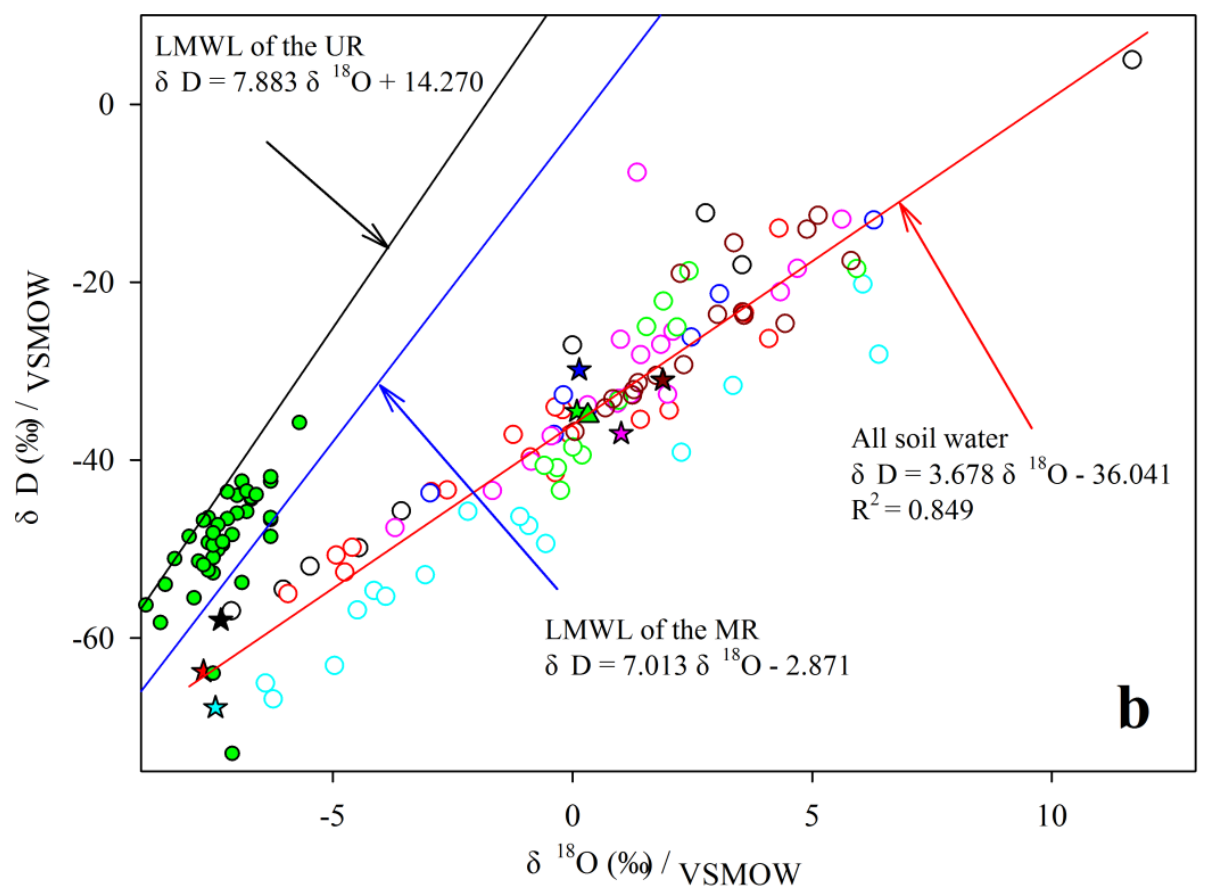

O M1-10 soil water

$\star \quad$ M1-10 xylem water of TR

O M1-12 soil water

$\star \quad$ M1-12 xylem water of TR

O M2-10 soil water

$\star \quad$ M2-10 xylem water of HA

○ M2-12 soil water

t M2-12 xylem water of HA

○. M3 soil water

t) M3 xylem water of HA

○ M4-10 soil water

t. M4-10 xylem water of RS

$\triangle$ M4-10 xylem water of NT

O M4-12 soil water

$\star \quad$ M4-12 xylem water of RS

- Shallow groundwater of the MR 

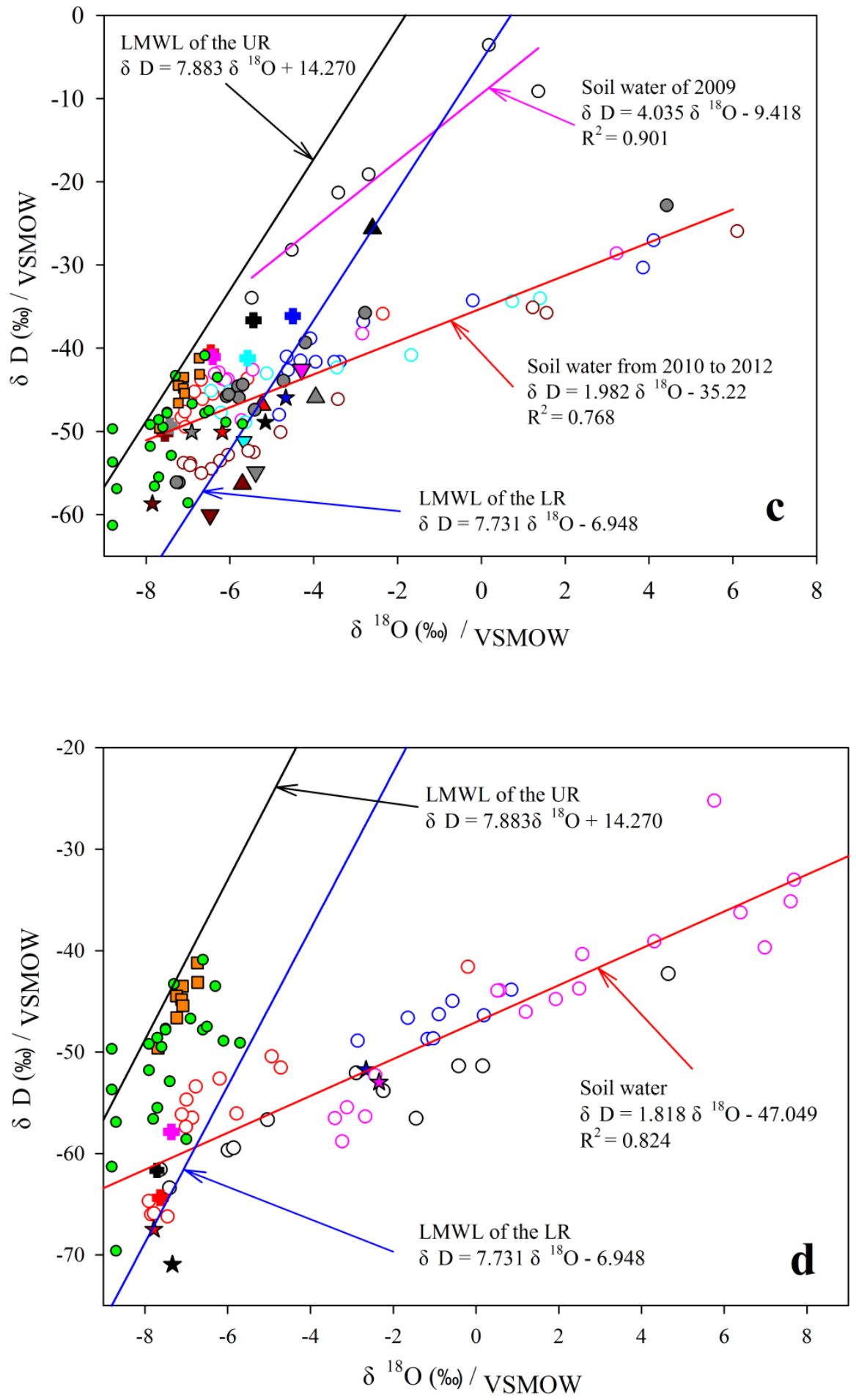

○ L1-12 soil water

$\star \quad$ L1-12 xylem water of PE

- L1-12 groundwater

○ L2-10 soil water

$\nabla \quad$ L2-10 xylem water of TR

- L2-10 groundwater L2-12 soil water

$\nabla \quad$ L2-12 xylem water of TR

- L2-12 groundwater

O L3-08 soil water

$\star \quad$ L3-08 xylem water of PE

$\nabla$ L3-08 xylem water of TR

- L3-08 xylem water of SA

- L3-08 groundwater

- L4-08 soil water

t L4-08 xylem water of PE

$\nabla \quad$ L4-08 xylem water of TR

$\triangle \quad$ L4-08 xylem water of SA

L4-08 groundwater

ㅁ River water of LR

- Shallow groundwater of the LR
O L5-10 soil water

$\star \quad$ L5-10 xylem water of HA

- L5-10 groundwater

- L5-12 soil water

t L5-12 xylem water of HA

- L5-12 groundwater

○ L6-10 soil water

$\star \quad$ L6-10 xylem water of RS

○ L6-12 soil water

t56-12 xylem water of RS

- L6-10 and L6-12 groundwater

River water of LR

- Shallow groundwater of the LR 
Fig. 4

a The mountain grassland zone of the UR
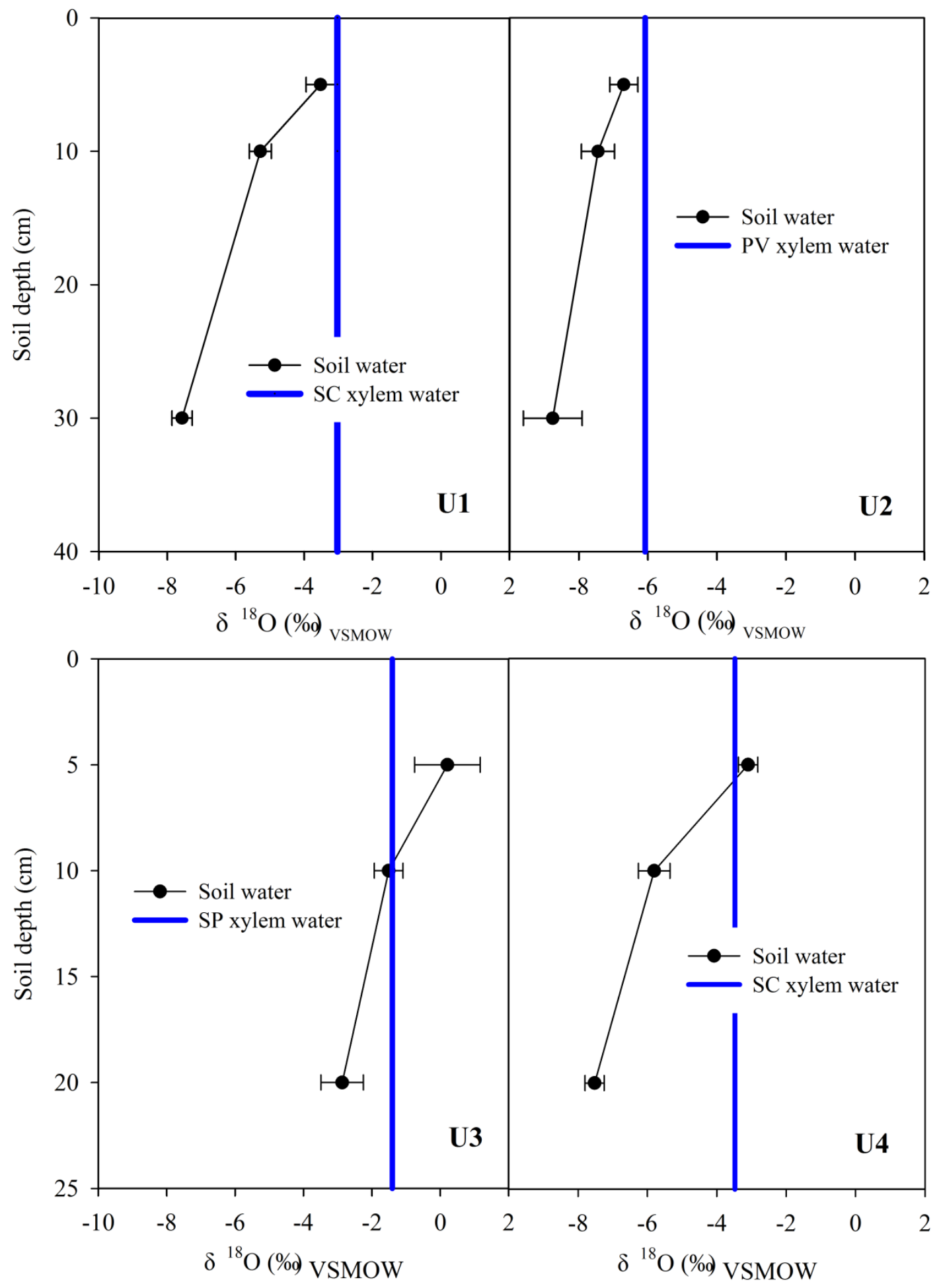
b The Qinghai Spruce forest of the UR
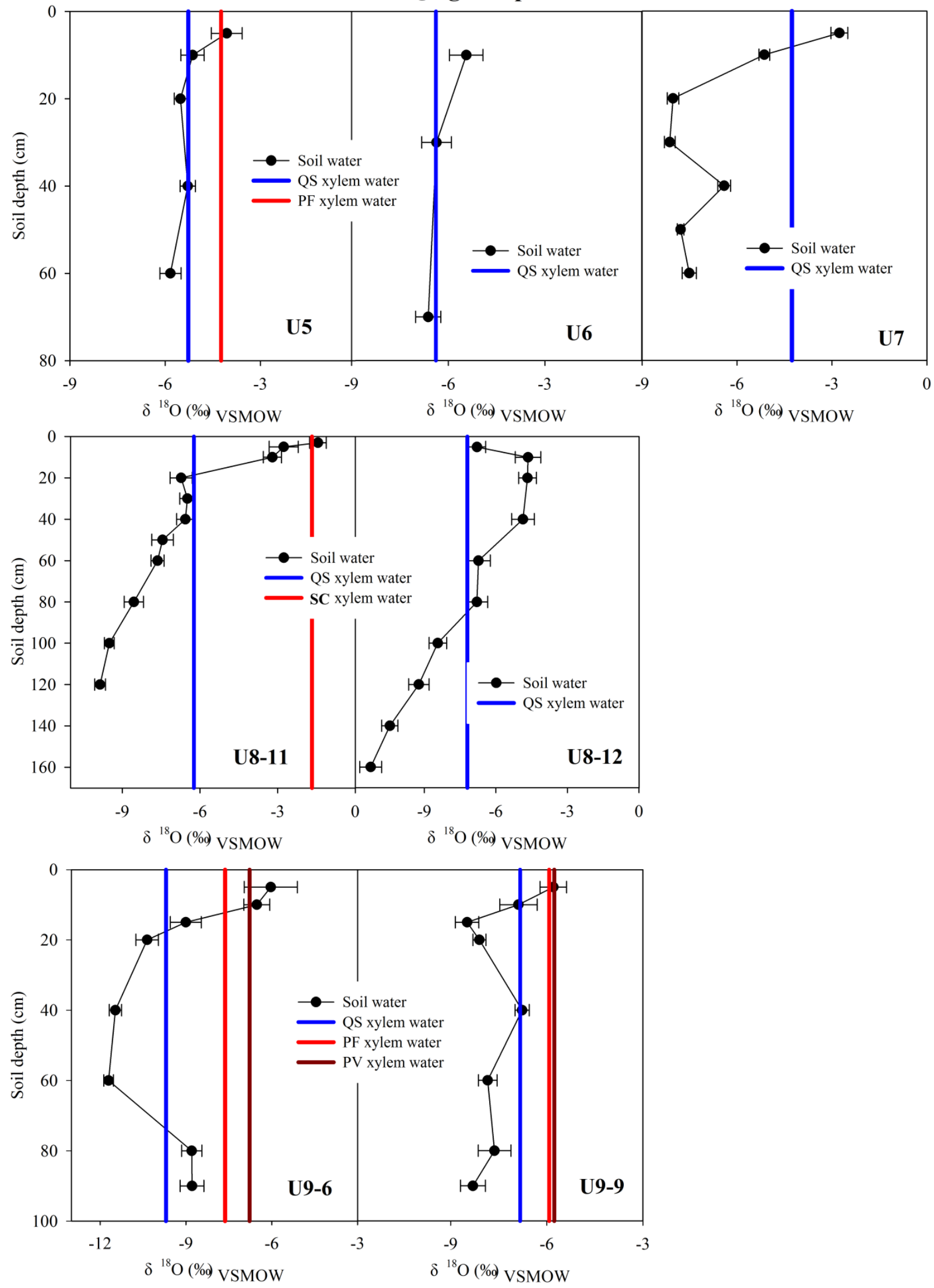

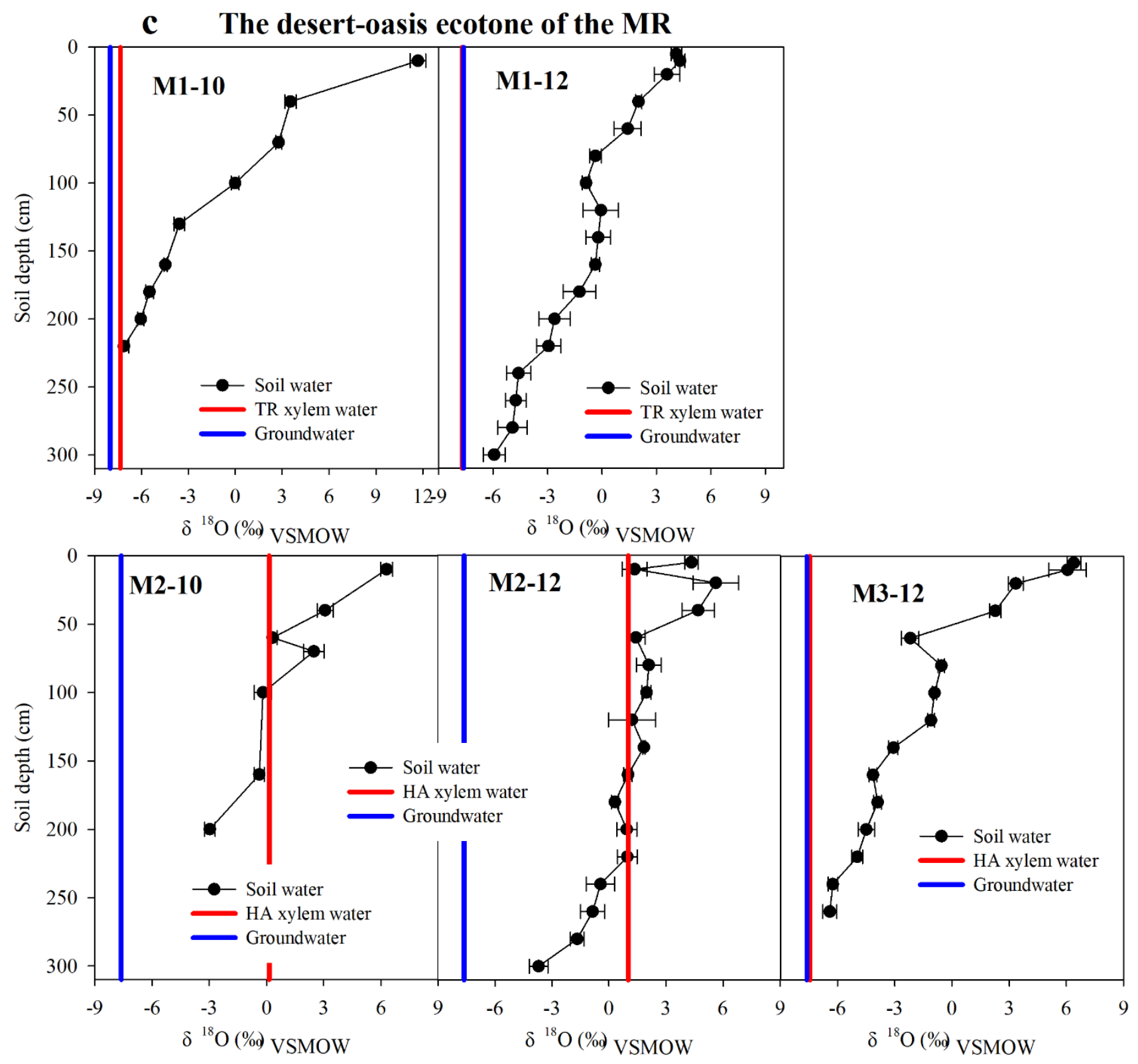


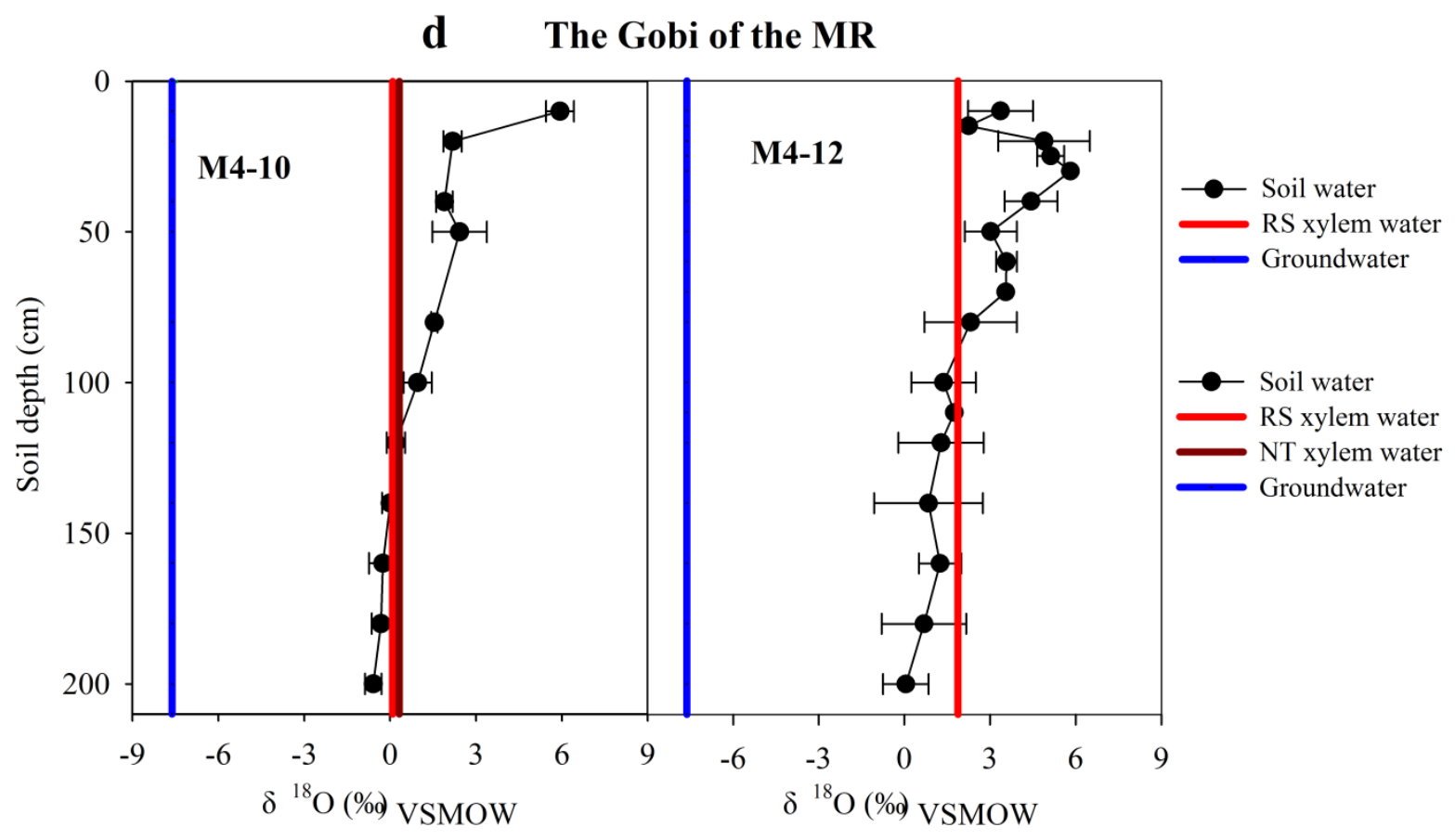


e The riparian forest of the LR

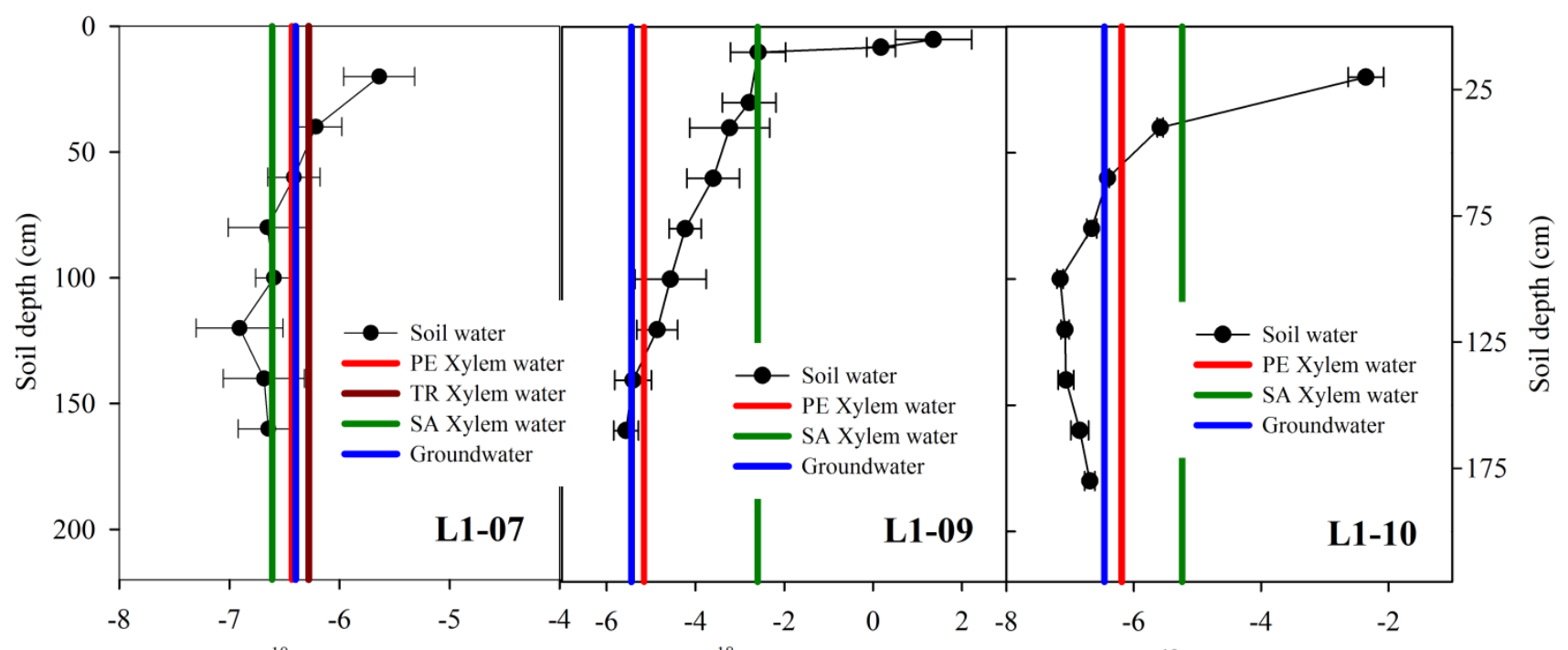

$\delta{ }^{18} \mathrm{O}(\%)$ vsmow $\left.\quad \delta{ }^{18} \mathrm{O}(\%)\right)_{\text {vsmow }} \quad \delta{ }^{18} \mathrm{O}(\%)$ vsmow
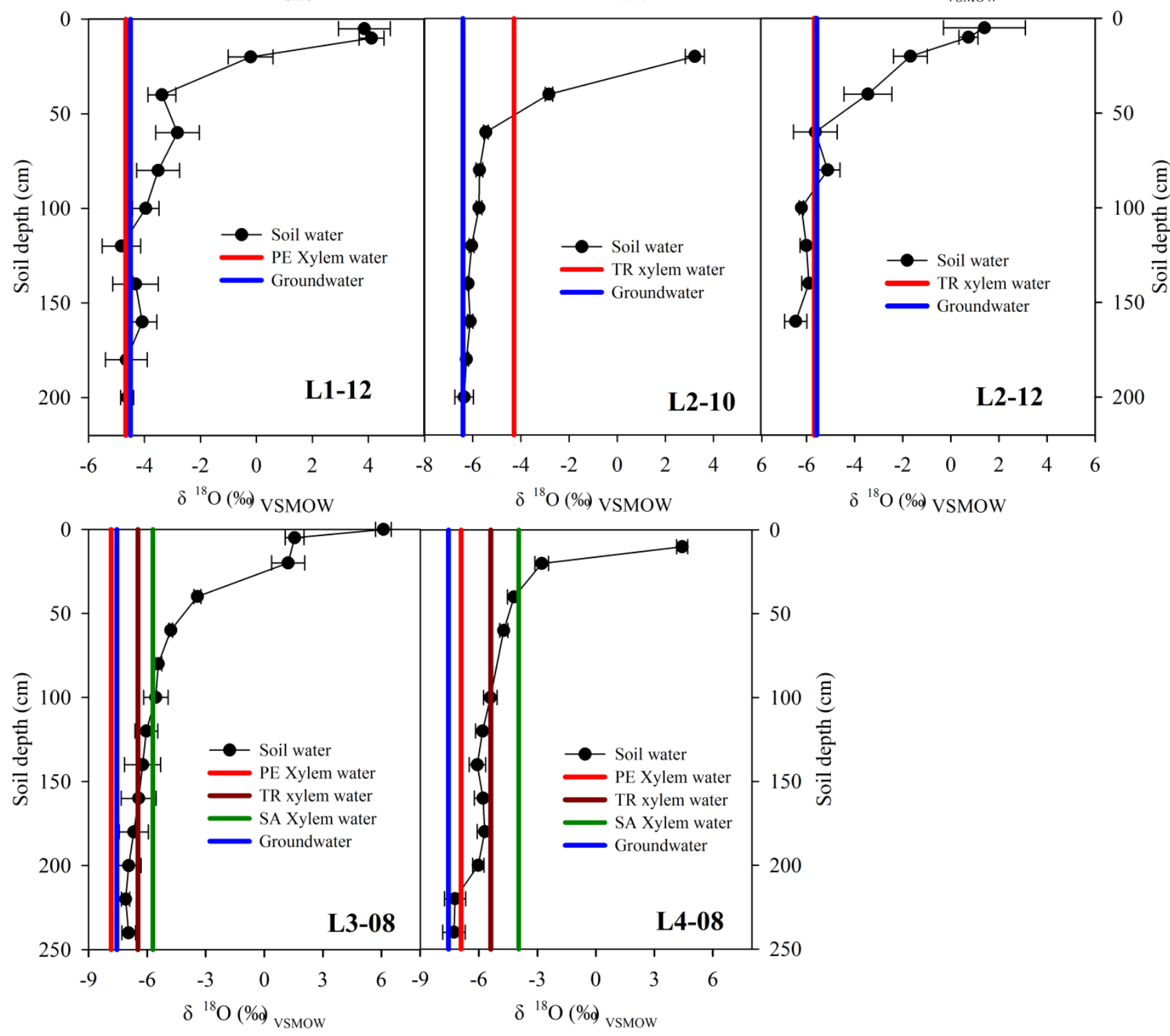


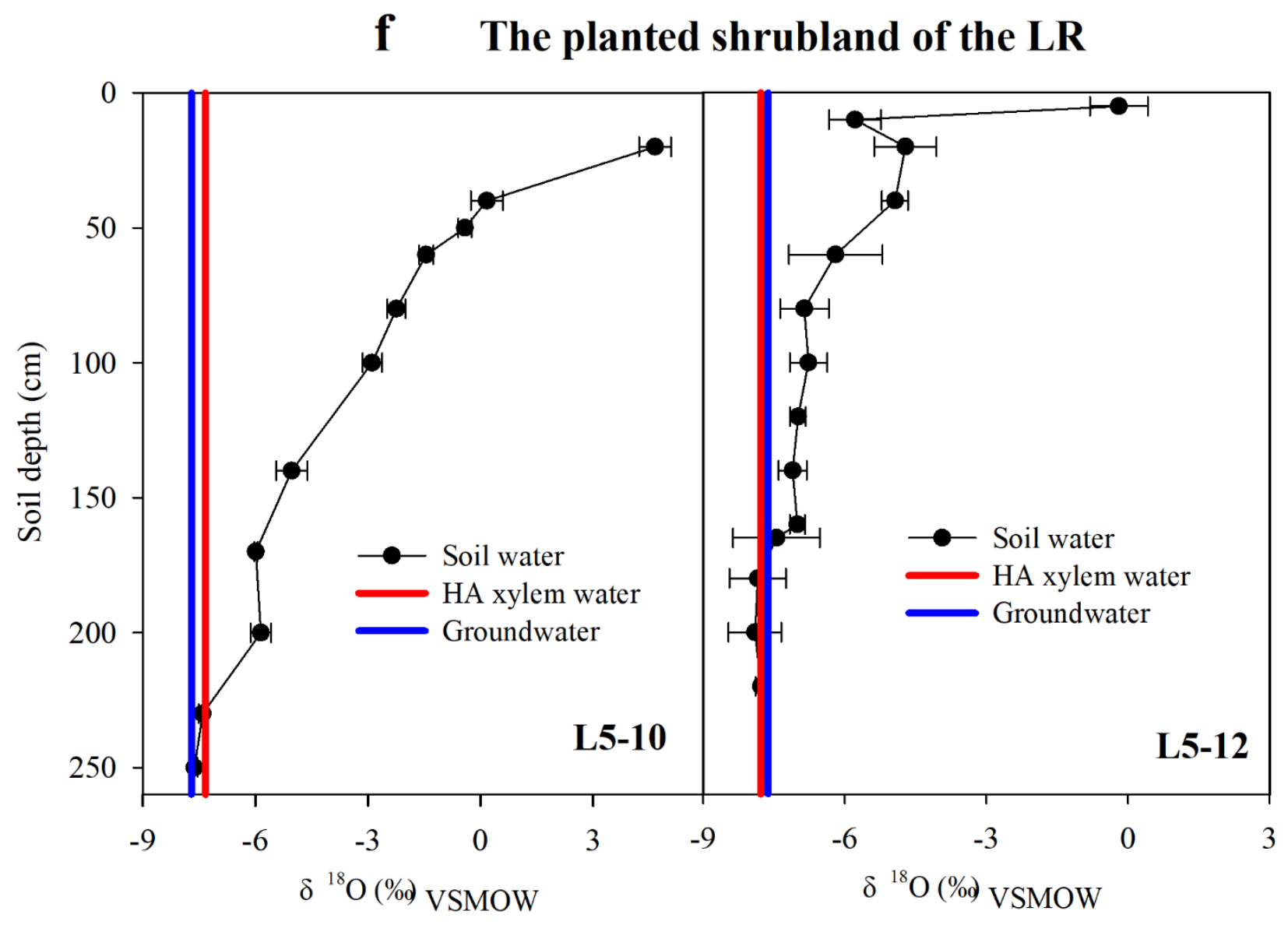




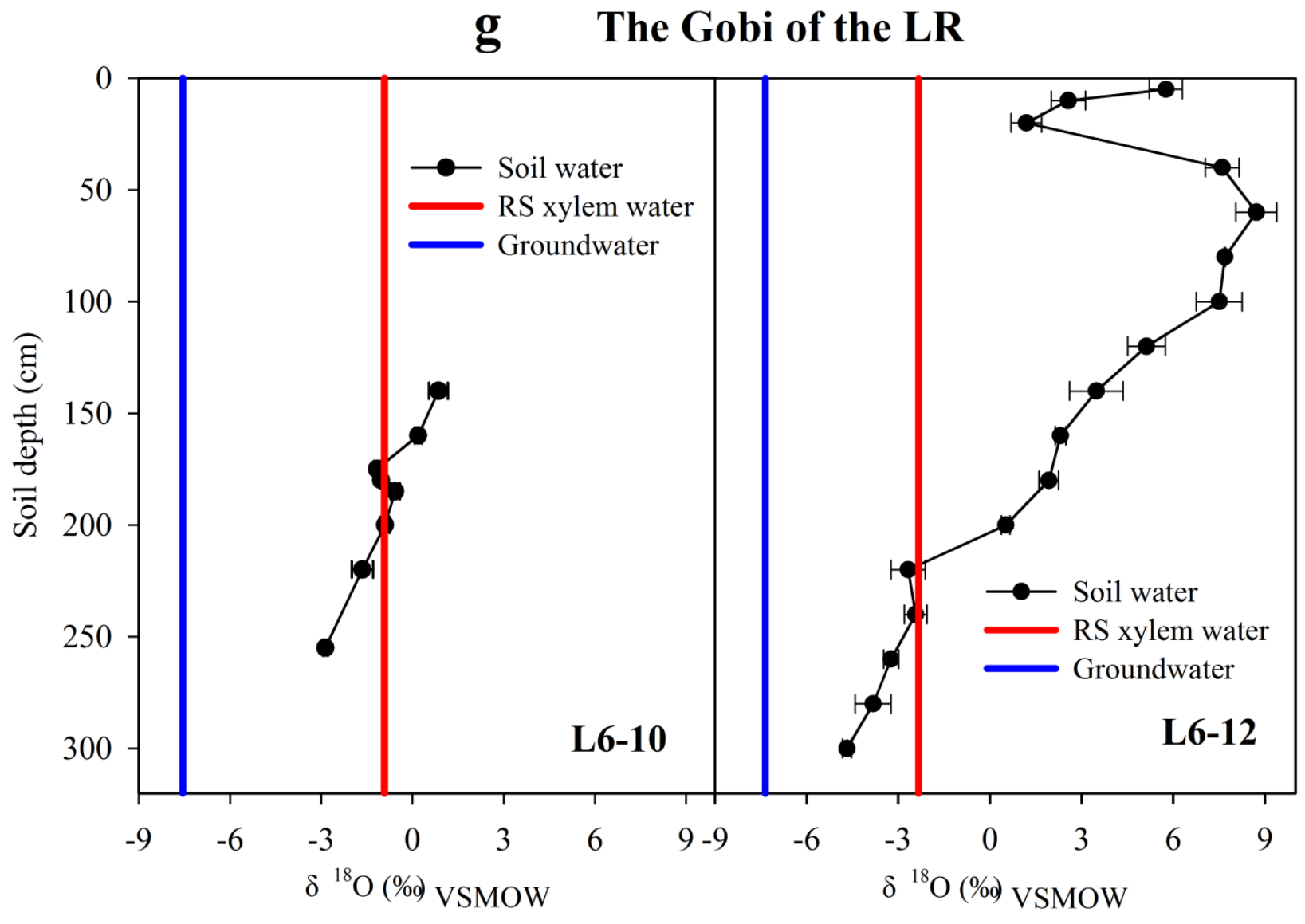


Fig. 5
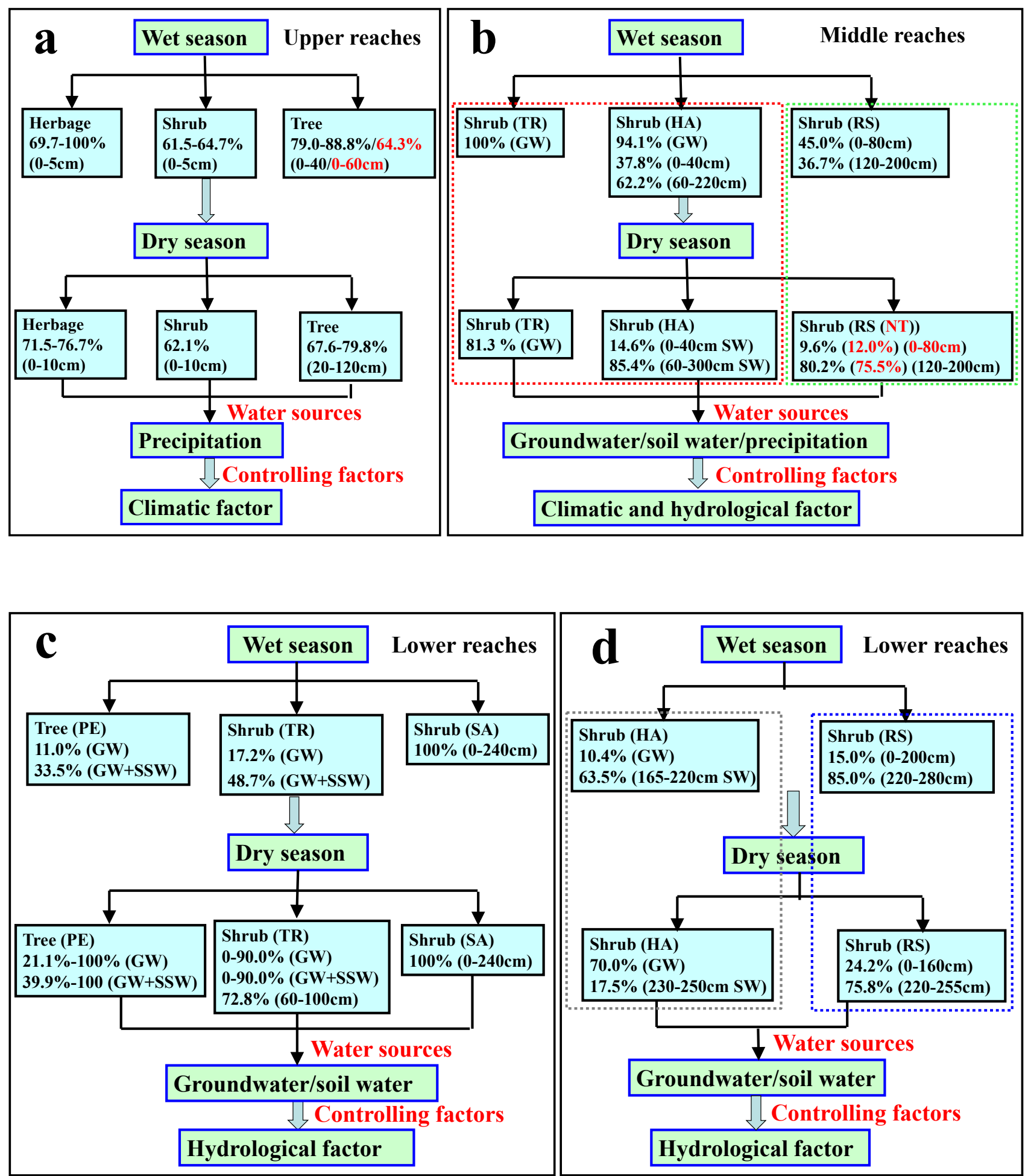
Table S1 Comparison of contribution rates $(\% \pm \mathrm{SD})$ of different water sources to plant species between deuterium fractionation (DF) and deuterium nonfractionation (NDF) using the Bayesian isotope mixing model (MixSIAR). The acronyms of plants are the same as the Table 1.

\begin{tabular}{|c|c|c|c|c|c|c|c|c|}
\hline \multirow[b]{2}{*}{ U7-DNF } & \multicolumn{7}{|c|}{$\delta^{18} \mathrm{O}$ and $\delta^{2} \mathrm{H}$ of soil water $(\%)$} & \multirow{2}{*}{$\begin{array}{l}\delta^{18} \mathrm{O} / \delta^{2} \mathrm{H} \text { of } \\
\text { xylem water }(\%)\end{array}$} \\
\hline & $5 \mathrm{~cm} \mathrm{SW}$ & $10 \mathrm{~cm} \mathrm{SW}$ & $20 \mathrm{~cm} \mathrm{SW}$ & $30 \mathrm{~cm} \mathrm{SW}$ & $40 \mathrm{~cm} \mathrm{SW}$ & $50 \mathrm{~cm} \mathrm{SW}$ & $60 \mathrm{~cm} \mathrm{SW}$ & \\
\hline$\delta^{18} \mathrm{O}$ & -2.76 & -5.14 & -8.02 & -8.13 & -6.41 & -7.78 & -7.51 & $\delta^{18} \mathrm{O}_{\mathrm{QS}}=-4.26$ \\
\hline$\delta^{2} \mathrm{H}$ & -18.39 & -41.16 & -58.97 & -50.75 & -40.03 & -46.36 & -47.89 & $\delta^{2} \mathrm{H}_{\mathrm{QS}}=-28.37$ \\
\hline $\operatorname{Mix}-\delta^{18} \mathrm{O}$ & $63.5 \pm 0.06$ & $8.4 \pm 0.08$ & $5.3 \pm 0.04$ & $5.1 \pm 0.04$ & $6.5 \pm 0.05$ & $5.4 \pm 0.04$ & $5.7 \pm 0.04$ & \\
\hline $\mathrm{Mix}^{2} \mathrm{H}$ & $64.7 \pm 0.03$ & $6.9 \pm 0.05$ & $4.8 \pm 0.05$ & $5.3 \pm 0.04$ & $6.6 \pm 0.05$ & $6.0 \pm 0.04$ & $5.6 \pm 0.04$ & \\
\hline $\operatorname{Mix}-\delta^{18} \mathrm{O} / \delta^{2} \mathrm{H}$ & $64.8 \pm 0.03$ & $6.7 \pm 0.05$ & $4.8 \pm 0.03$ & $5.3 \pm 0.04$ & $6.7 \pm 0.05$ & $6.0 \pm 0.04$ & $5.7 \pm 0.04$ & \\
\hline U9-9- DNF & $3 \sim 5 \mathrm{~cm} \mathrm{SW}$ & $5 \sim 10 \mathrm{~cm} \mathrm{SW}$ & $10 \sim 20 \mathrm{~cm} \mathrm{SW}$ & $20 \sim 40 \mathrm{~cm} \mathrm{SW}$ & $40-60 \mathrm{~cm} \mathrm{SW}$ & $80 \sim 90 \mathrm{~cm} \mathrm{SW}$ & & $\delta^{18} \mathrm{O}_{\mathrm{QS}}=-6.83$ \\
\hline$\delta^{18} \mathrm{O}$ & -5.8 & -6.88 & -8.29 & -6.77 & -7.74 & -8.31 & & $\delta^{2} \mathrm{HQS}_{\mathrm{Q}}=-47.06$ \\
\hline$\delta^{2} \mathrm{H}$ & -44.36 & -50.06 & -56.28 & -43.94 & -47.83 & -52.41 & & \\
\hline $\operatorname{Mix}-\delta^{18} \mathrm{O}$ & $27.3 \pm 0.15$ & $19.9 \pm 0.16$ & $9.9 \pm 0.07$ & $21.9 \pm 0.19$ & $11.7 \pm 0.09$ & $9.4 \pm 0.07$ & & \\
\hline $\mathrm{Mix}^{2} \mathrm{H}$ & $26.4 \pm 0.18$ & $11.8 \pm 0.09$ & $7.5 \pm 0.05$ & $27.4 \pm 0.17$ & $17.3 \pm 0.15$ & $9.5 \pm 0.06$ & & \\
\hline $\operatorname{Mix}-\delta^{18} \mathrm{O} / \delta^{2} \mathrm{H}$ & $32.0 \pm 0.15$ & $13.3 \pm 0.09$ & $7.6 \pm 0.05$ & $24.7 \pm 0.16$ & $13.4 \pm 0.10$ & $9.1 \pm 0.06$ & & \\
\hline $\operatorname{Mix}-\delta^{18} \mathrm{O}$ & $64.7 \pm 0.18$ & $12.5 \pm 0.17$ & $4.9 \pm 0.04$ & $7.5 \pm 0.06$ & $5.4 \pm 0.04$ & $5.0 \pm 0.04$ & & $\delta^{18} \mathrm{O}_{\mathrm{PF}}=-5.92$ \\
\hline $\mathrm{Mix}^{2} \mathrm{H}$ & $33.4 \pm 0.31$ & $4.8 \pm 0.04$ & $3.2 \pm 0.02$ & $48.9 \pm 0.31$ & $5.8 \pm 0.05$ & $4.0 \pm 0.03$ & & $\delta^{2} \mathrm{H}_{\mathrm{PF}}=-44.32$ \\
\hline$M i x-\delta^{18} \mathrm{O} / \delta^{2} \mathrm{H}$ & $76.8 \pm 0.09$ & $4.3 \pm 0.03$ & $2.8 \pm 0.02$ & $8.2 \pm 0.08$ & $4.5 \pm 0.04$ & $3.3 \pm 0.02$ & & \\
\hline M4-12-DNF & $10-15 \mathrm{~cm} \mathrm{SW}$ & $20-40 \mathrm{~cm} \mathrm{SW}$ & $50-70 \mathrm{~cm} \mathrm{SW}$ & $80 \mathrm{~cm} \mathrm{SW}$ & $100-120 \mathrm{~cm} \mathrm{SW}$ & $120-160 \mathrm{~cm} \mathrm{SW}$ & $180-200 \mathrm{~cm} \mathrm{SW}$ & $\delta^{18} \mathrm{O}_{\mathrm{RS}}=1.88$ \\
\hline$\delta^{18} \mathrm{O}$ & 2.81 & 5.07 & 3.38 & 2.32 & 1.47 & 1.05 & 0.37 & $\delta^{2} \mathrm{H}_{\mathrm{RS}}=-31.02$ \\
\hline$\delta^{2} \mathrm{H}$ & -17.31 & -17.2 & -23.58 & -29.29 & -31.3 & -32.92 & -35.48 & \\
\hline $\operatorname{Mix}-\delta^{18} \mathrm{O}$ & $12.2 \pm 0.10$ & $7.8 \pm 0.05$ & $10.6 \pm 0.08$ & $14.4 \pm 0.13$ & $18.2 \pm 0.15$ & $18.3 \pm 0.15$ & $18.4 \pm 0.13$ & \\
\hline $\mathrm{Mix}^{2}{ }^{2} \mathrm{H}$ & $5.0 \pm 0.03$ & $5.1 \pm 0.04$ & $6.7 \pm 0.05$ & $11.5 \pm 0.10$ & $17.0 \pm 0.17$ & $23.8 \pm 0.21$ & $30.9 \pm 0.19$ & \\
\hline$M i x-\delta^{18} \mathrm{O} / \delta^{2} \mathrm{H}$ & $4.6 \pm 0.03$ & $5.5 \pm 0.04$ & $7.0 \pm 0.05$ & $12.9 \pm 0.11$ & $18.5 \pm 0.18$ & $24.4 \pm 0.21$ & $27.2 \pm 0.18$ & \\
\hline L6-12- DNF & $5-20 \mathrm{~cm} \mathrm{SW}$ & $40-100 \mathrm{~cm} \mathrm{SW}$ & $120 \mathrm{~cm} \mathrm{SW}$ & $140-160 \mathrm{~cm} \mathrm{SW}$ & $200 \mathrm{~cm} \mathrm{SW}$ & $220-240 \mathrm{~cm} \mathrm{SW}$ & $260-280 \mathrm{~cm} \mathrm{SW}$ & $\delta^{18} \mathrm{RS}=-2.34$ \\
\hline$\delta^{18} \mathrm{O}$ & 2.97 & 7.17 & 4.31 & 1.87 & 0.52 & -2.55 & -3.25 & $\delta^{2} \mathrm{H}_{\mathrm{RS}}=-52.97$ \\
\hline
\end{tabular}




\begin{tabular}{|c|c|c|c|c|c|c|c|c|}
\hline$\delta^{2} \mathrm{H}$ & -36.5 & -36.03 & -39.08 & -44.86 & -43.94 & -54.32 & -56.93 & \\
\hline $\operatorname{Mix}-\delta^{18} \mathrm{O}$ & $2.9 \pm 0.02$ & $2.2 \pm 0.01$ & $2.7 \pm 0.02$ & $3.3 \pm 0.03$ & $3.8 \pm 0.03$ & $18.4 \pm 0.26$ & $66.6 \pm 0.25$ & \\
\hline $\operatorname{Mix}^{2} \mathrm{H}$ & $4.7 \pm 0.03$ & $4.7 \pm 0.03$ & $5.1 \pm 0.04$ & $6.1 \pm 0.05$ & $6.1 \pm 0.05$ & $29.3 \pm 0.26$ & $44.0 \pm 0.26$ & \\
\hline $\operatorname{Mix}-\delta^{18} \mathrm{O} / \delta^{2} \mathrm{H}$ & $3.2 \pm 0.02$ & $2.3 \pm 0.02$ & $2.7 \pm 0.02$ & $3.5 \pm 0.03$ & $4.0 \pm 0.03$ & $20.2 \pm 0.26$ & $64.2 \pm 0.25$ & \\
\hline M1-10-DF & $10 \mathrm{~cm} \mathrm{SW}$ & $40-70 \mathrm{~cm} \mathrm{SW}$ & $100 \mathrm{~cm} \mathrm{SW}$ & $130-160 \mathrm{~cm} \mathrm{SW}$ & $180-200 \mathrm{~cm} \mathrm{SW}$ & $220 \mathrm{~cm} \mathrm{SW}$ & GW & $\delta^{18} \mathrm{O}_{\mathrm{TR}}=-7.34$ \\
\hline$\delta^{18} \mathrm{O}$ & 11.68 & 3.16 & 0.00 & -4.02 & -5.76 & -7.12 & -7.99 & $\delta^{2} \mathrm{H}_{\mathrm{TR}}=-58.00$ \\
\hline$\delta^{2} \mathrm{H}$ & 4.99 & -15.14 & -27.09 & -47.81 & -53.25 & -56.96 & -50.17 & \\
\hline $\operatorname{Mix}-\delta^{18} \mathrm{O}$ & $1.1 \pm 0.01$ & $1.6 \pm 0.01$ & $1.8 \pm 0.01$ & $2.6 \pm 0.02$ & $3.3 \pm 0.03$ & $8.3 \pm 0.17$ & $81.3 \pm 0.16$ & \\
\hline $\mathrm{Mix}^{-2} \mathrm{H}$ & $0.6 \pm 0.00$ & $0.8 \pm 0.01$ & $0.9 \pm 0.01$ & $1.5 \pm 0.01$ & $1.9 \pm 0.02$ & $92.6 \pm 0.03$ & $1.7 \pm 0.02$ & \\
\hline $\operatorname{Mix}-\delta^{18} \mathrm{O} / \delta^{2} \mathrm{H}$ & $0.5 \pm 0.00$ & $0.6 \pm 0.00$ & $0.7 \pm 0.01$ & $1.2 \pm .0 .01$ & $1.6 \pm 0.01$ & $93.8 \pm 0.03$ & $1.7 \pm 0.02$ & \\
\hline L2-12-DF & $5-10 \mathrm{~cm} \mathrm{SW}$ & $20 \mathrm{~cm} \mathrm{SW}$ & $40 \mathrm{~cm} \mathrm{SW}$ & $60-80 \mathrm{~cm} \mathrm{SW}$ & $100-140 \mathrm{~cm} \mathrm{SW}$ & $160 \mathrm{~cm} \mathrm{SW}$ & GW & $\delta^{18} \mathrm{O}_{\mathrm{TR}}=-5.66$ \\
\hline$\delta^{18} \mathrm{O}$ & 1.07 & -1.68 & -3.45 & -5.38 & -6.04 & -6.45 & -5.58 & $\delta^{2} \mathrm{H}_{\mathrm{TR}}=-51.19$ \\
\hline$\delta^{2} \mathrm{H}$ & -34.19 & -40.84 & -42.33 & -45.98 & -46.11 & -45.13 & -41.2 & \\
\hline $\operatorname{Mix}-\delta^{18} \mathrm{O}$ & $3.4 \pm 0.22$ & $4.5 \pm 0.03$ & $6.8 \pm 0.07$ & $13.5 \pm 0.15$ & $23.0 \pm 0.22$ & $31.5 \pm 0.22$ & $17.2 \pm 0.18$ & \\
\hline $\mathrm{Mix}^{2}{ }^{2} \mathrm{H}$ & $7.4 \pm 0.11$ & $13.1 \pm 0.18$ & $6.6 \pm 0.05$ & $14.9 \pm 0.19$ & $8.8 \pm 0.09$ & $42.6 \pm 0.24$ & $6.6 \pm 0.06$ & \\
\hline $\operatorname{Mix}-\delta^{18} \mathrm{O} / \delta^{2} \mathrm{H}$ & $4.5 \pm 0.04$ & $6.7 \pm 0.09$ & $6.1 \pm 0.05$ & $14.2 \pm 0.18$ & $10.4 \pm 0.12$ & $51.1 \pm 0.20$ & $7.0 \pm 0.07$ & \\
\hline L5-10-DF & $20 \mathrm{~cm} \mathrm{SW}$ & $40-60 \mathrm{~cm} \mathrm{SW}$ & $80-100 \mathrm{~cm} \mathrm{SW}$ & $140-160 \mathrm{~cm} \mathrm{SW}$ & $170-200 \mathrm{~cm} \mathrm{SW}$ & $230-250 \mathrm{~cm} \mathrm{SW}$ & $\mathrm{GW}$ & $\delta^{18} \mathrm{O}_{\mathrm{HA}}=-7.34$ \\
\hline$\delta^{18} \mathrm{O}$ & 4.65 & -0.57 & -2.57 & -5.04 & -5.92 & -7.52 & -7.71 & $\delta^{2} \mathrm{H}_{\mathrm{HA}}=-70.94$ \\
\hline$\delta^{2} \mathrm{H}$ & -42.28 & -53.09 & -52.94 & -56.68 & -59.56 & -62.49 & -61.66 & \\
\hline $\operatorname{Mix}-\delta^{18} \mathrm{O}$ & $1.5 \pm 0.01$ & $1.9 \pm 0.01$ & $2.3 \pm 0.02$ & $3.1 \pm 0.03$ & $3.8 \pm 0.03$ & $17.5 \pm 0.28$ & $70.0 \pm 0.26$ & \\
\hline $\mathrm{Mix}^{2}{ }^{2} \mathrm{H}$ & $0.1 \pm 0.00$ & $0.1 \pm 0.00$ & $0.1 \pm 0.00$ & $0.2 \pm 0.00$ & $0.2 \pm 0.00$ & $99.1 \pm 0.00$ & $0.2 \pm 0.00$ & \\
\hline $\operatorname{Mix}-\delta^{18} \mathrm{O} / \delta^{2} \mathrm{H}$ & $0.1 \pm 0.00$ & $0.1 \pm 0.00$ & $0.1 \pm 0.00$ & $0.1 \pm 0.00$ & $0.2 \pm 0.00$ & $49.5 \pm 0.50$ & $49.9 \pm 0.43$ & \\
\hline L3-08-DF & $0-5 \mathrm{~cm} \mathrm{SW}$ & $5-20 \mathrm{~cm} \mathrm{SW}$ & $40-60 \mathrm{~cm} \mathrm{SW}$ & $80-120 \mathrm{~cm} \mathrm{SW}$ & $140-180 \mathrm{~cm} \mathrm{SW}$ & $200-240 \mathrm{~cm} \mathrm{SW}$ & $\mathrm{GW}$ & $\delta^{18} \mathrm{O}_{\mathrm{PE}}=-7.85$ \\
\hline$\delta^{18} \mathrm{O}$ & 6.11 & 1.39 & -4.11 & -5.68 & -6.45 & -7 & -7.55 & $\delta^{2} \mathrm{H}_{\mathrm{PE}}=-58.69$ \\
\hline$\delta^{2} \mathrm{H}$ & -25.94 & -35.43 & -48.12 & -52.57 & -54.35 & -53.91 & -50.2 & \\
\hline $\operatorname{Mix}-\delta^{18} \mathrm{O}$ & $1.3 \pm 0.01$ & $1.6 \pm 0.01$ & $2.5 \pm 0.02$ & $3.2 \pm 0.03$ & $57.1 \pm 0.04$ & $5.8 \pm 0.12$ & $28.6 \pm 0.38$ & \\
\hline $\mathrm{Mix}^{2}{ }^{2} \mathrm{H}$ & $0.7 \pm 0.01$ & $0.9 \pm 0.01$ & $68.0 \pm 0.40$ & $1.6 \pm 0.02$ & $1.8 \pm 0.02$ & $1.8 \pm 0.02$ & $25.3 \pm 0.41$ & \\
\hline
\end{tabular}




\begin{tabular}{|c|c|c|c|c|c|c|c|c|}
\hline $\operatorname{Mix}-\delta^{18} \mathrm{O} / \delta^{2} \mathrm{H}$ & $0.3 \pm 0.00$ & $0.3 \pm 0.00$ & $0.5 \pm 0.00$ & $0.7 \pm 0.01$ & $0.8 \pm 0.01$ & $0.8 \pm 0.01$ & $96.6 \pm 0.02$ & \\
\hline $\operatorname{Mix}-\delta^{18} \mathrm{O}$ & $2.5 \pm 0.00$ & $3.1 \pm 0.00$ & $5.4 \pm 0.00$ & $9.1 \pm 0.10$ & $18.2 \pm 0.20$ & $24.0 \pm 0.20$ & $37.7 \pm 0.30$ & $\delta^{18} \mathrm{O}_{\mathrm{TR}}=-6.47$ \\
\hline $\mathrm{Mix}^{2}{ }^{2} \mathrm{H}$ & $0.3 \pm 0.00$ & $0.3 \pm 0.00$ & $0.5 \pm 0.00$ & $0.6 \pm 0.01$ & $0.7 \pm 0.01$ & $0.6 \pm 0.01$ & $97.0 \pm 0.01$ & $\delta^{2} \mathrm{H}_{\mathrm{TR}}=-60.03$ \\
\hline $\mathrm{Mix}-\delta^{18} \mathrm{O} / \delta^{2} \mathrm{H}$ & $0.3 \pm 0.00$ & $0.4 \pm 0.00$ & $0.6 \pm 0.01$ & $0.7 \pm 0.01$ & $48.7 \pm 0.50$ & $0.7 \pm 0.01$ & $48.6 \pm 0.50$ & \\
\hline $\operatorname{Mix}-\delta^{18} \mathrm{O}$ & $3.6 \pm 0.02$ & $4.7 \pm 0.03$ & $8.7 \pm 0.07$ & $18.3 \pm 0.19$ & $28.4 \pm 0.24$ & $36.4 \pm 0.25$ & & $\delta^{18} \mathrm{OSA}_{\mathrm{SA}}=-5.70$ \\
\hline $\mathrm{Mix}-{ }^{2} \mathrm{H}$ & $0.8 \pm 0.01$ & $1.0 \pm 0.01$ & $1.6 \pm 0.01$ & $2.2 \pm 0.02$ & $92.1 \pm 0.04$ & $2.4 \pm 0.02$ & & $\delta^{2} \mathrm{H}_{\mathrm{SA}}=-56.31$ \\
\hline $\operatorname{Mix}-\delta^{18} \mathrm{O} / \delta^{2} \mathrm{H}$ & $0.8 \pm 0.01$ & $1.0 \pm 0.01$ & $1.6 \pm 0.01$ & $2.2 \pm 0.02$ & $91.9 \pm 0.04$ & $2.5 \pm 0.02$ & & \\
\hline
\end{tabular}

Note: Data of red bold indicate both $\delta^{18} \mathrm{O}$ and $\delta^{2} \mathrm{H}$ values of plant xylem water were not within the range of values of all potential water sources. 
Table S2 Contribution rates $(\% \pm \mathrm{SD})$ of different water sources to plant species with deuterium fractionation (DF) based on $\delta^{18} \mathrm{O}$ alone, $\delta^{2} \mathrm{H}$ alone and both $\delta^{18} \mathrm{O}$ and $\delta^{2} \mathrm{H}$ by the Iso-Source model (Iso- $\delta^{18} \mathrm{O}$, Iso- $\delta^{2} \mathrm{H}$ and Iso- $\delta^{18} \mathrm{O} / \delta^{2} \mathrm{H}$ ) and the Bayesian isotope mixing model $\left(\mathrm{Mix}-\delta^{18} \mathrm{O}\right.$, Mix $-\delta^{2} \mathrm{H}$ and $\mathrm{Mix}$ $\left.-\delta^{18} \mathrm{O} / \delta^{2} \mathrm{H}\right)$. The acronyms of plants are the same as the Table 1 .

\begin{tabular}{|c|c|c|c|c|c|c|c|c|}
\hline \multirow[b]{2}{*}{ M1-10-DF } & \multicolumn{7}{|c|}{$\delta^{18} \mathrm{O}$ and $\delta^{2} \mathrm{H}$ of soil water $(\%)$} & \multirow{2}{*}{$\begin{array}{l}\delta^{18} \mathrm{O} / \delta^{2} \mathrm{H} \text { of } \\
\text { xylem water }(\%)\end{array}$} \\
\hline & $10 \mathrm{~cm} \mathrm{SW}$ & 40-70cm SW & $100 \mathrm{~cm} \mathrm{SW}$ & $130-160 \mathrm{~cm} \mathrm{SW}$ & $180-200 \mathrm{~cm} \mathrm{SW}$ & $220 \mathrm{~cm} \mathrm{SW}$ & GW & \\
\hline$\delta^{18} \mathrm{O}$ & 11.68 & 3.16 & 0 & -4.02 & -5.76 & -7.12 & -7.99 & $\delta^{18} \mathrm{O}_{\mathrm{TR}}=-7.34$ \\
\hline$\delta^{2} \mathrm{H}$ & 4.99 & -15.14 & -27.09 & -47.81 & -53.25 & -56.96 & -50.17 & $\delta^{2} \mathrm{HTR}_{\mathrm{TR}}=-58.00$ \\
\hline Iso- $-\delta^{18} \mathrm{O}$ & $0.3 \pm 0.01$ & $0.8 \pm 0.01$ & $1.3 \pm 0.02$ & $3.1 \pm 0.03$ & $5.9 \pm 0.05$ & $15.9 \pm 0.14$ & $72.6 \pm 0.12$ & \\
\hline $\mathbf{M i x}-\delta^{18} \mathbf{O}$ & $1.1 \pm 0.01$ & $1.6 \pm 0.01$ & $1.8 \pm 0.01$ & $2.6 \pm 0.02$ & $3.3 \pm 0.03$ & $8.3 \pm 0.17$ & $81.3 \pm 0.16$ & \\
\hline Iso- $\delta^{2} \mathrm{H}$ & / & l & / & / & l & l & / & \\
\hline $\mathbf{M i x}-\delta^{2} \mathbf{H}$ & $0.6 \pm 0.00$ & $0.8 \pm 0.01$ & $0.9 \pm 0.01$ & $1.5 \pm 0.01$ & $1.9 \pm 0.02$ & $92.6 \pm 0.03$ & $1.7 \pm 0.02$ & \\
\hline Iso- $\delta^{18} \mathrm{O} / \delta^{2} \mathrm{H}$ & l & l & / & / & l & l & / & \\
\hline$M i x-\delta^{18} O / \delta^{2} H$ & $0.5 \pm 0.00$ & $0.6 \pm 0.00$ & $0.7 \pm 0.01$ & $1.2 \pm .0 .01$ & $1.6 \pm 0.01$ & $93.8 \pm 0.03$ & $1.7 \pm 0.02$ & \\
\hline L2-12-DF & $5-10 \mathrm{~cm} \mathrm{SW}$ & $20 \mathrm{~cm} \mathrm{SW}$ & $40 \mathrm{~cm} \mathrm{SW}$ & $60-80 \mathrm{~cm} \mathrm{SW}$ & $100-140 \mathrm{~cm} \mathrm{SW}$ & $160 \mathrm{~cm} \mathrm{SW}$ & $\mathrm{GW}$ & $\delta^{18} \mathrm{O}_{\mathrm{TR}}=-5.66$ \\
\hline$\delta^{18} \mathrm{O}$ & 1.07 & -1.68 & -3.45 & -5.38 & -6.04 & -6.45 & -5.58 & $\delta^{2} \mathrm{HTR}_{\mathrm{TR}}=-51.19$ \\
\hline$\delta^{2} \mathrm{H}$ & -34.19 & -40.84 & -42.33 & -45.98 & -46.11 & -45.13 & -41.2 & \\
\hline Iso- $-\delta^{18} \mathrm{O}$ & $1.6 \pm 0.02$ & $2.8 \pm 0.03$ & $4.7 \pm 0.04$ & $13.5 \pm 0.12$ & $25.8 \pm 0.20$ & $35.3 \pm 0.18$ & $16.3 \pm 0.14$ & \\
\hline$M i x-\delta^{18} O$ & $3.4 \pm 0.22$ & $4.5 \pm 0.03$ & $6.8 \pm 0.07$ & $13.5 \pm 0.15$ & $23.0 \pm 0.22$ & $31.5 \pm 0.22$ & $17.2 \pm 0.18$ & \\
\hline Iso- $\delta^{2} \mathrm{H}$ & I & l & 1 & / & I & l & I & \\
\hline $\mathbf{M i x}-\delta^{2} \mathbf{H}$ & $7.4 \pm 0.11$ & $13.1 \pm 0.18$ & $6.6 \pm 0.05$ & $14.9 \pm 0.19$ & $8.8 \pm 0.09$ & $42.6 \pm 0.24$ & $6.6 \pm 0.06$ & \\
\hline Iso- $\delta^{18} \mathrm{O} / \delta^{2} \mathrm{H}$ & I & l & I & / & I & I & I & \\
\hline $\mathbf{M i x}-\delta^{18} \mathbf{O} / \delta^{2} \mathbf{H}$ & $4.5 \pm 0.04$ & $6.7 \pm 0.09$ & $6.1 \pm 0.05$ & $14.2 \pm 0.18$ & $10.4 \pm 0.12$ & $51.1 \pm 0.20$ & $7.0 \pm 0.07$ & \\
\hline L5-10-DF & $20 \mathrm{~cm} \mathrm{SW}$ & $40-60 \mathrm{~cm} \mathrm{SW}$ & $80-100 \mathrm{~cm} \mathrm{SW}$ & $140-160 \mathrm{~cm} \mathrm{SW}$ & $170-200 \mathrm{~cm} \mathrm{SW}$ & $230-250 \mathrm{~cm} \mathrm{SW}$ & GW & $\delta^{18} \mathrm{OHA}_{\mathrm{HA}}=-7.34$ \\
\hline$\delta^{18} \mathrm{O}$ & 4.65 & -0.57 & -2.57 & -5.04 & -5.92 & -7.52 & -7.71 & $\delta^{2} \mathrm{H}_{\mathrm{HA}}=-70.94$ \\
\hline$\delta^{2} \mathrm{H}$ & -42.28 & -53.09 & -52.94 & -56.68 & -59.56 & -62.49 & -61.66 & \\
\hline Iso- $-\delta^{18} \mathrm{O}$ & $0.3 \pm 0.01$ & $0.8 \pm 0.01$ & $1.3 \pm 0.01$ & $2.8 \pm 0.03$ & $4.5 \pm 0.04$ & $33.8 \pm 0.03$ & $56.4 \pm 0.03$ & \\
\hline $\operatorname{Mix}-\delta^{18} O$ & $1.5 \pm 0.01$ & $1.9 \pm 0.01$ & $2.3 \pm 0.02$ & $3.1 \pm 0.03$ & $3.8 \pm 0.03$ & $17.5 \pm 0.28$ & $70.0 \pm 0.26$ & \\
\hline
\end{tabular}




\begin{tabular}{|c|c|c|c|c|c|c|c|c|}
\hline Iso- $\delta^{2} \mathrm{H}$ & / & I & I & l & / & I & I & \\
\hline $\mathbf{M i x}-\delta^{2} \mathbf{H}$ & $0.1 \pm 0.00$ & $0.1 \pm 0.00$ & $0.1 \pm 0.00$ & $0.2 \pm 0.00$ & $0.2 \pm 0.00$ & $99.1 \pm 0.00$ & $0.2 \pm 0.00$ & \\
\hline Iso- $\delta^{18} \mathrm{O} / \delta^{2} \mathrm{H}$ & l & l & I & I & I & I & I & \\
\hline $\mathbf{M i x}-\delta^{18} \mathbf{O} / \delta^{2} \mathbf{H}$ & $0.1 \pm 0.00$ & $0.1 \pm 0.00$ & $0.1 \pm 0.00$ & $0.1 \pm 0.00$ & $0.2 \pm 0.00$ & $49.5 \pm 0.50$ & $49.9 \pm 0.43$ & \\
\hline L3-08-DF & $0-5 \mathrm{~cm} \mathrm{SW}$ & $5-20 \mathrm{~cm} \mathrm{SW}$ & $40-60 \mathrm{~cm} \mathrm{SW}$ & $80-120 \mathrm{~cm} \mathrm{SW}$ & $140-180 \mathrm{~cm} \mathrm{SW}$ & $200-240 \mathrm{~cm} \mathrm{SW}$ & GW & $\delta^{18} \mathrm{OPE}_{\mathrm{PE}}=-7.85$ \\
\hline$\delta^{18} \mathrm{O}$ & 6.11 & 1.39 & -4.11 & -5.68 & -6.45 & -7.00 & -7.55 & $\delta^{2} \mathrm{H}_{\mathrm{PE}}=-58.69$ \\
\hline$\delta^{2} \mathrm{H}$ & -25.94 & -35.43 & -48.12 & -52.57 & -54.35 & -53.91 & -50.2 & \\
\hline Iso- $\delta^{18} \mathrm{O}$ & I & l & I & l & l & / & $100 \% *$ & \\
\hline$M i x-\delta^{18} \mathbf{O}$ & $1.3 \pm 0.01$ & $1.6 \pm 0.01$ & $2.5 \pm 0.02$ & $3.2 \pm 0.03$ & $57.1 \pm 0.04$ & $5.8 \pm 0.12$ & $28.6 \pm 0.38$ & \\
\hline Iso- $\delta^{2} \mathrm{H}$ & l & l & l & l & l & l & / & \\
\hline$M i x-\delta^{2} H$ & $0.7 \pm 0.01$ & $0.9 \pm 0.01$ & $68.0 \pm 0.40$ & $1.6 \pm 0.02$ & $1.8 \pm 0.02$ & $1.8 \pm 0.02$ & $25.3 \pm 0.41$ & \\
\hline Iso- $\delta^{18} \mathrm{O} / \delta^{2} \mathrm{H}$ & / & l & l & I & l & / & / & \\
\hline$M i x-\delta^{18} \mathbf{O} / \delta^{2} \mathbf{H}$ & $0.3 \pm 0.00$ & $0.3 \pm 0.00$ & $0.5 \pm 0.00$ & $0.7 \pm 0.01$ & $0.8 \pm 0.01$ & $0.8 \pm 0.01$ & $96.6 \pm 0.02$ & \\
\hline Iso- $\delta^{18} \mathrm{O}$ & $1.2 \pm 0.01$ & $2.0 \pm 0.02$ & $5.8 \pm 0.05$ & $10.9 \pm 0.09$ & $17.8 \pm 0.15$ & $26.4 \pm 0.20$ & $36.0 \pm 0.19$ & $\delta^{18} \mathrm{O}_{\mathrm{TR}}=-6.47$ \\
\hline $\operatorname{Mix}-\delta^{18} \mathrm{O}$ & $2.5 \pm 0.00$ & $3.1 \pm 0.00$ & $5.4 \pm 0.00$ & $9.1 \pm 0.10$ & $18.2 \pm 0.20$ & $24.0 \pm 0.20$ & $37.7 \pm 0.30$ & $\delta^{2} \mathrm{H}_{\mathrm{TR}}=-60.03$ \\
\hline Iso- $\delta^{2} \mathrm{H}$ & I & I & I & I & I & / & I & \\
\hline $\mathbf{M i x}-\delta^{2} \mathbf{H}$ & $0.3 \pm 0.00$ & $0.3 \pm 0.00$ & $0.5 \pm 0.00$ & $0.6 \pm 0.01$ & $0.7 \pm 0.01$ & $0.6 \pm 0.01$ & $97.0 \pm 0.01$ & \\
\hline Iso- $\delta^{18} \mathrm{O} / \delta^{2} \mathrm{H}$ & I & l & I & I & l & l & I & \\
\hline$M i x-\delta^{18} \mathbf{O} / \delta^{2} \mathbf{H}$ & $0.3 \pm 0.00$ & $0.4 \pm 0.00$ & $0.6 \pm 0.01$ & $0.7 \pm 0.01$ & $48.7 \pm 0.50$ & $0.7 \pm 0.01$ & $48.6 \pm 0.50$ & \\
\hline Iso- $-\delta^{18} \mathrm{O}$ & $2.1 \pm 0.02$ & $3.5 \pm 0.03$ & $10.5 \pm 0.06$ & $20.8 \pm 0.17$ & $29.0 \pm 0.21$ & $34.1 \pm 0.20$ & & $\delta^{18} \mathrm{O}_{\mathrm{SA}}=-5.70$ \\
\hline$M i x-\delta^{18} \mathbf{O}$ & $3.6 \pm 0.02$ & $4.7 \pm 0.03$ & $8.7 \pm 0.07$ & $18.3 \pm 0.19$ & $28.4 \pm 0.24$ & $36.4 \pm 0.25$ & & $\delta^{2} \mathrm{H}_{\mathrm{SA}}=-56.31$ \\
\hline Iso- $\delta^{2} \mathrm{H}$ & l & l & l & / & l & l & & \\
\hline $\mathbf{M i x}-\delta^{2} \mathbf{H}$ & $0.8 \pm 0.01$ & $1.0 \pm 0.01$ & $1.6 \pm 0.01$ & $2.2 \pm 0.02$ & $92.1 \pm 0.04$ & $2.4 \pm 0.02$ & & \\
\hline Iso- $\delta^{18} \mathrm{O} / \delta^{2} \mathrm{H}$ & / & 1 & 1 & I & I & / & & \\
\hline$M i x-\delta^{18} O / \delta^{2} \mathbf{H}$ & $0.8 \pm 0.01$ & $1.0 \pm 0.01$ & $1.6 \pm 0.01$ & $2.2 \pm 0.02$ & $91.9 \pm 0.04$ & $2.5 \pm 0.02$ & & \\
\hline
\end{tabular}


Fig. S1 Precipitation of the Heihe River Basin during the study period of the upper reaches (a), middle reaches (b) and lower reaches (c).

Fig. S2 The local meteoric water lines of the Heihe River Basin.

Fig. S1
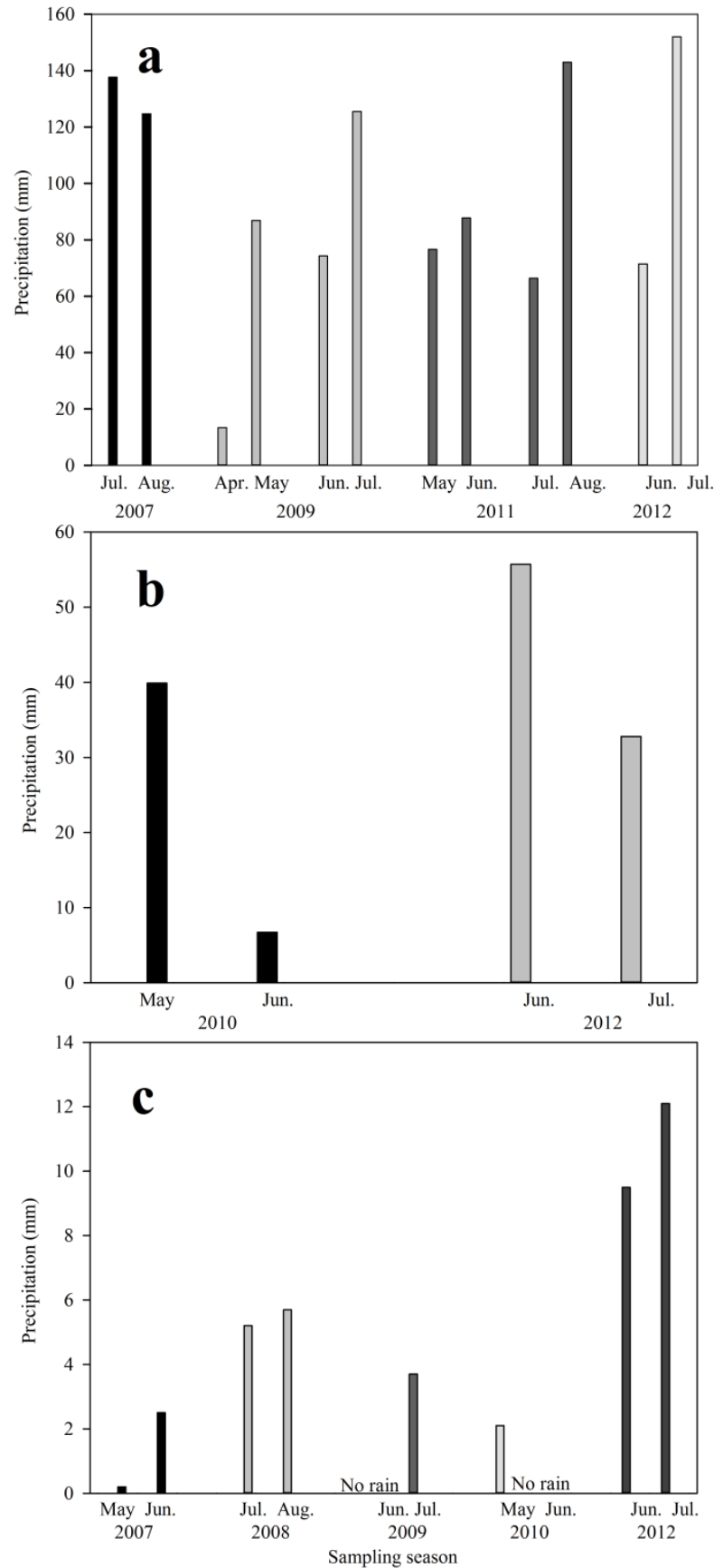
Fig. S2

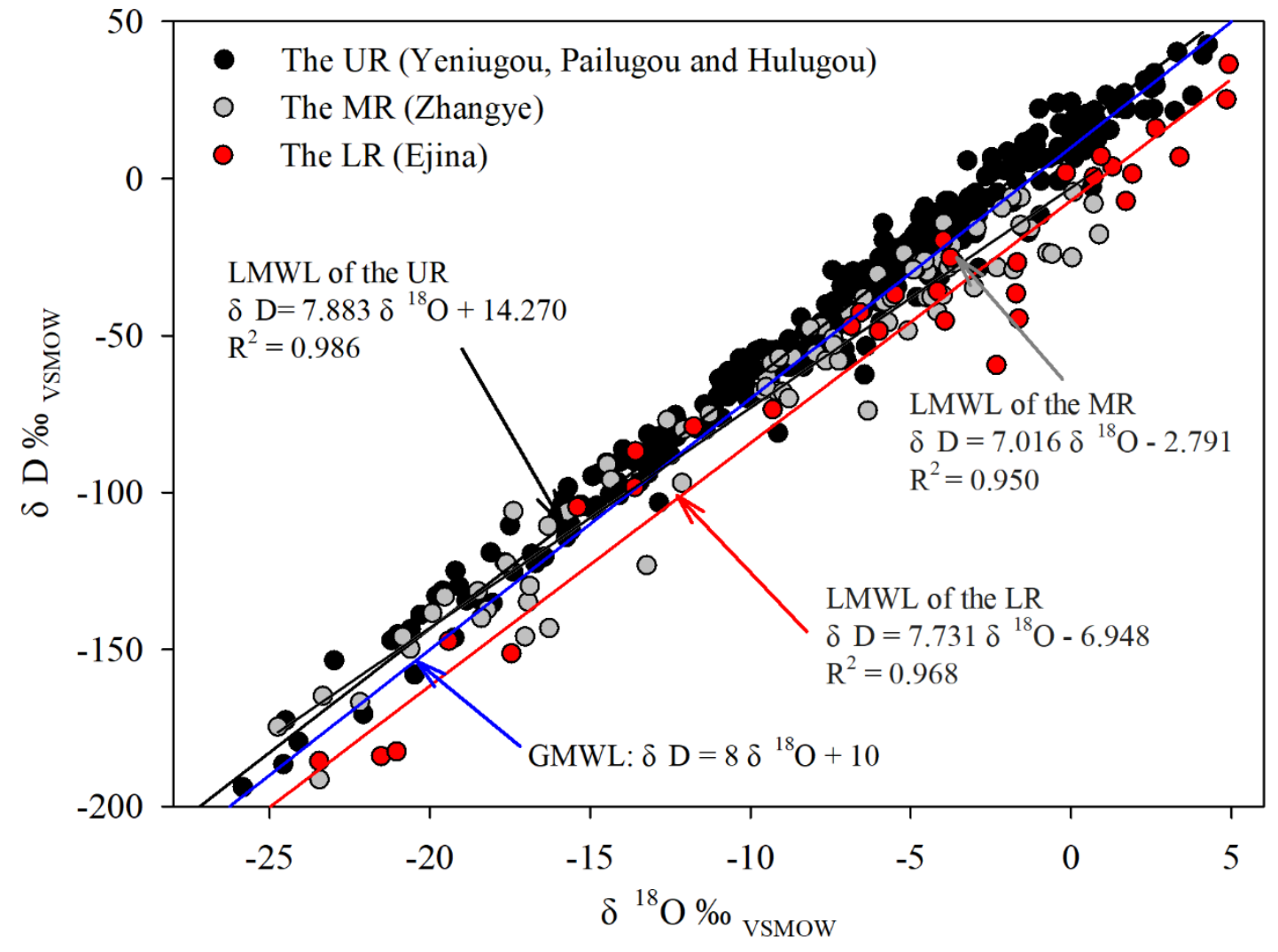

